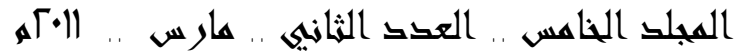

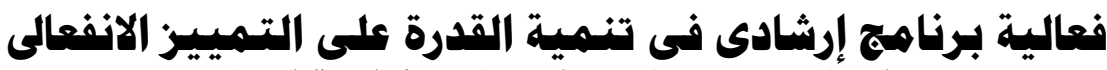

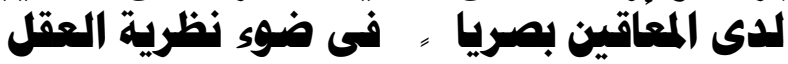

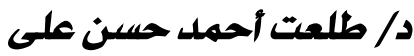

أستاذ الصحة النفسية المساعد

كلية التربية - جامعة بنى سويف المسافيف

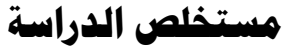

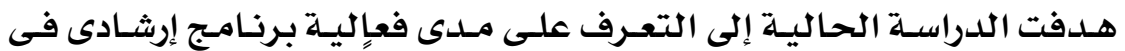

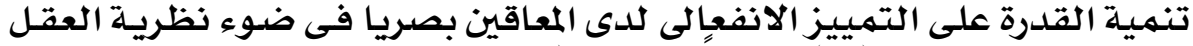

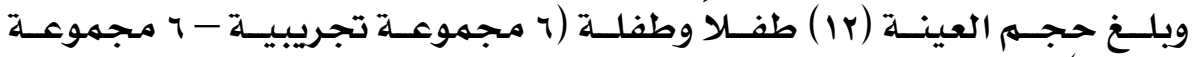

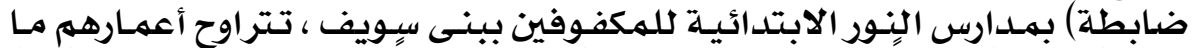

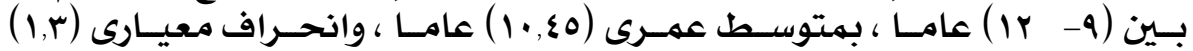

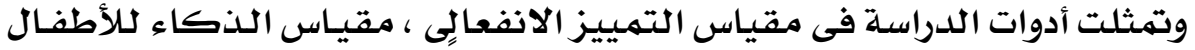

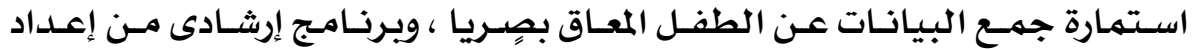

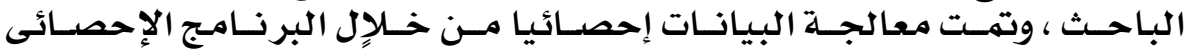

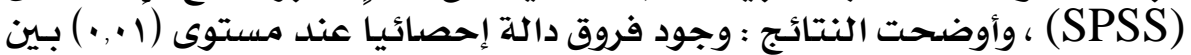

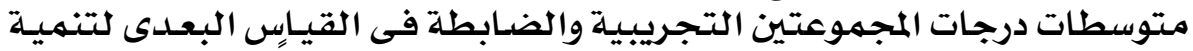

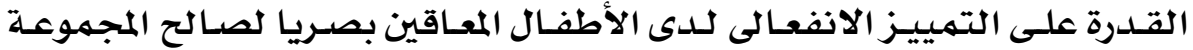

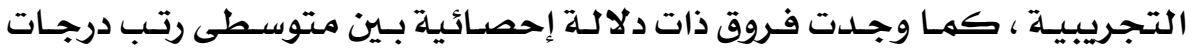

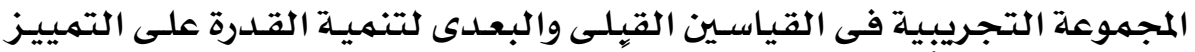

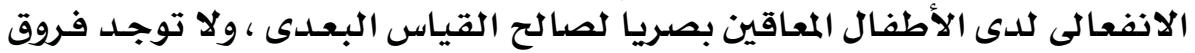

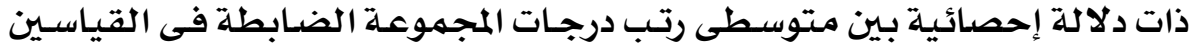

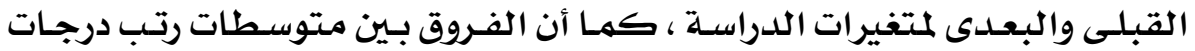

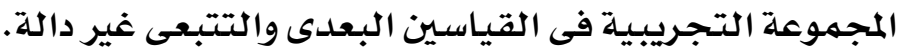

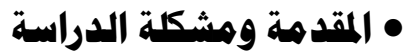

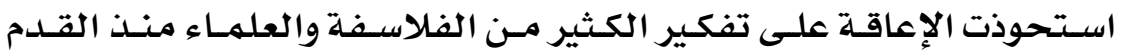

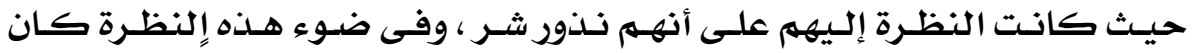

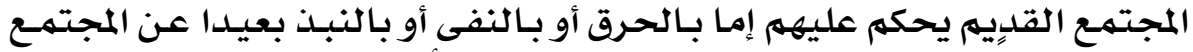

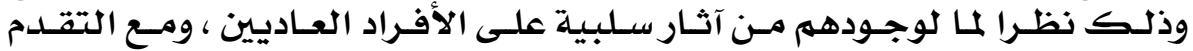

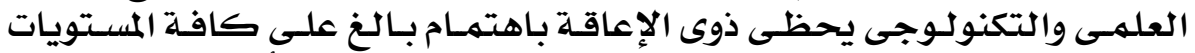

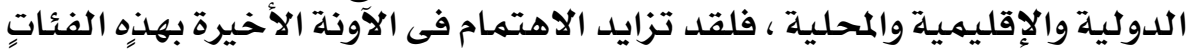

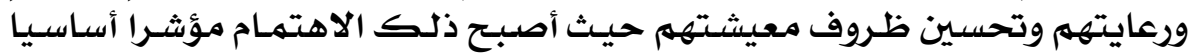

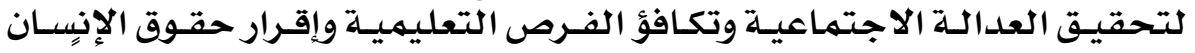

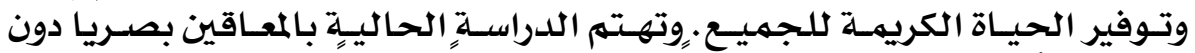

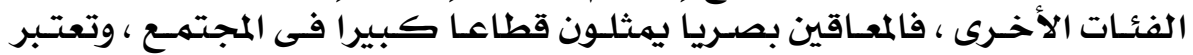

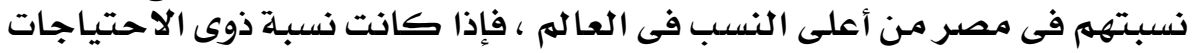

\section{$V Y$}




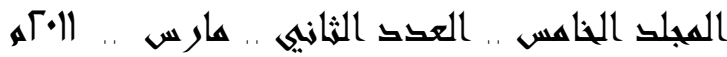

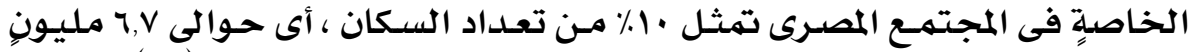

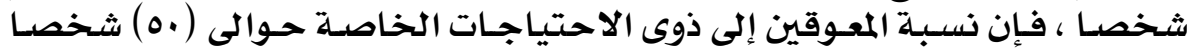

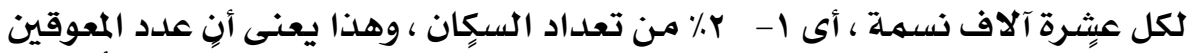

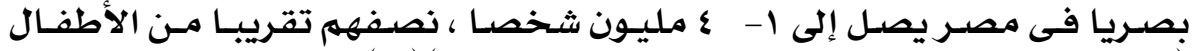

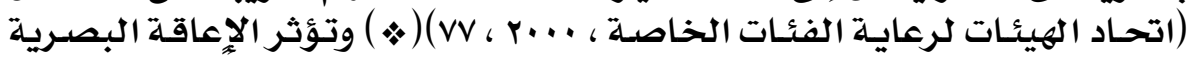

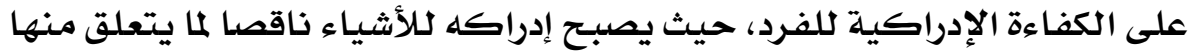

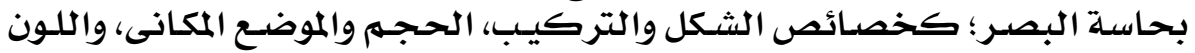

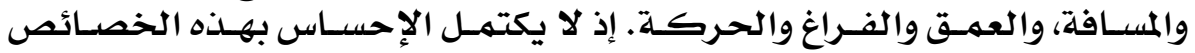

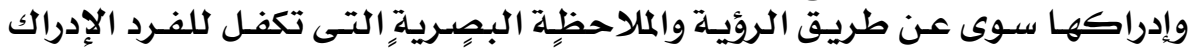

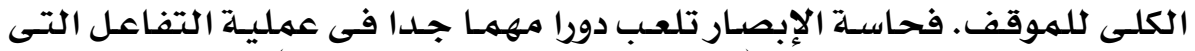

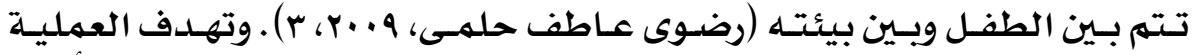

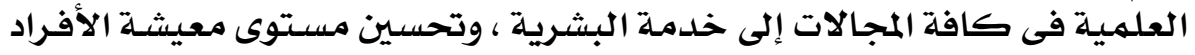

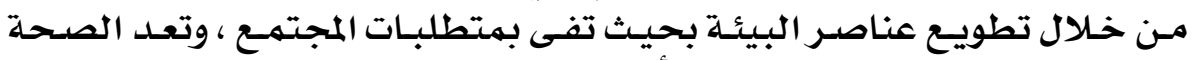

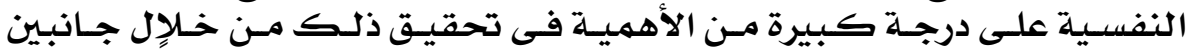

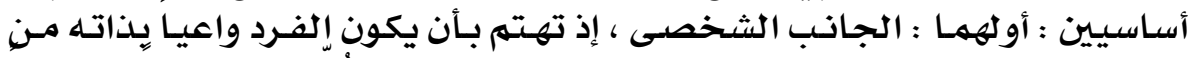

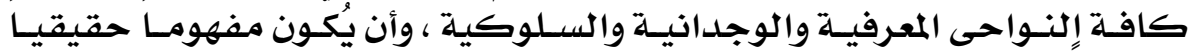

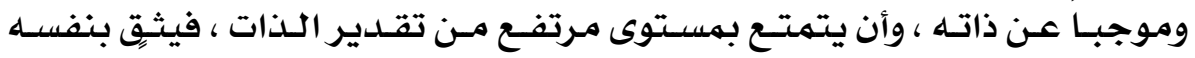

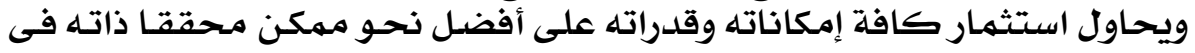

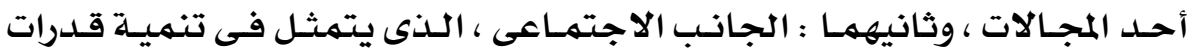

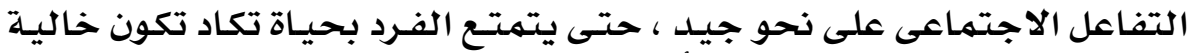

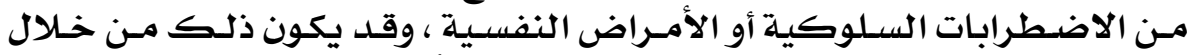

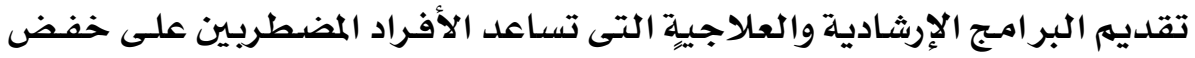

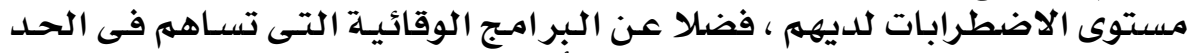

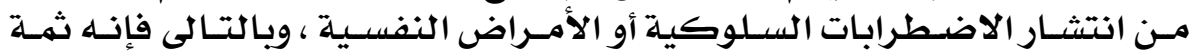

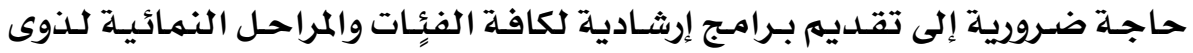

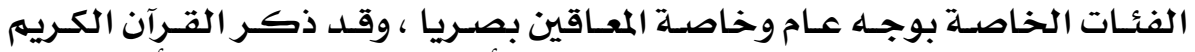

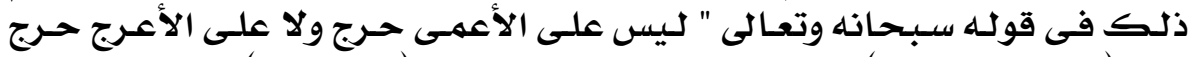

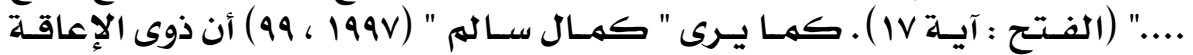

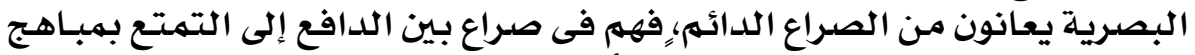

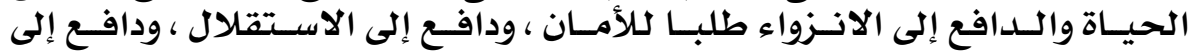

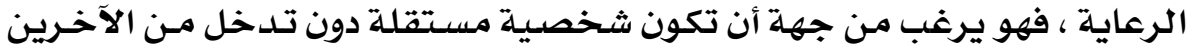

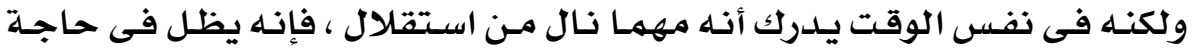

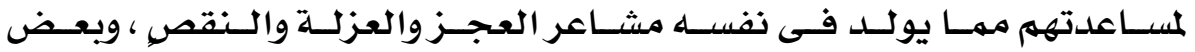

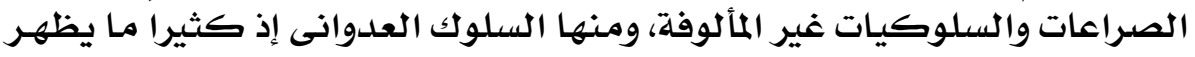

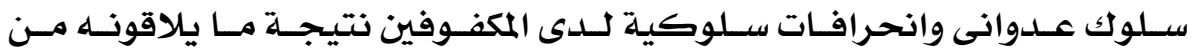

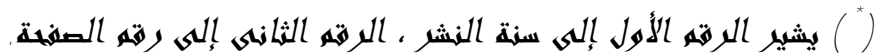

\section{$\vee \varepsilon$}

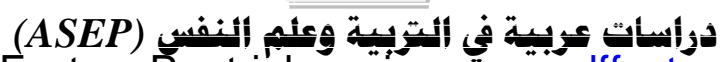

PDF created with pdfFactory Pro trial version www.pdffactory.com 
المجلى الخامس .. العقد الثخانيه .. هارس .. |ا•؟م.

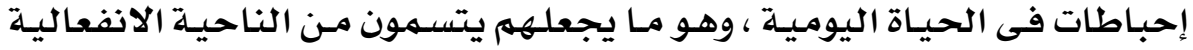

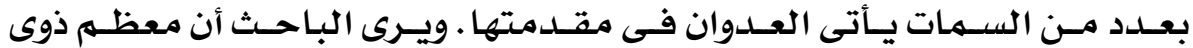

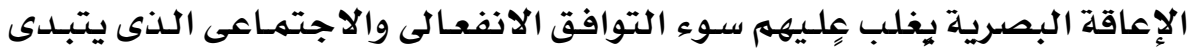

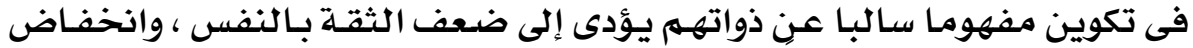

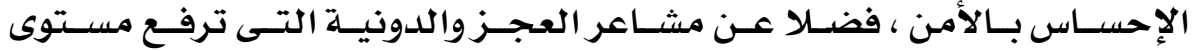

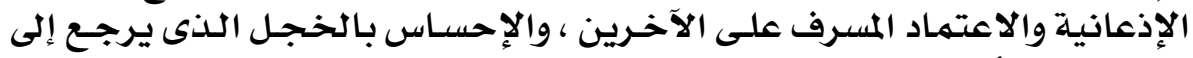

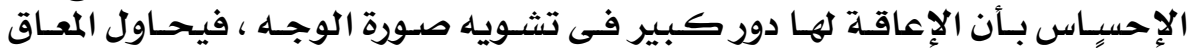

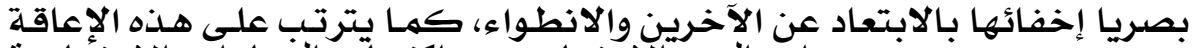

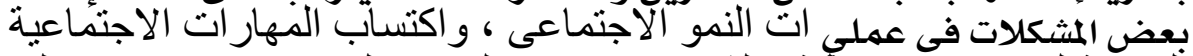

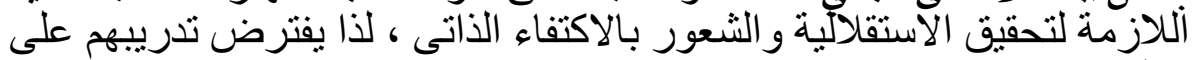

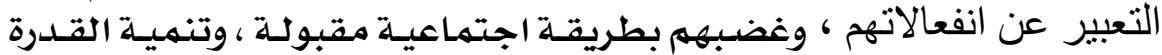

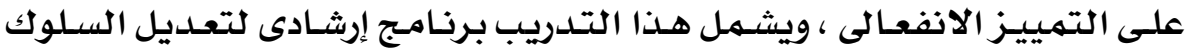
فى ضوء نظريـة العقل.

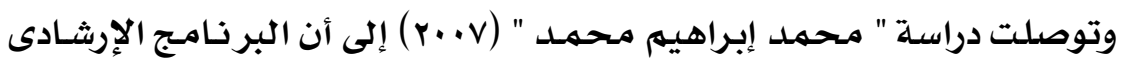

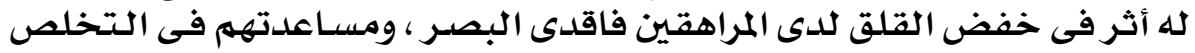

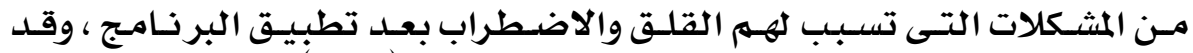

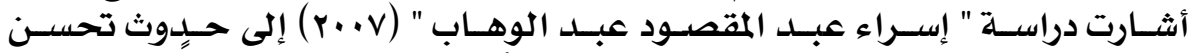

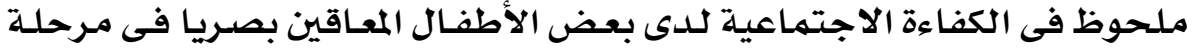

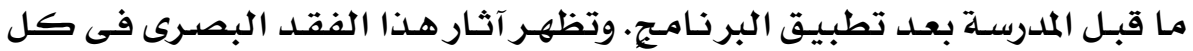

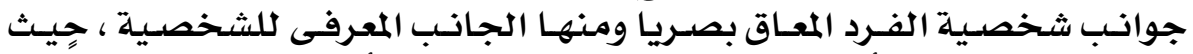

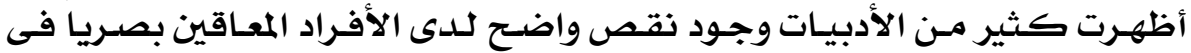

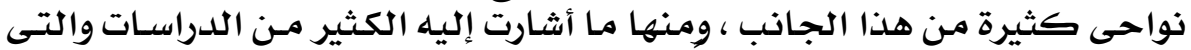

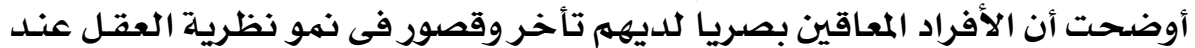

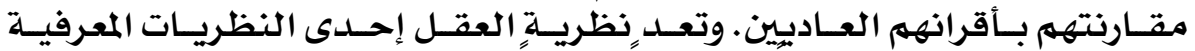

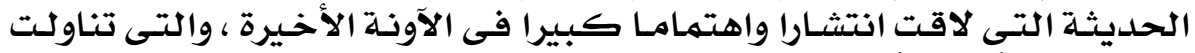

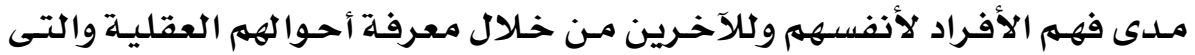

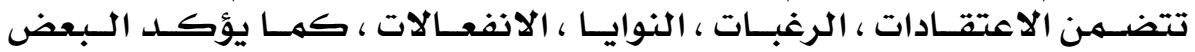

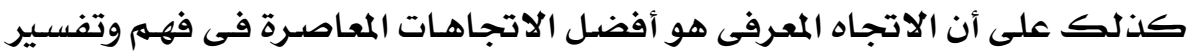

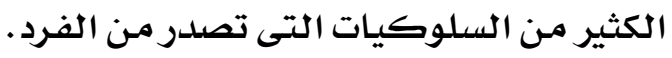

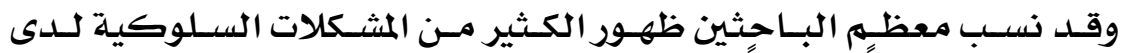

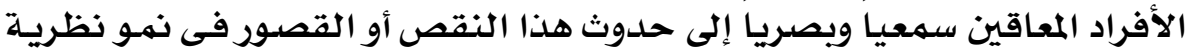

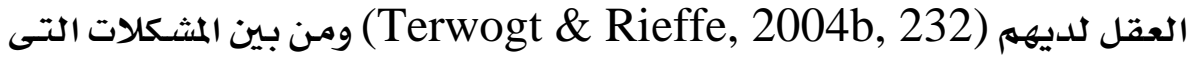

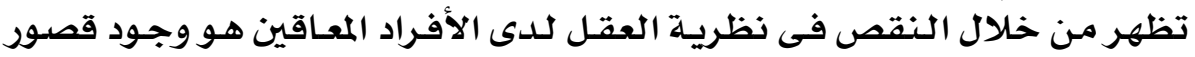

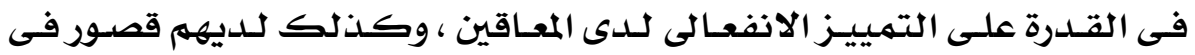

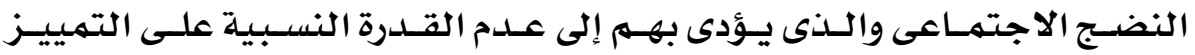

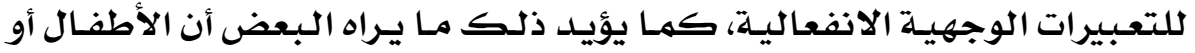

\section{V०}


المجلد الخاهس .. العكد الثمانيه .. هارس .. ال「مه

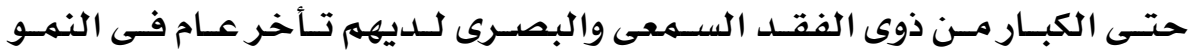

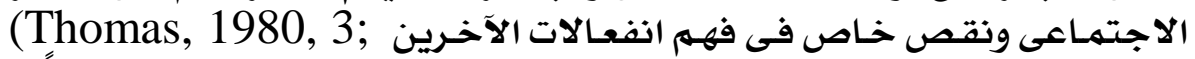

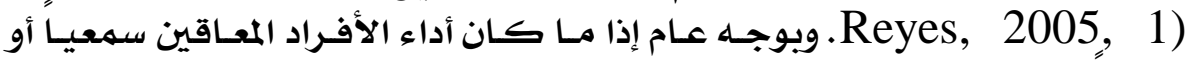

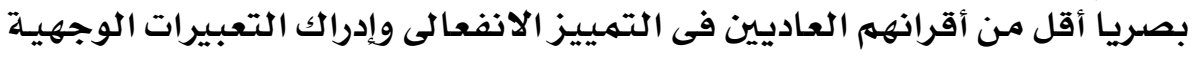

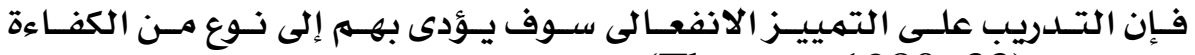

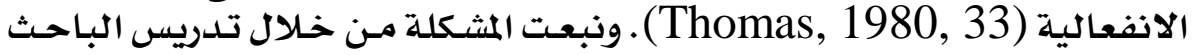

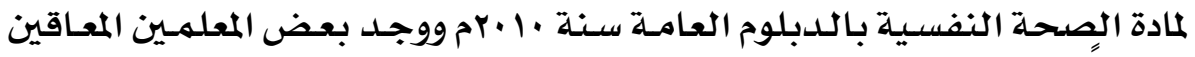

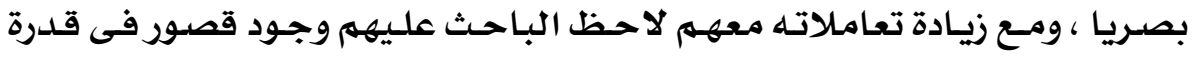

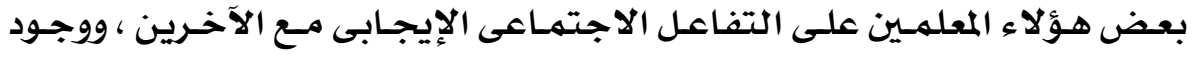

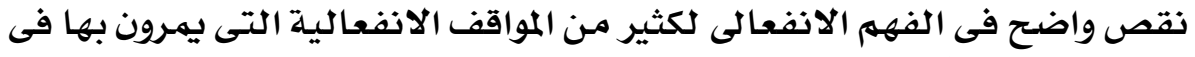

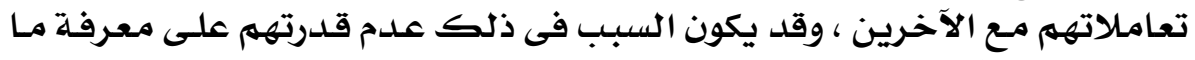

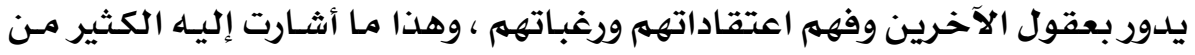

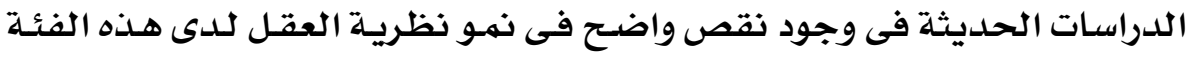

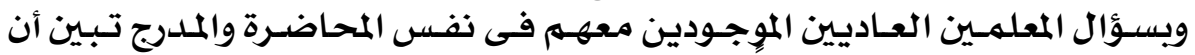

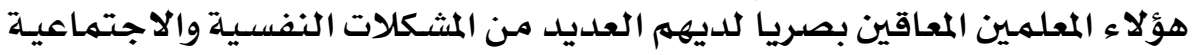

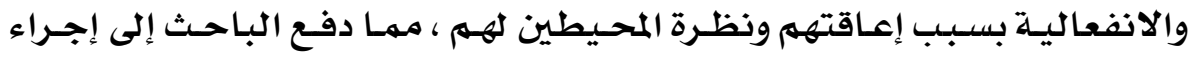

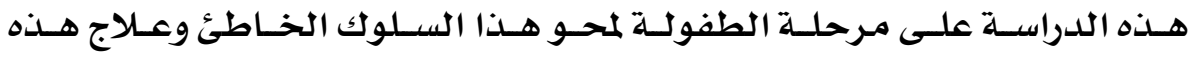

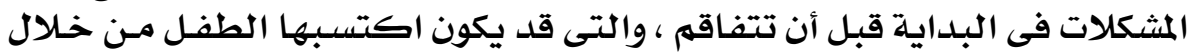
التنشئة الاجتماعية في البداية السلبيلة.

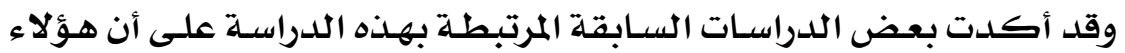

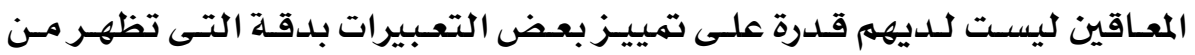

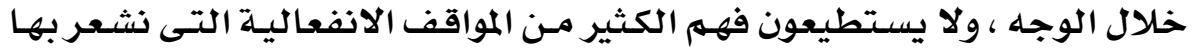

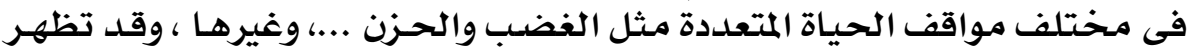

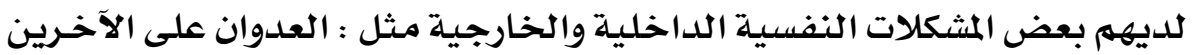

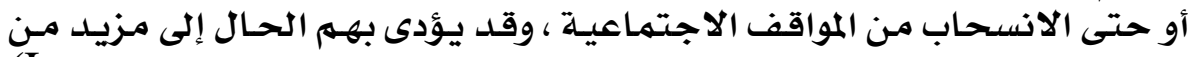

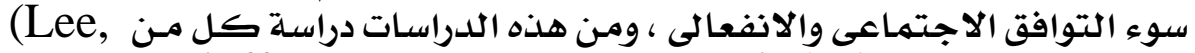
2000), (Rieffe \& Terwogt, 2004), (Aitshul, 2005), (Reyes, 2005), (Dyck \& Denver, 2003), (Thomas, 1980), (Weisel,

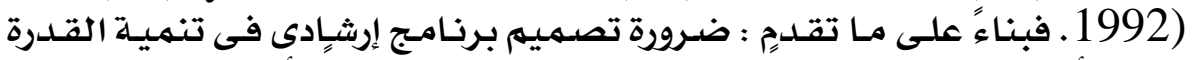

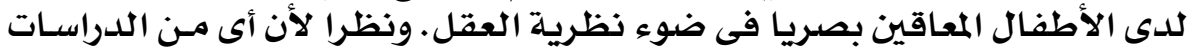

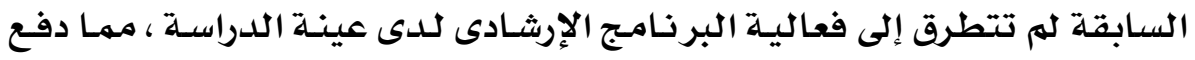

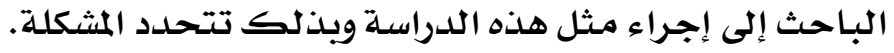

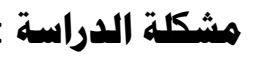

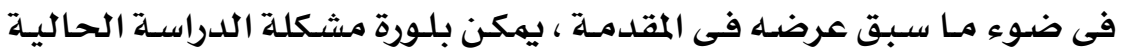

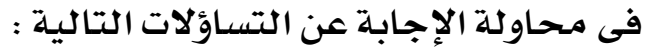

\section{V7}




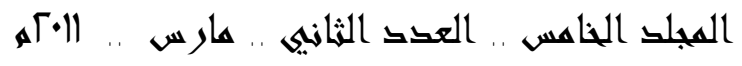

ا- هل توجد فروق دالة إحصائياً بين متوسطى رتب درجات المديات المجموعتين

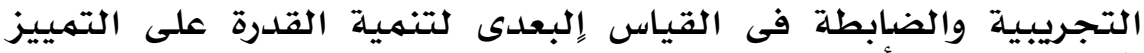

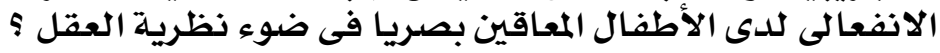

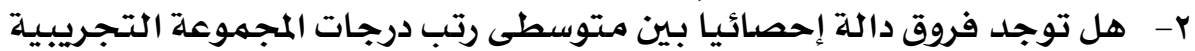

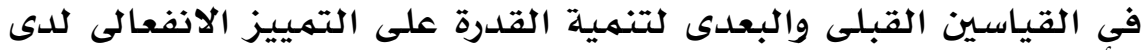

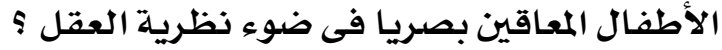

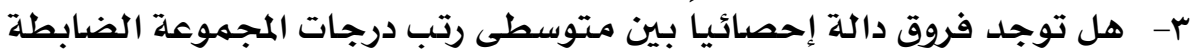

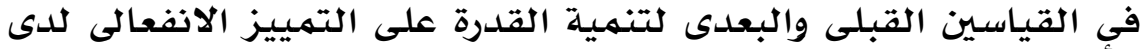

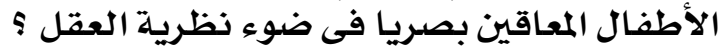

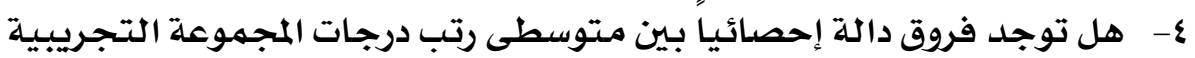

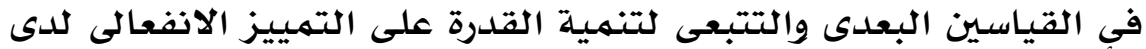

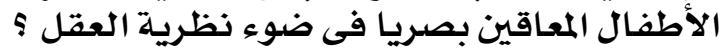

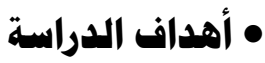 تهدف الدراسـة الحالية إلى :}

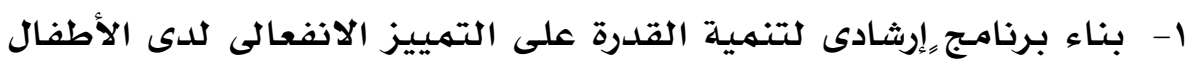

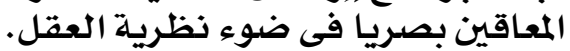

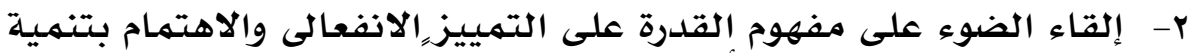

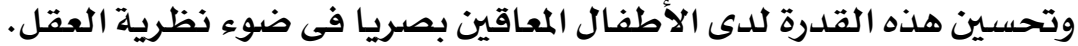

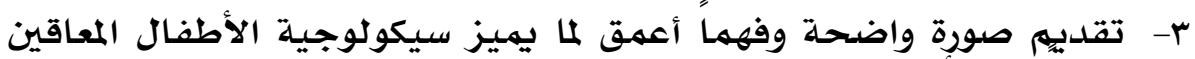

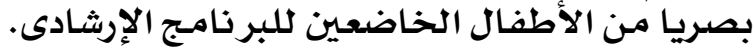

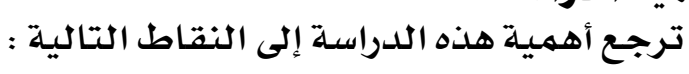

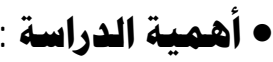

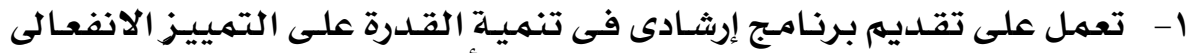

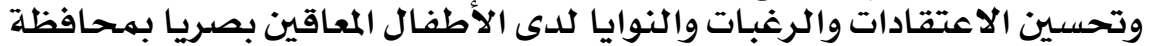

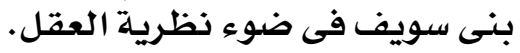

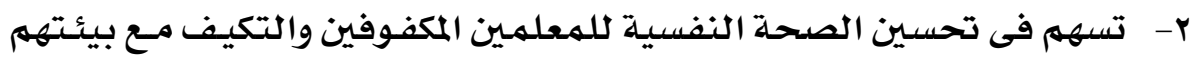

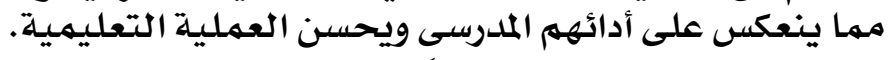

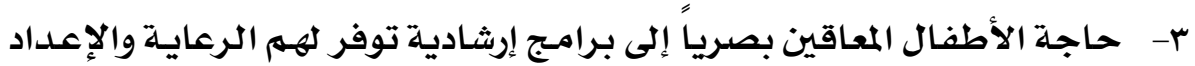

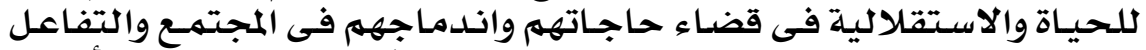

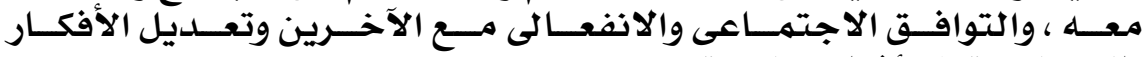
الكلاعقلانية إلى أفكار عقلانية الاجتية.

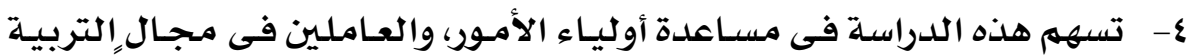

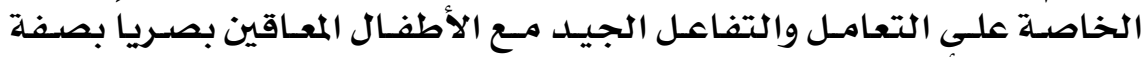

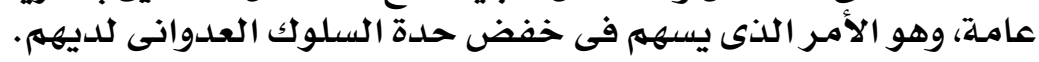

\section{VV}




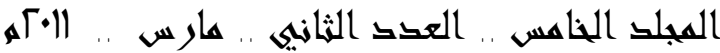

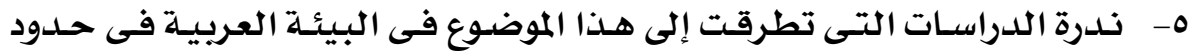

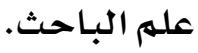

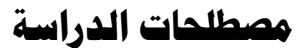

ا البرناهج الإرشادى : Counseling Program

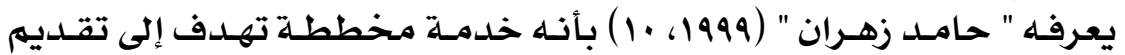

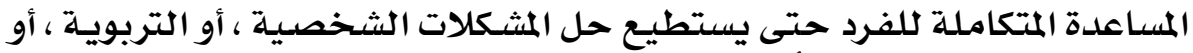

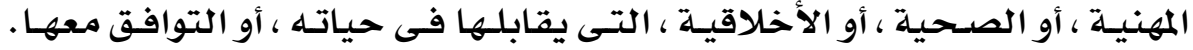

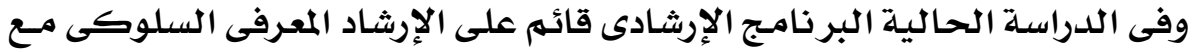

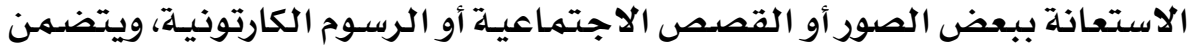

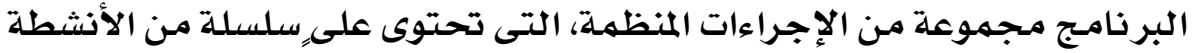

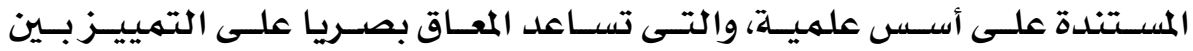

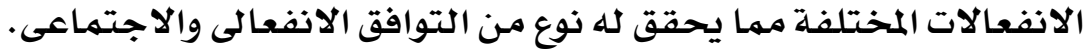

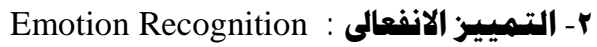

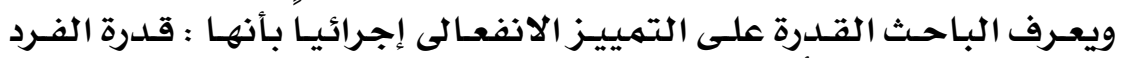

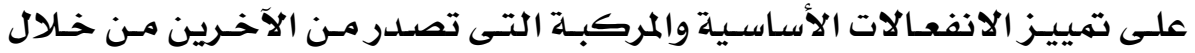

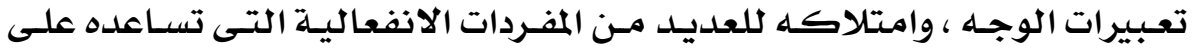

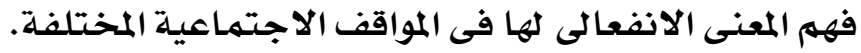

المعاقون بصريا : Visually Handicapped

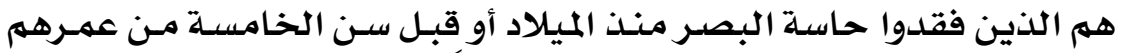

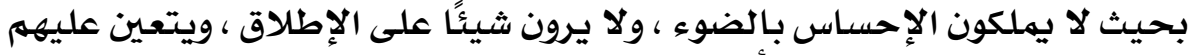

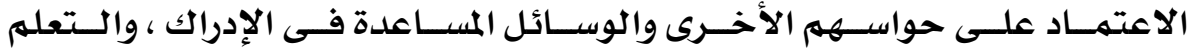

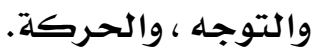

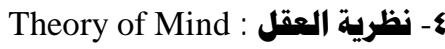

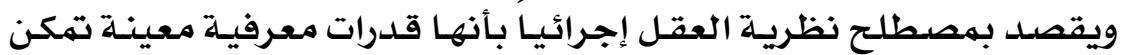

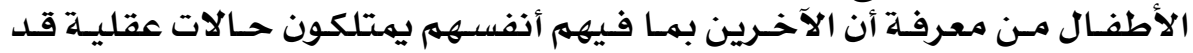

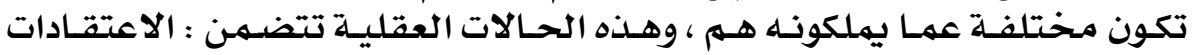

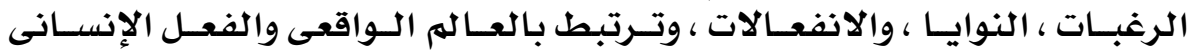

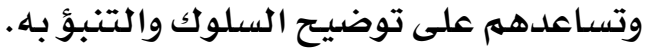

S- التوافق الاجتماءى : Social Adjustment

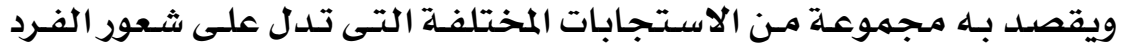

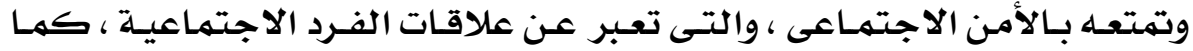

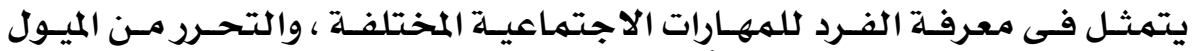

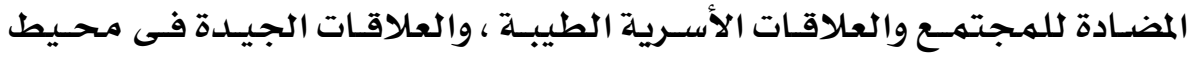

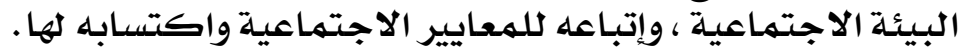

\section{$\vee \wedge$}


المجلد الخاهس .. العكد الثمانيه .. هارس .. 1ا•؟ه.

1- التوافق الانفعالى : Emotional Adjustment

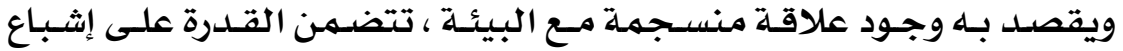

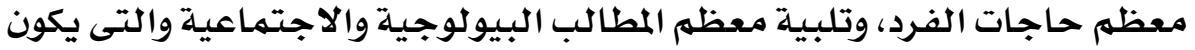

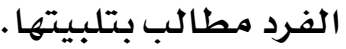
• الإطسار النظرى والدراسات السابقة :

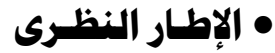

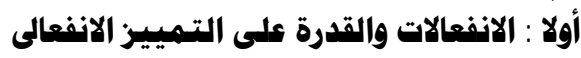

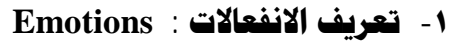

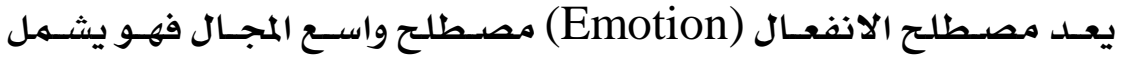

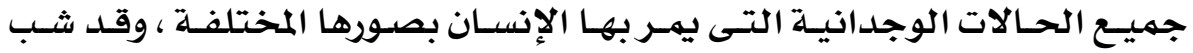

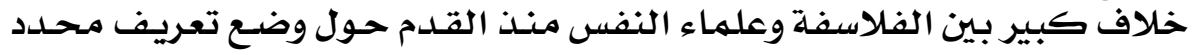

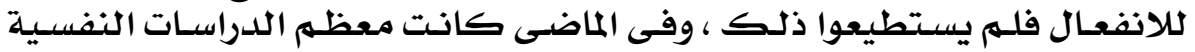

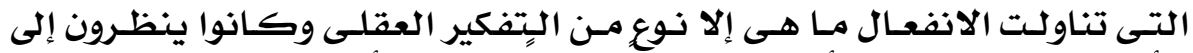

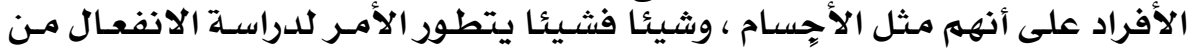

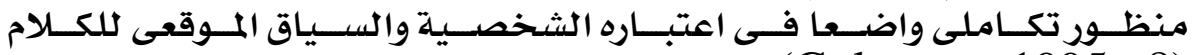

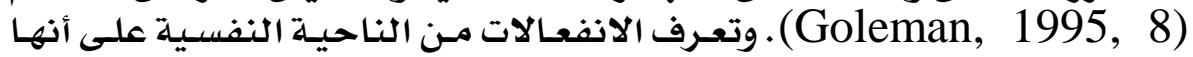

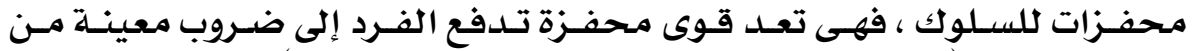

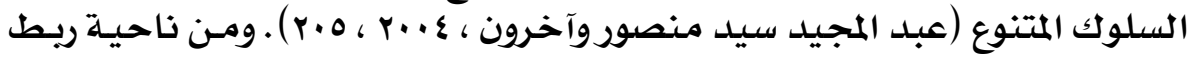

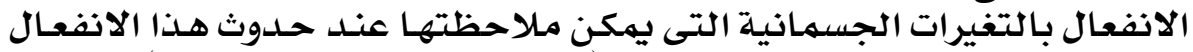

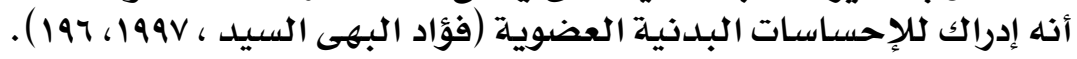

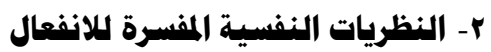

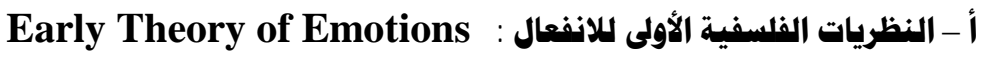
أ-1 - أفلاطون وأرسطو

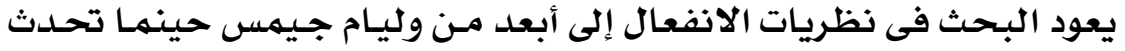

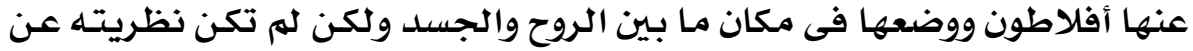

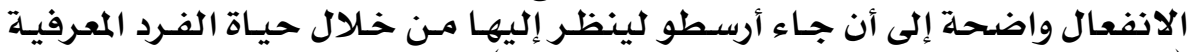

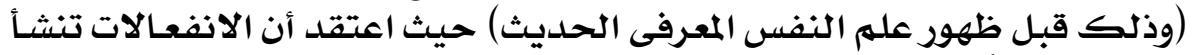

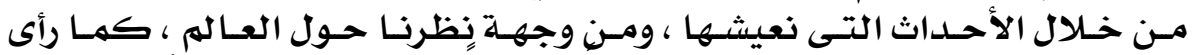

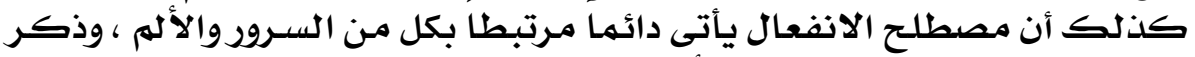

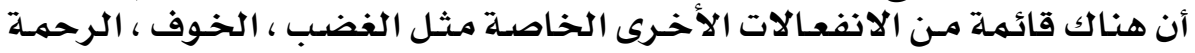

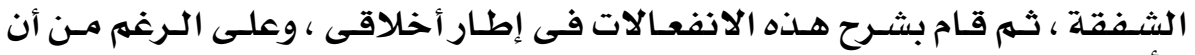

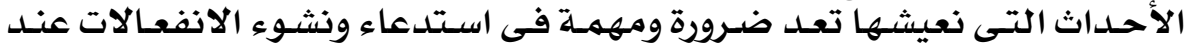

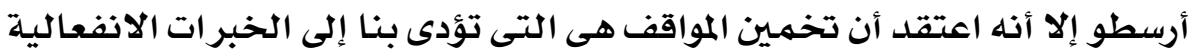

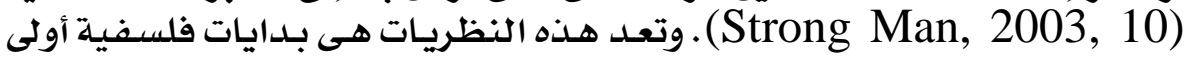
للحديث عن موضوع الانفعالات.

\section{$\checkmark 9$}


المجلى الخاهس .. العذق الثخانيه .. عارس .. ال؟مه

أ-r نظرية داروين : Darwin Theory

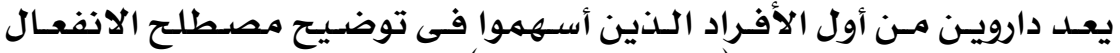

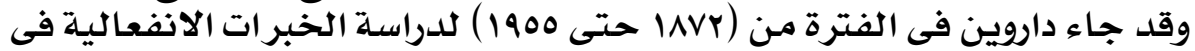

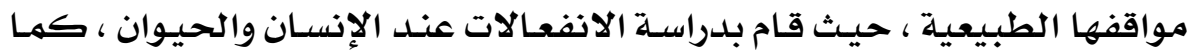

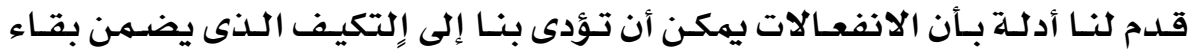

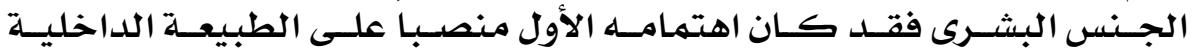

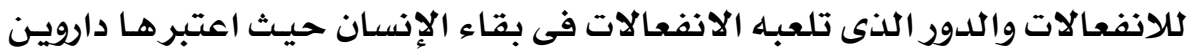

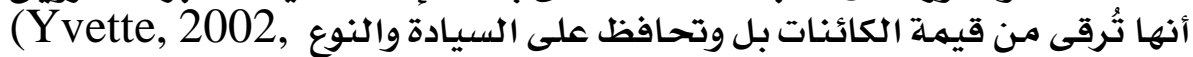

أ-r- نظرية هاكدوجال : Mcdougall Theory

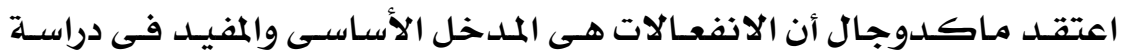

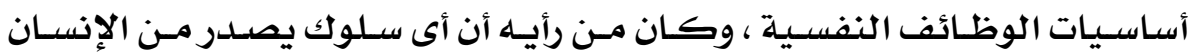

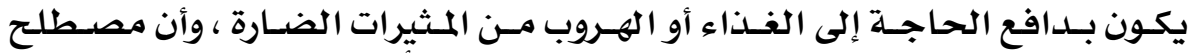

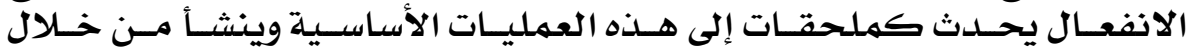

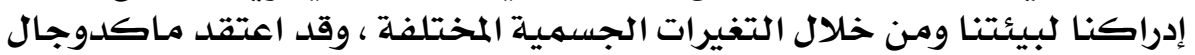

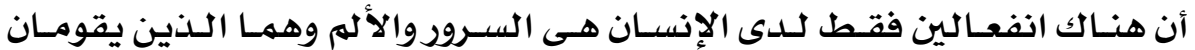

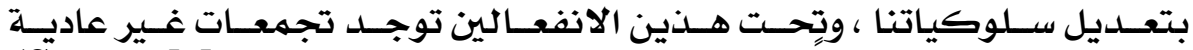

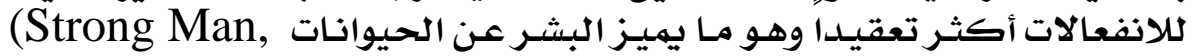

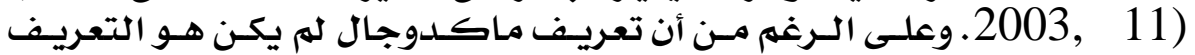

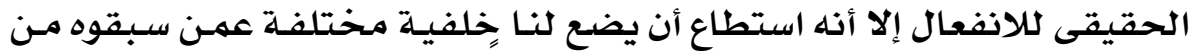

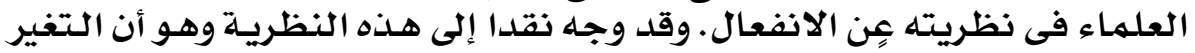

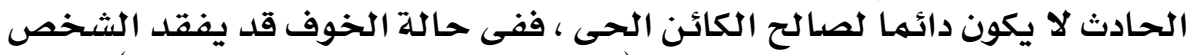

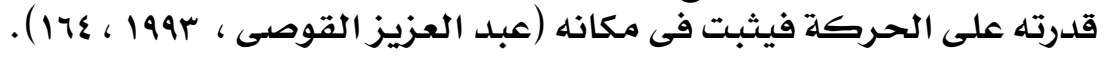

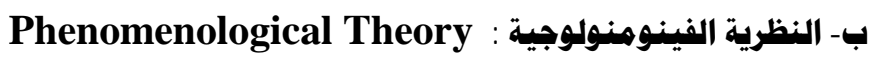

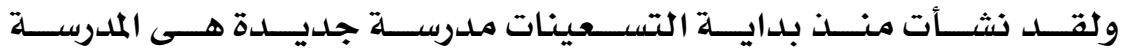

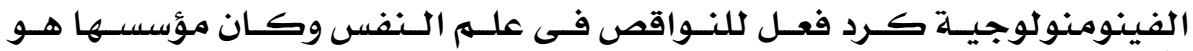

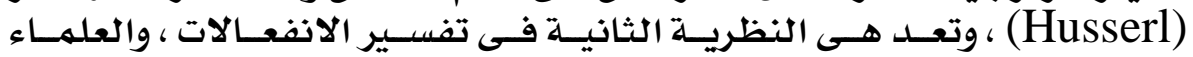

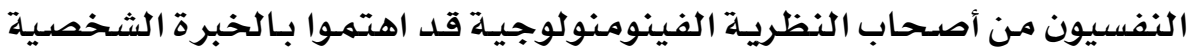

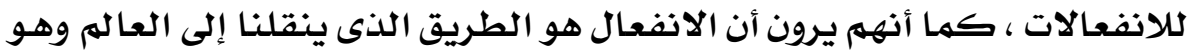

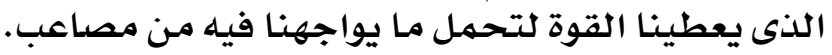

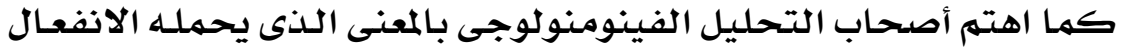

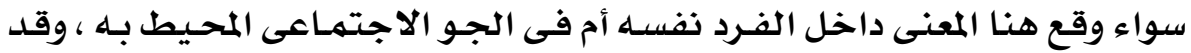

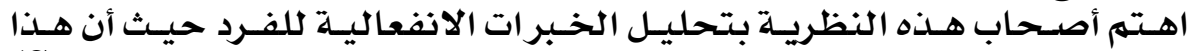

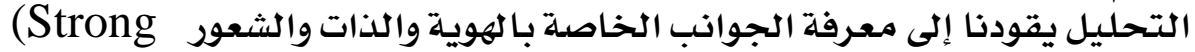
.Man, 2003, 37)

\section{$\Lambda$.}


المجلى الخامس .. العقد الثخانيه .. عارس .. ال「م.

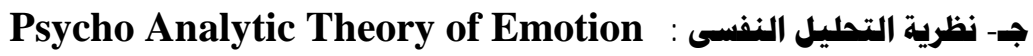

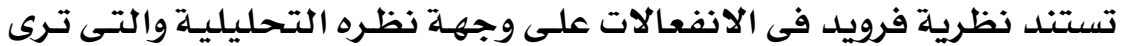

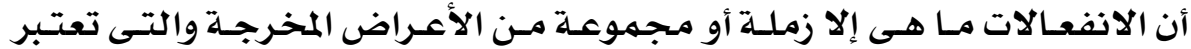

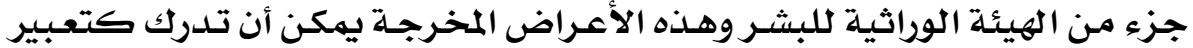

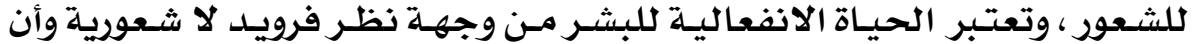

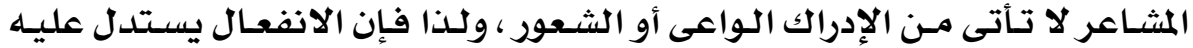

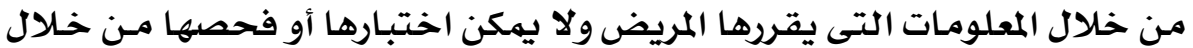
الملاحظة فقط (Rose, 1998, 8-9)

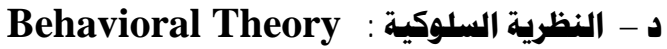

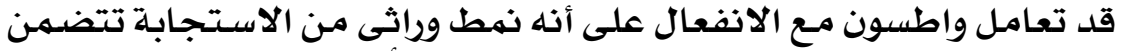

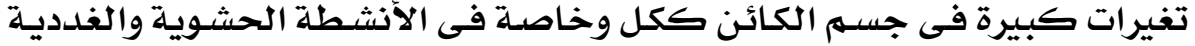

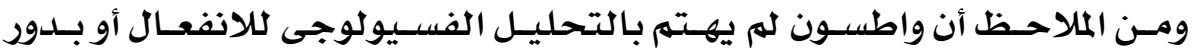

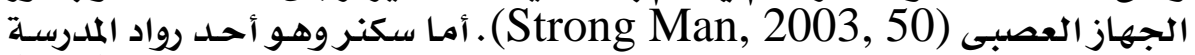

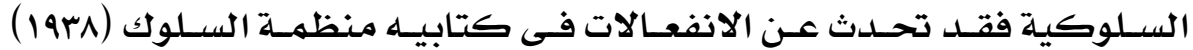

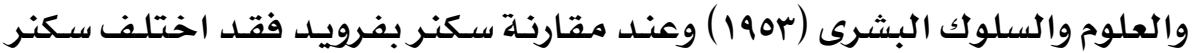

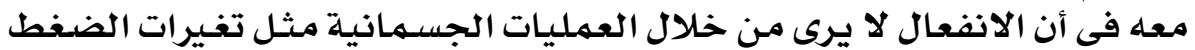

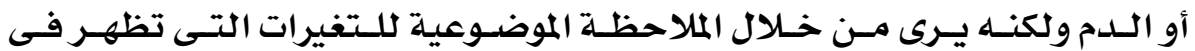
السلوكيات والاستجابـات المتعلمـة (Rose, 1998, 10).

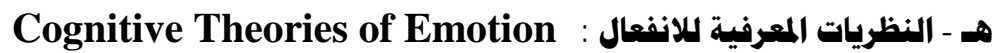

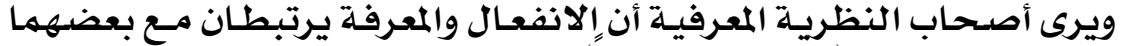

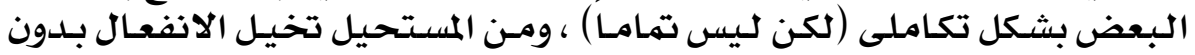

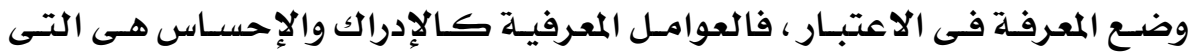

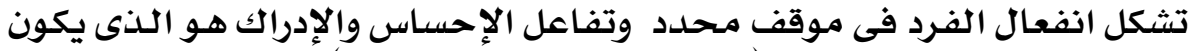

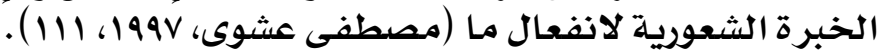

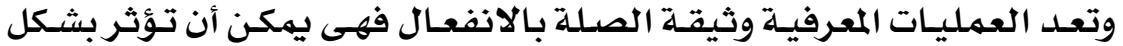

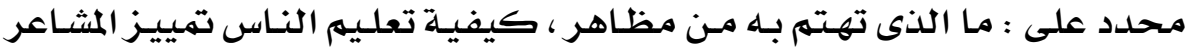

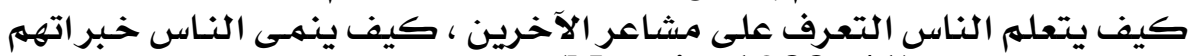
الانفعالية المعقدة (Nannis, 1988, 41).

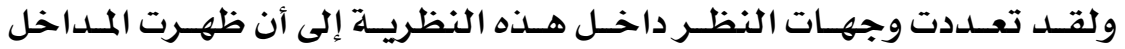

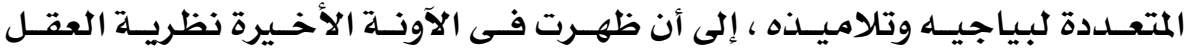

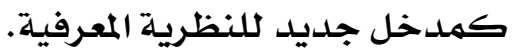

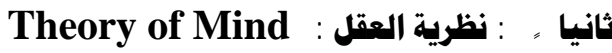

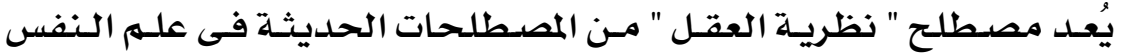

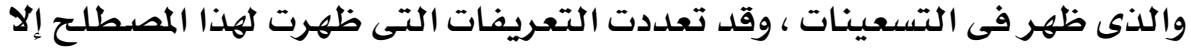

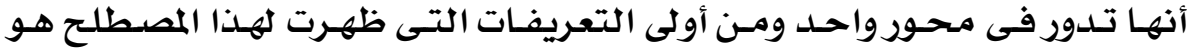

\section{$\wedge 1$}


المجلد الخاهس .. العكد الثخانيه .. هارس .. المهم

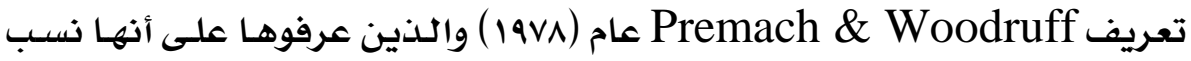

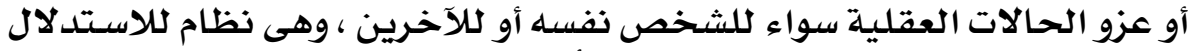

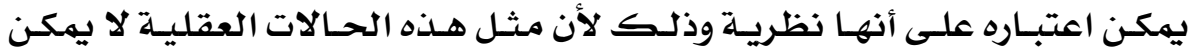

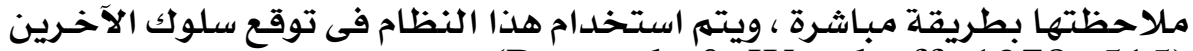

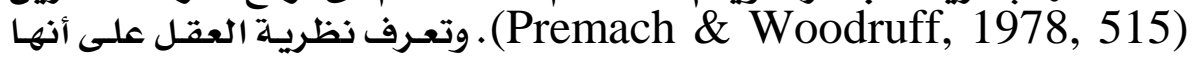

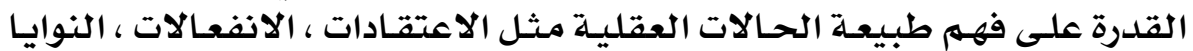

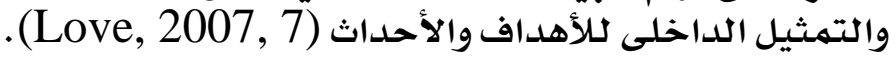

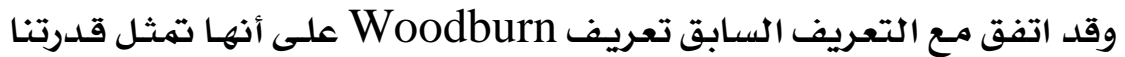

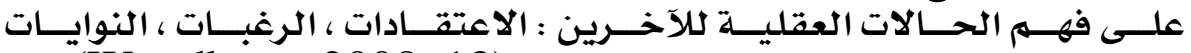

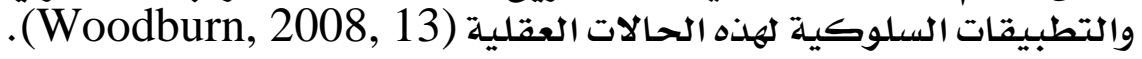

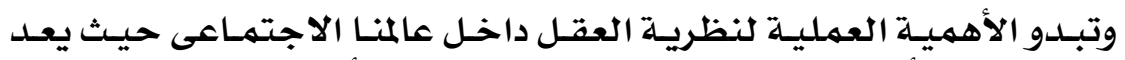

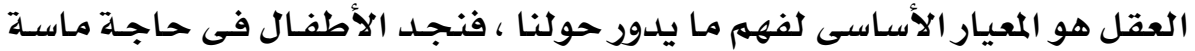

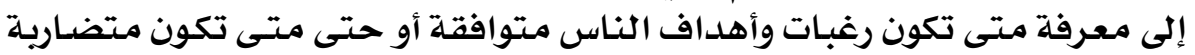

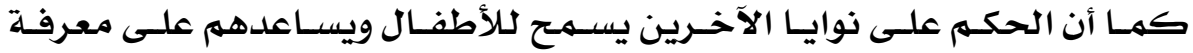

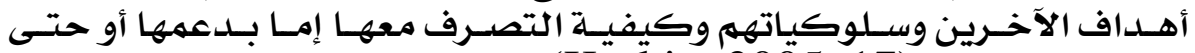
محاولة معالجتها (Keskin, 2005, 17).

أ - نهو نظرية العقل : Development of Theory of Mind

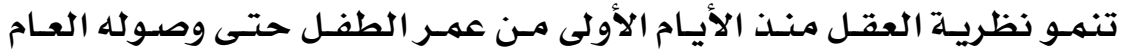

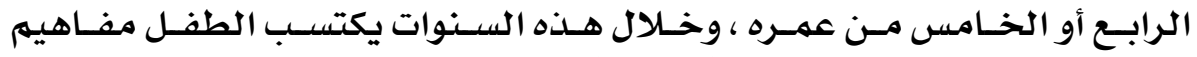

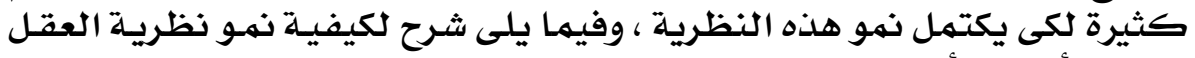
خلال الأعوام الأولى من عمل عمر الطفل.

أ-1 السنة الأولى هن العمر : The First Year of Life

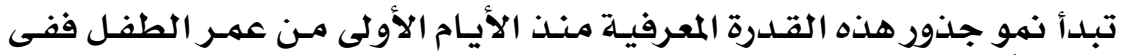

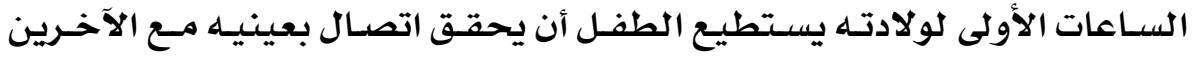

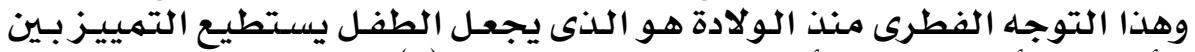

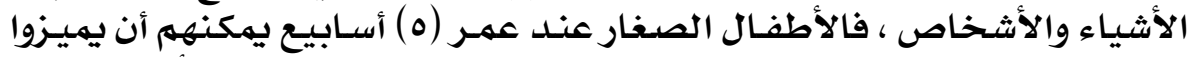

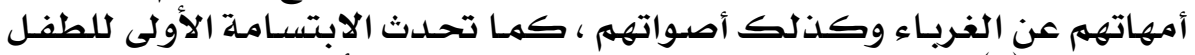

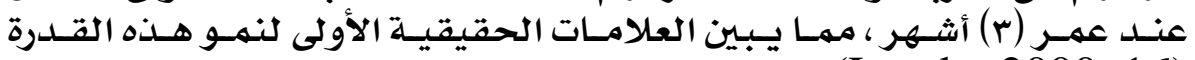
.(Lundy, 2000, 16)

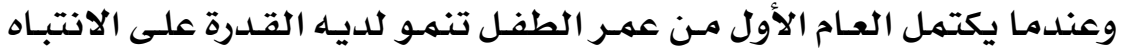

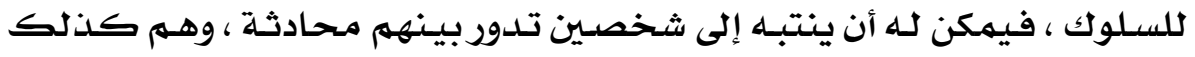

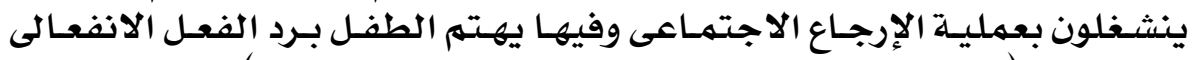

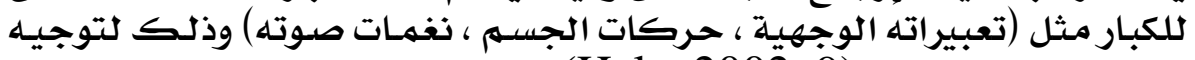
سلوكياتهم الداخلية (Hale, 2002, 9).

\section{$\Lambda Y$}


المجلى الخامس .. العقد الثخانيه .. هارس .. |ا•؟م.

أ-r- السنة الثانية هن العهر : The Second Year of Life

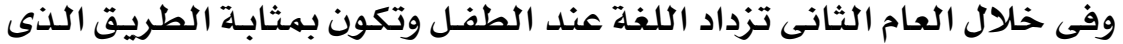

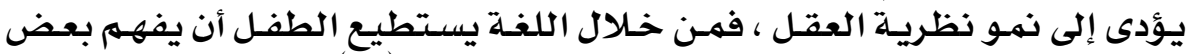

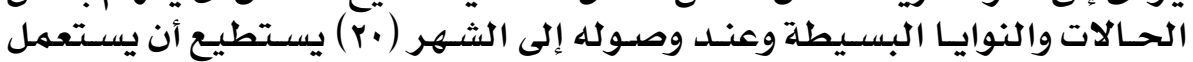

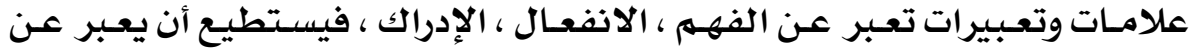

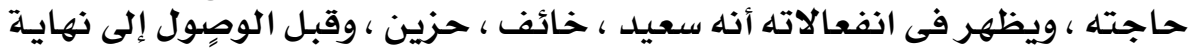

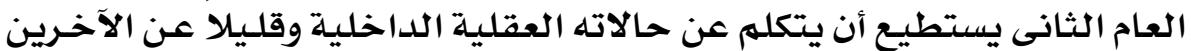
(Lundy, 2000, 19)

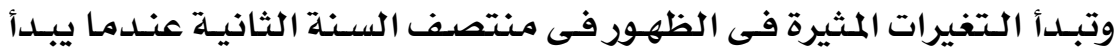

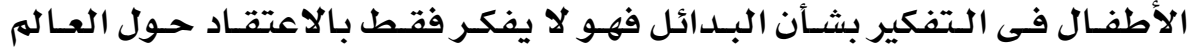

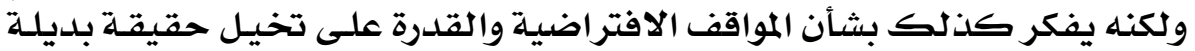

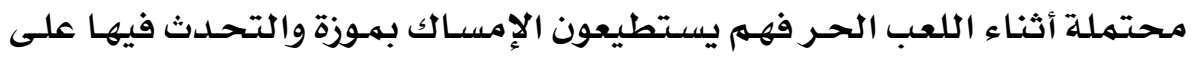

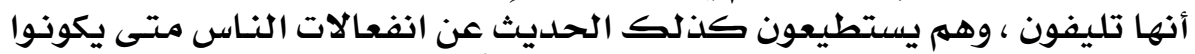

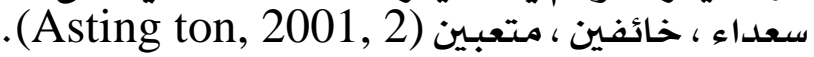

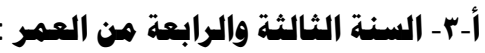

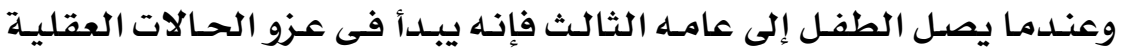

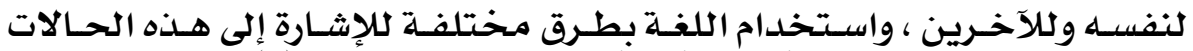

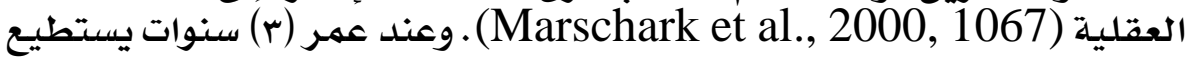

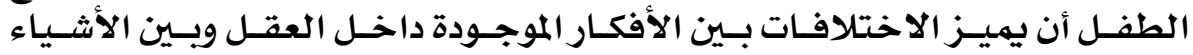

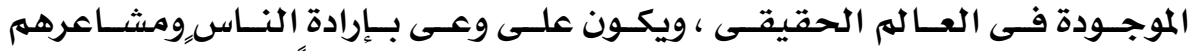

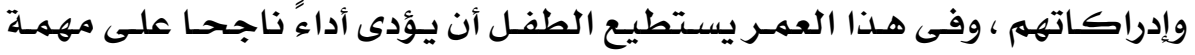

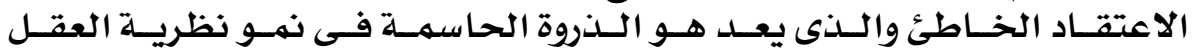
.(Astington, 2001, 3)

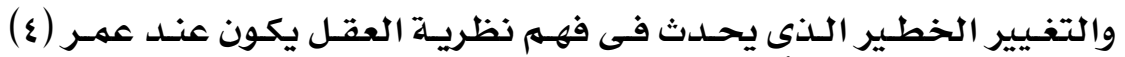

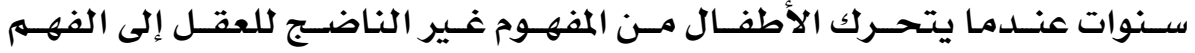

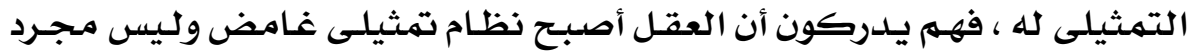

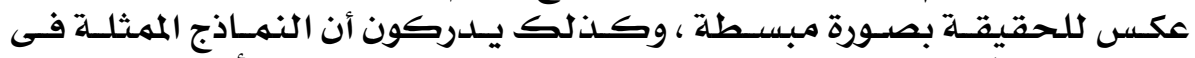

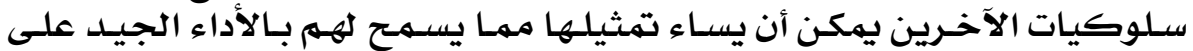

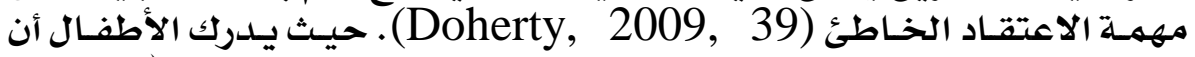

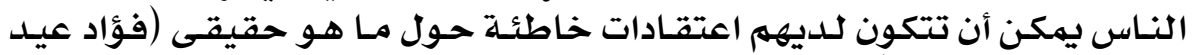

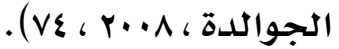

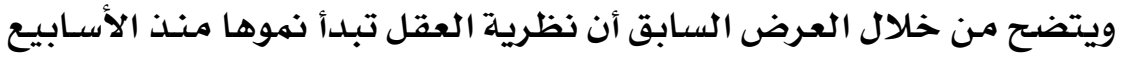

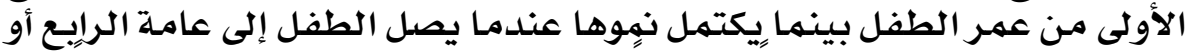

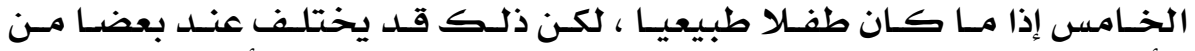

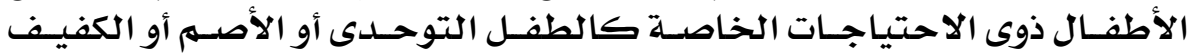

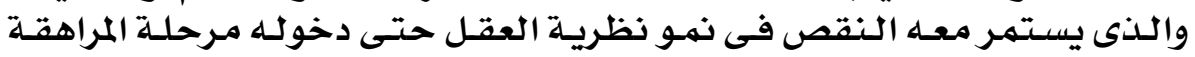

\section{$\Lambda \mathrm{r}$}




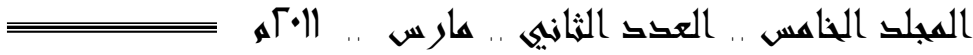

وهـذا يفسـروجـود كثير مـن مشـكلات الاتصـال والتفاعـل مـع كـثير مـن هـؤلاء

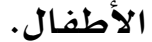

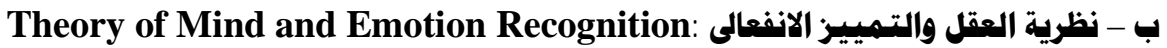

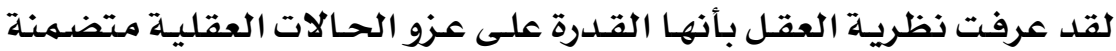

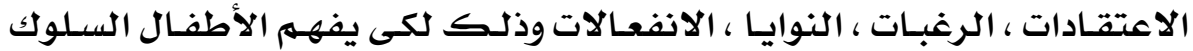

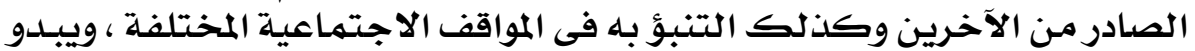

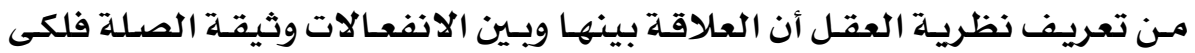

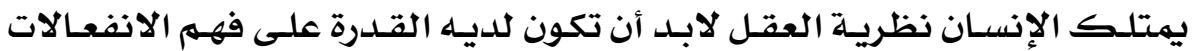

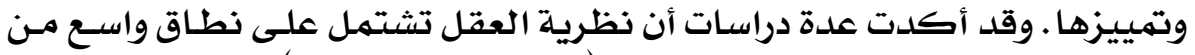

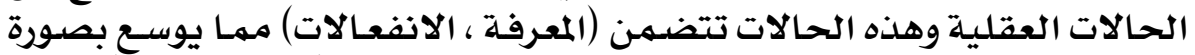

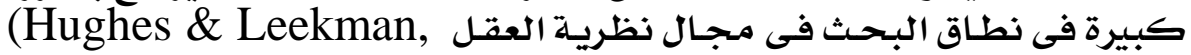

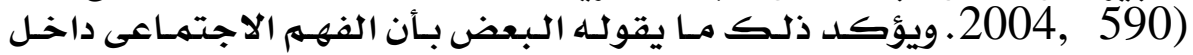

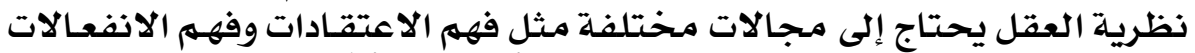
الصادرة من الآخرين (Bosacki \& Astington, 1999, 238).

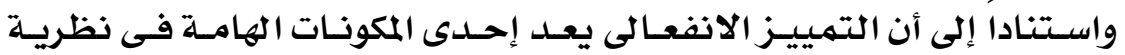

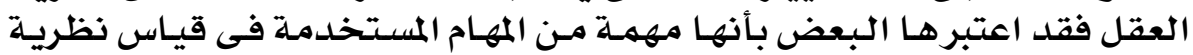

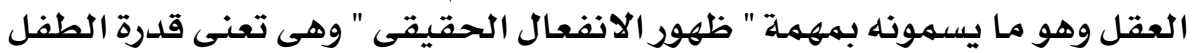

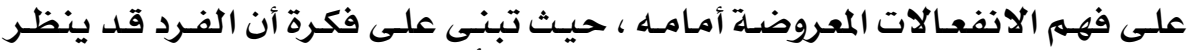

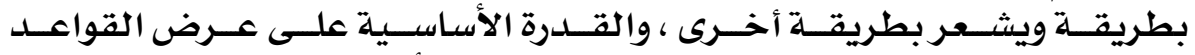

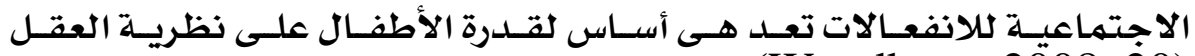
.(Woodburn, 2008, 20)

ولذلك فإِن أى قصور فى نظريـة العقل يؤدى إلى نقص القد القدرة على التميـيز

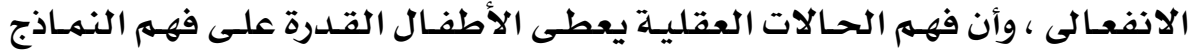

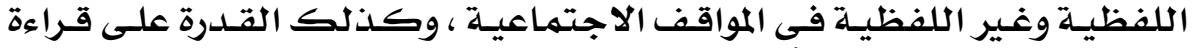

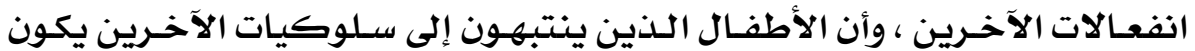
ذلك متنباً له بالنواتج الانفين الانفعالية (Woodburn, 2008, 42).

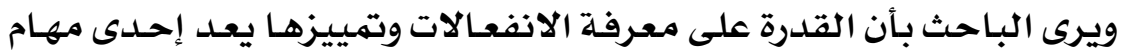

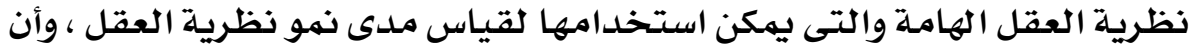

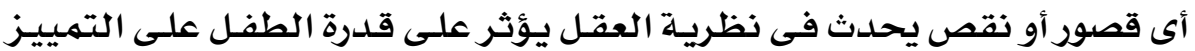

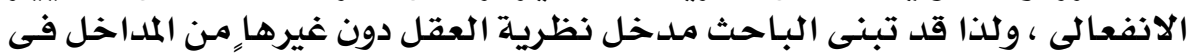

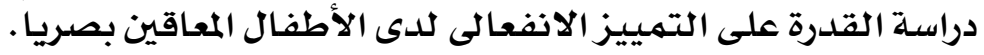

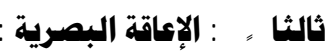

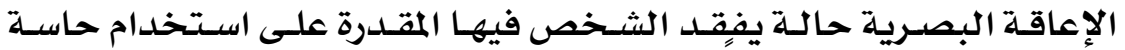

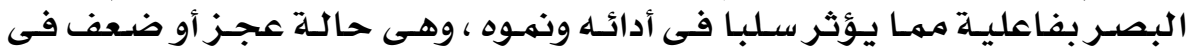

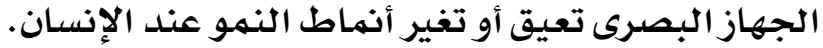

\section{$\wedge \varepsilon$}




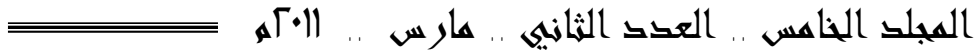

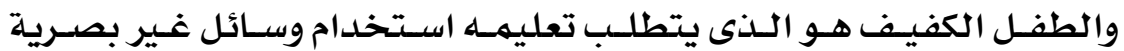

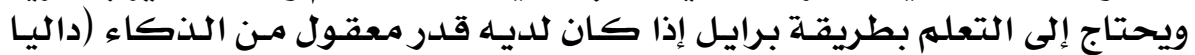

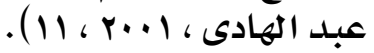

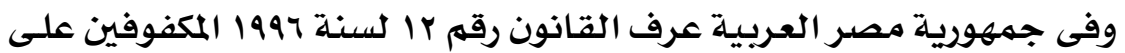

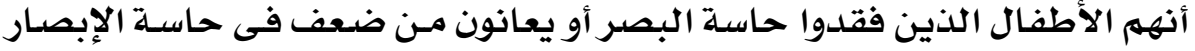

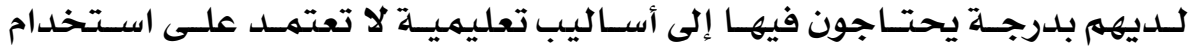

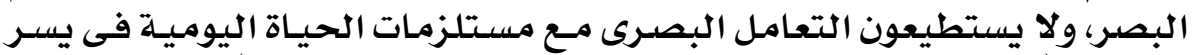
وكفاءة (اتحاد هيئات رعاية الفئات الخاصة والمعوقين، 1991، 79 79 ).

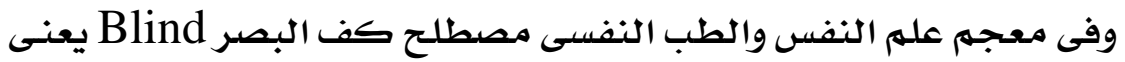

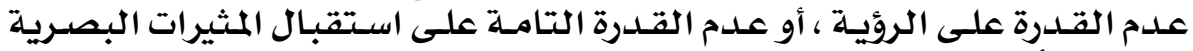

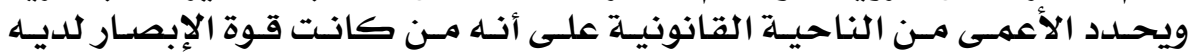

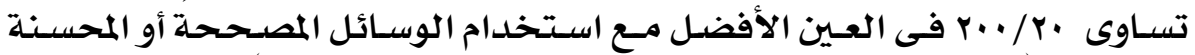

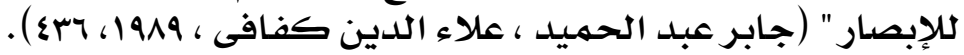

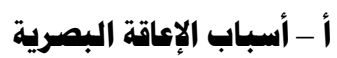

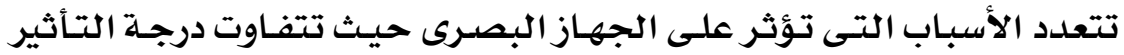
من الإصابة بالعمى الجزئى إلى الإصابة بالعمى الكلى العي ، ومن أهمها ما يلى :

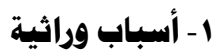

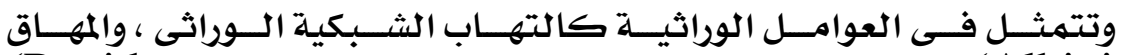

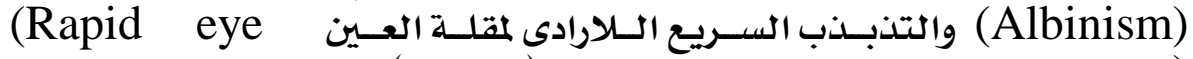

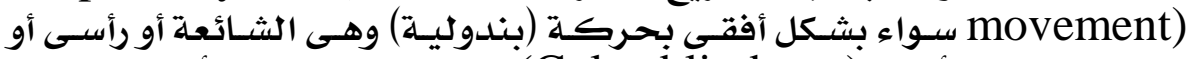

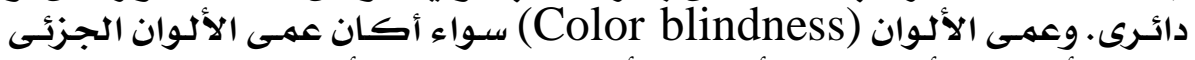

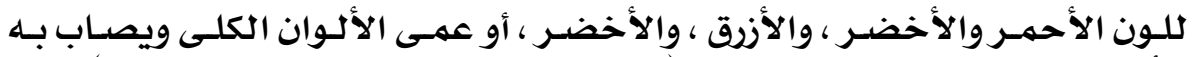

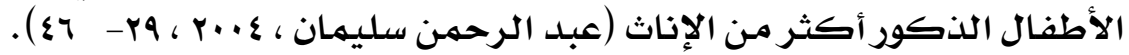

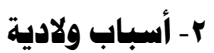

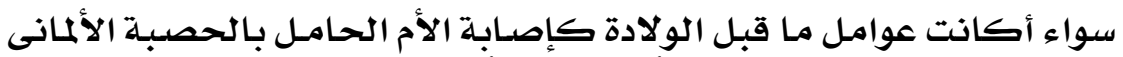

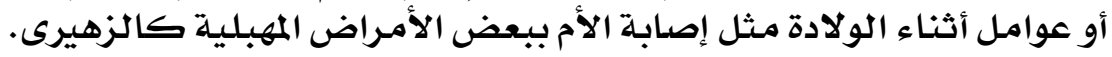

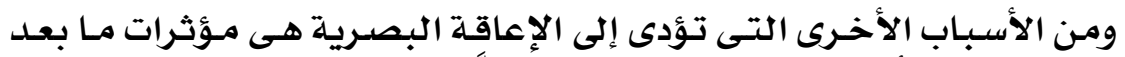

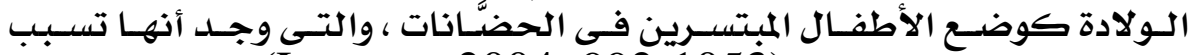

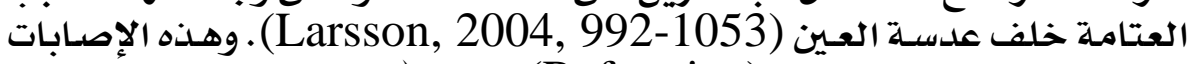

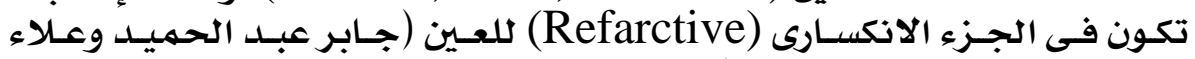

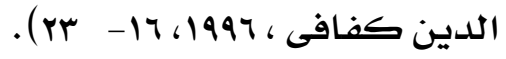

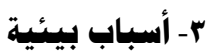
كانتشار العمى النهرى في أفريقيا أو نقص فيتامين " أنس أ " في آسيا وأفريقيا

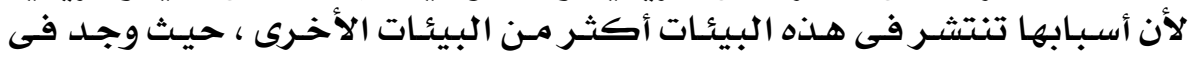

\section{$\wedge \bullet$}

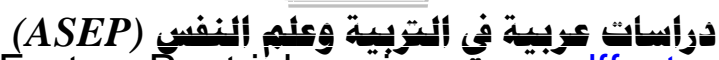

PDF created with pdfFactory Pro trial veršion www.pdffactory.com 


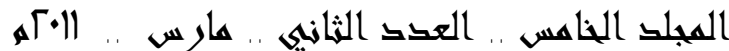

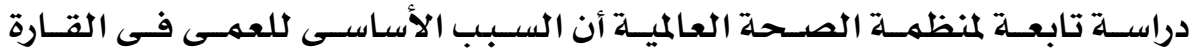

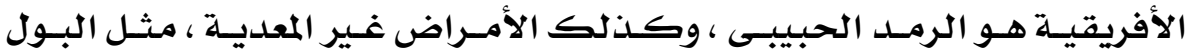

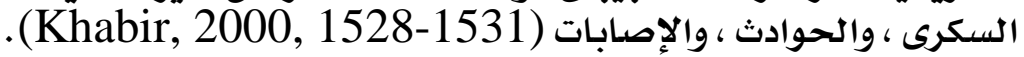

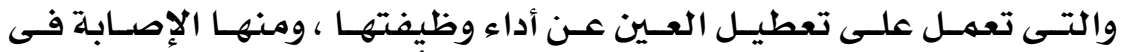

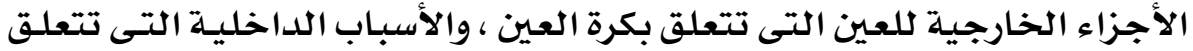

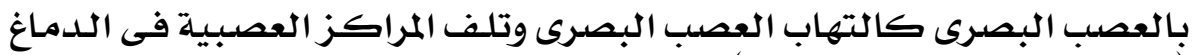

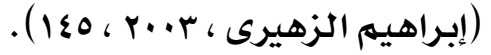

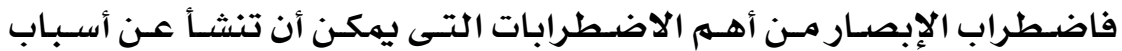

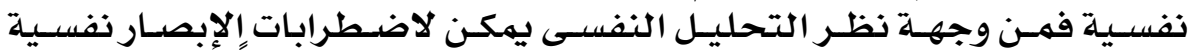

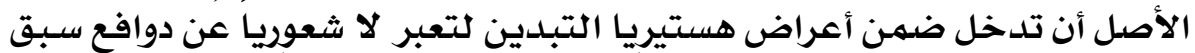

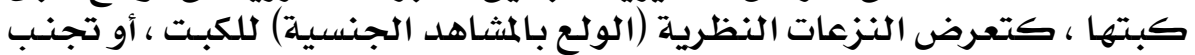

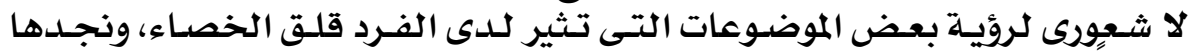

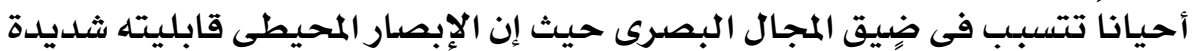

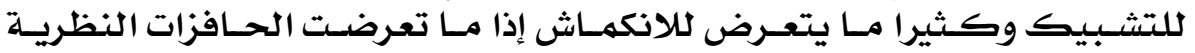
للكبت، فالبصر المحيطى أقل أهمية لتلأنا.

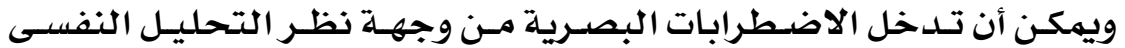

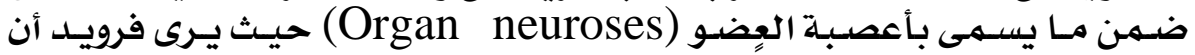

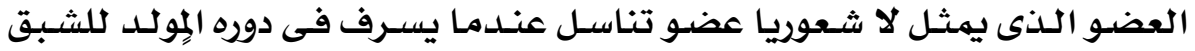

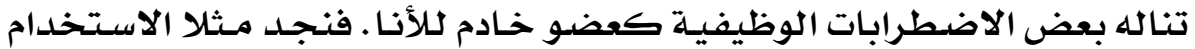

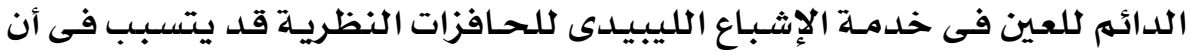

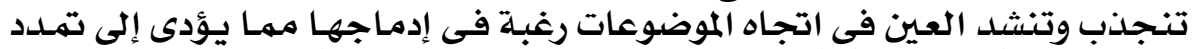

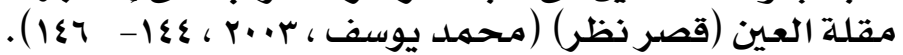

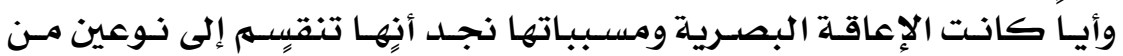

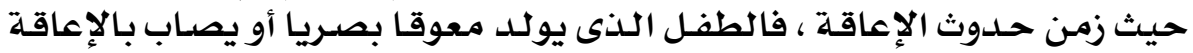

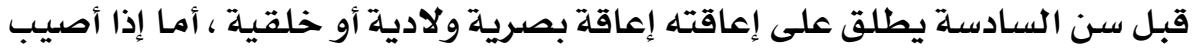

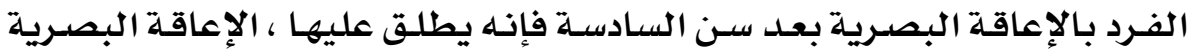

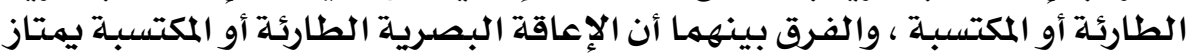

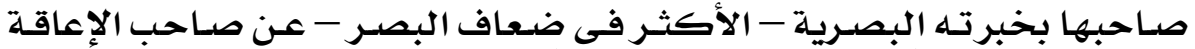

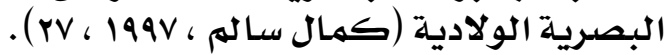

بالبصائص المميرة للطفل المعاق بصِريا

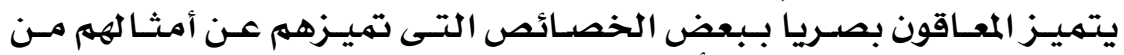

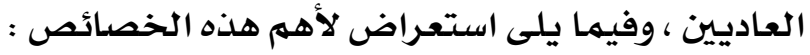

\section{$\Lambda 7$}


المجلى الخامس .. العقد الثخانيه .. هارس .. |ا•؟م.

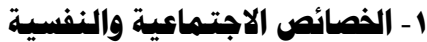

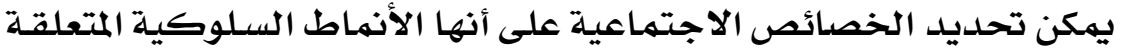

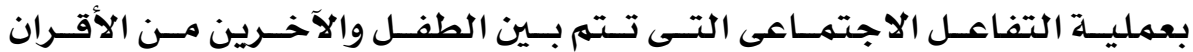

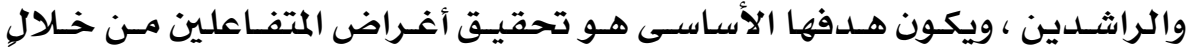

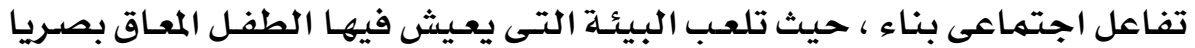

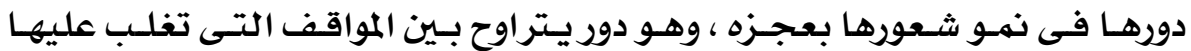

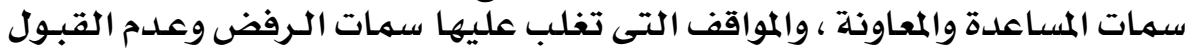

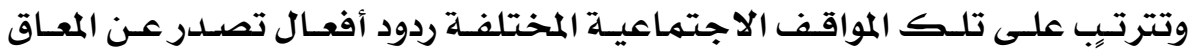

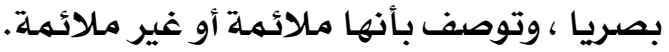

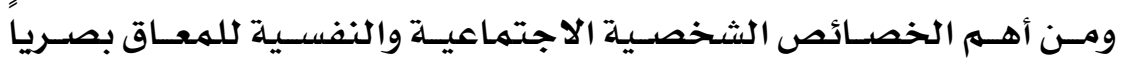

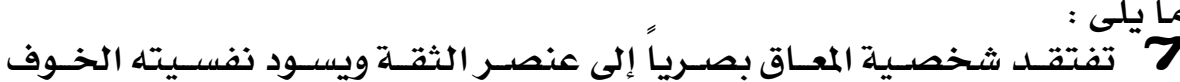

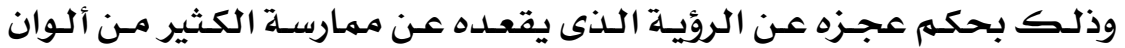

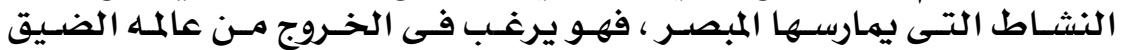

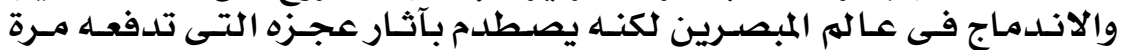

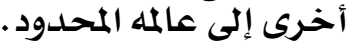

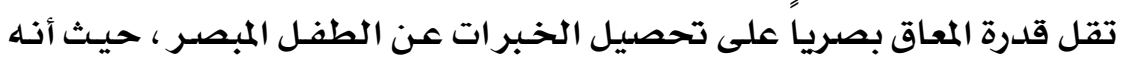

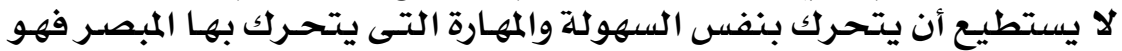

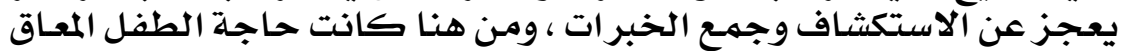

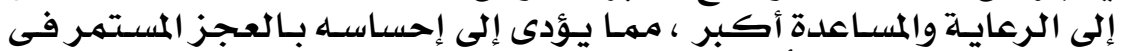

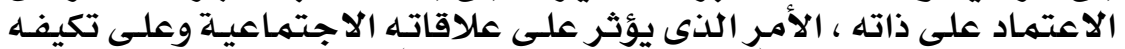

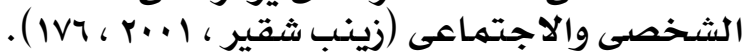

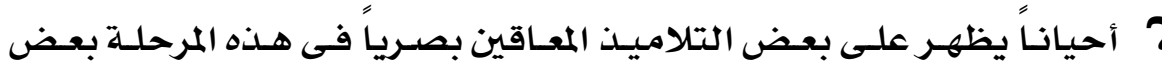

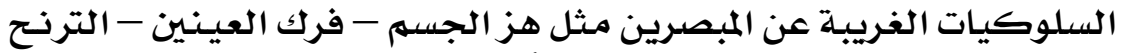

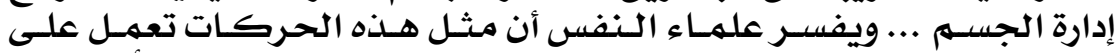

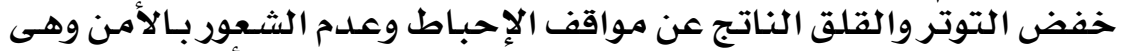

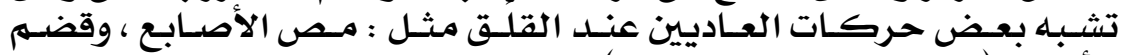

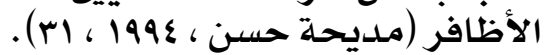

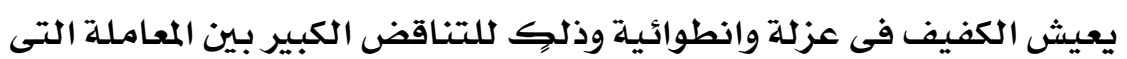

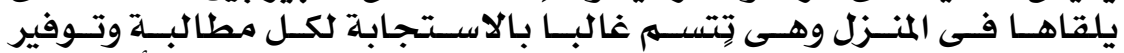

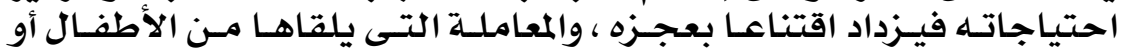

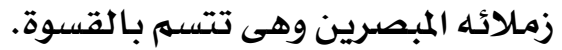

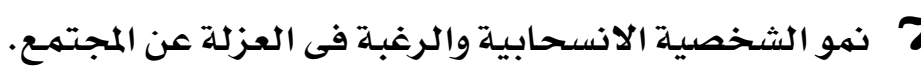

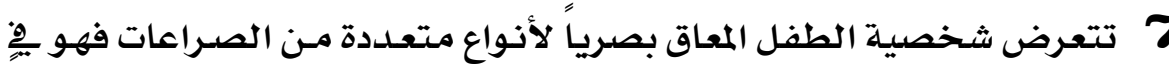

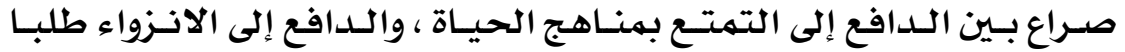

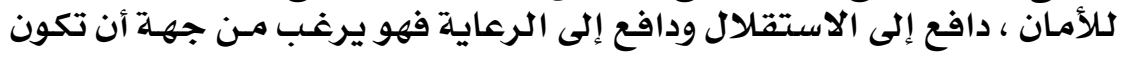

\section{$\Lambda \mathrm{V}$}


المجلى الخاهس .. العكق الثمانيه .. هارس .. 1ا•؟م.

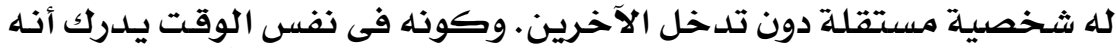

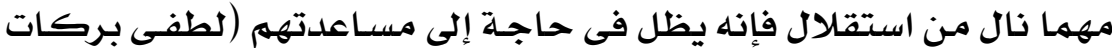
.(19، 1911

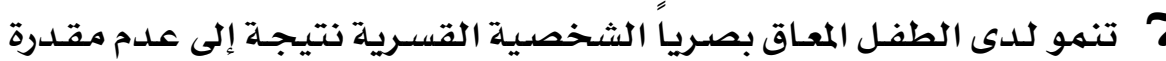

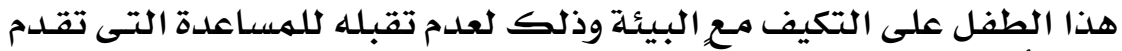
إليه لأنه يرفض عجز الطزه تمامـا.

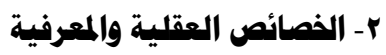

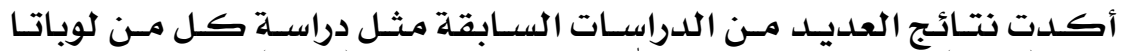
فروف دopata

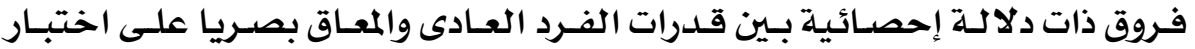

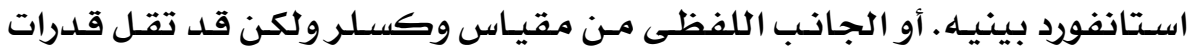

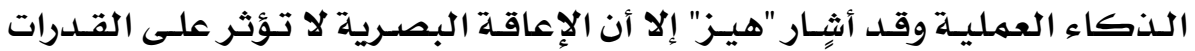

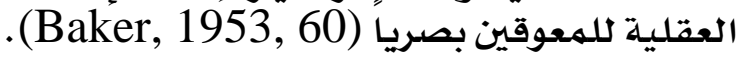

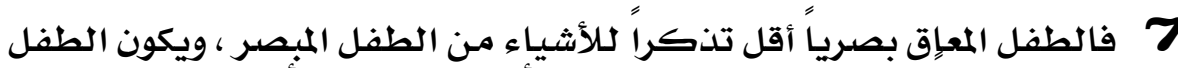

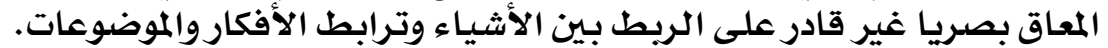

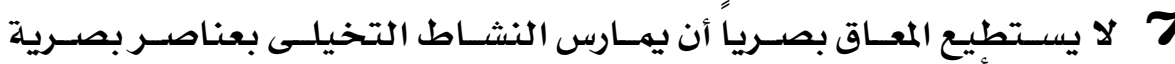

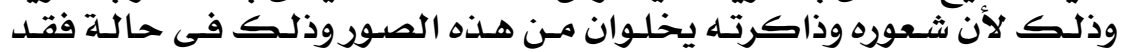

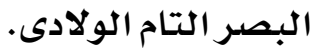

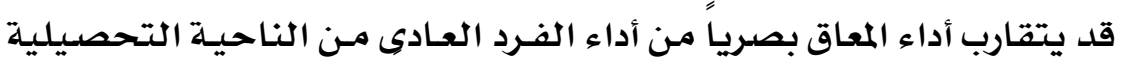

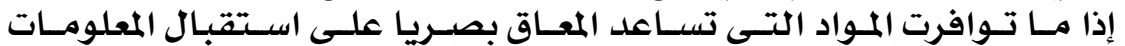

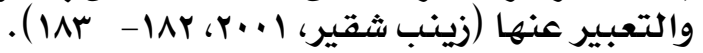

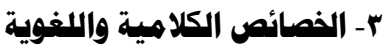

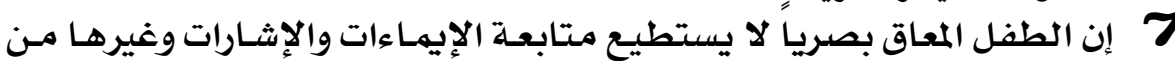

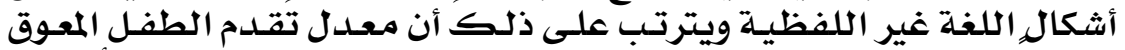

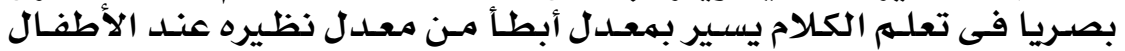

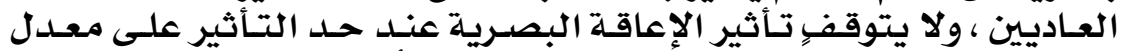

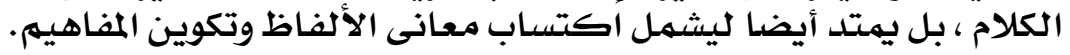

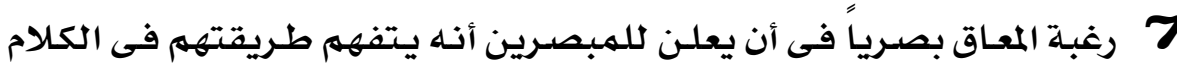

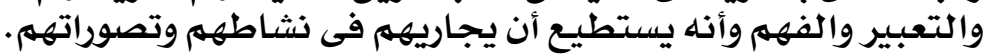

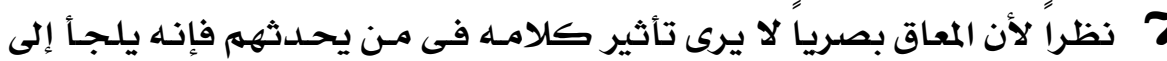

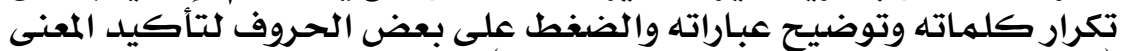

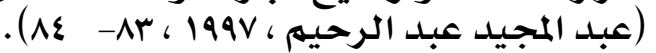

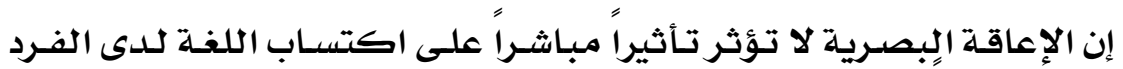

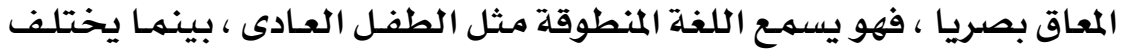

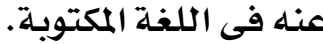

\section{$\wedge \wedge$}




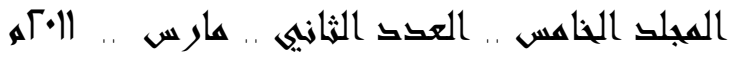

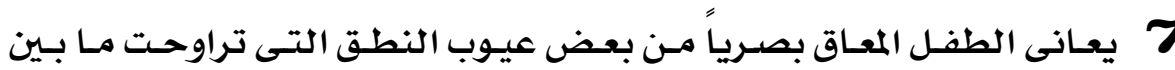

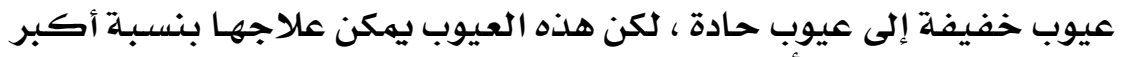
من علاج مثيله من الأطفال الصفي عيول

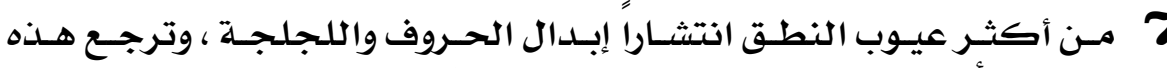

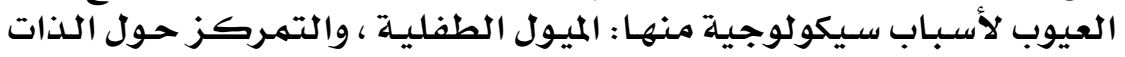

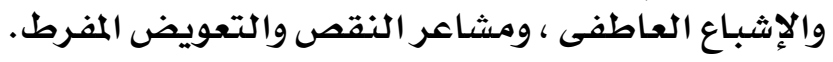

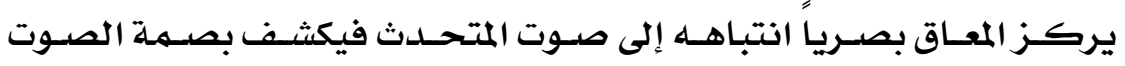

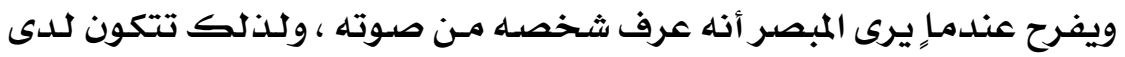

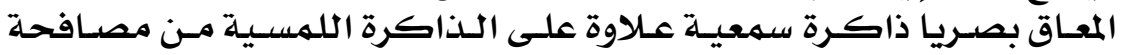

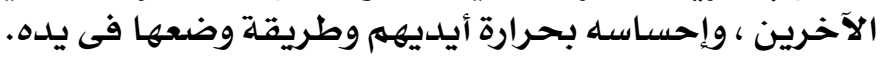

؟- خصائص التوجه والحركة

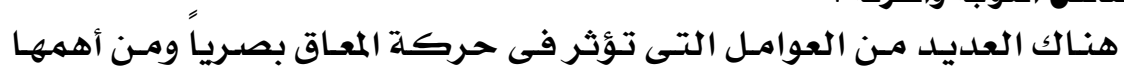

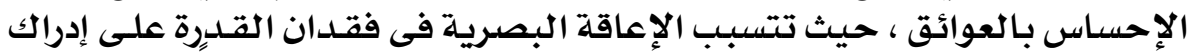

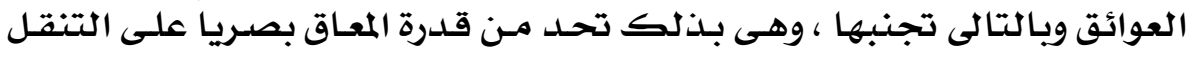

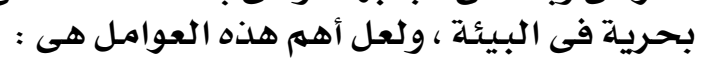

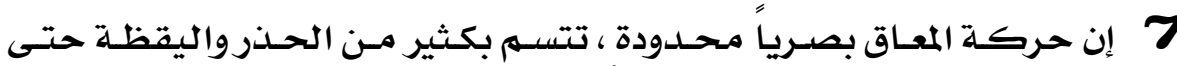

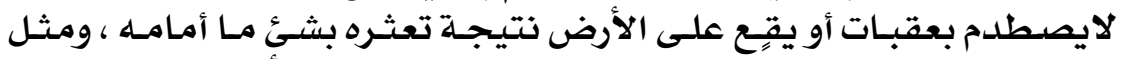

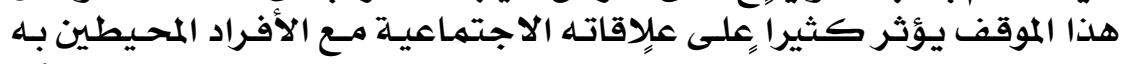

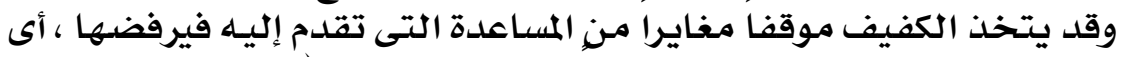

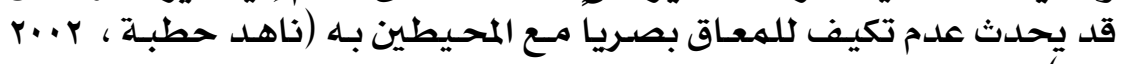
(ir

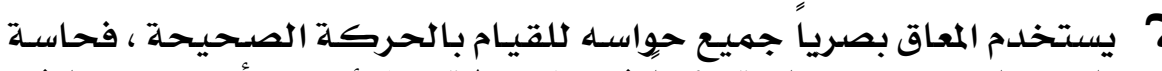

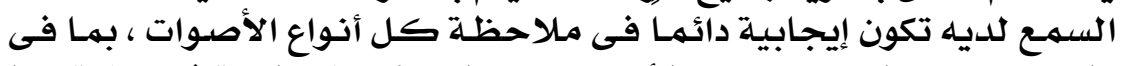

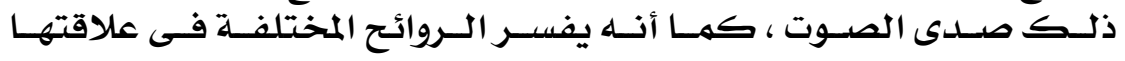

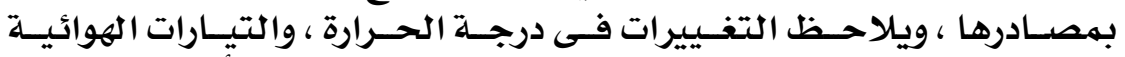

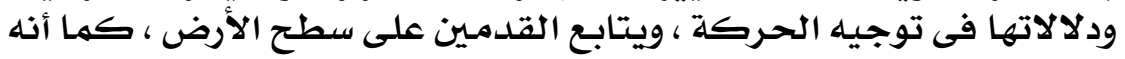

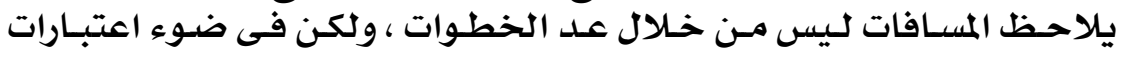
الزمن والحركة والمبـات والصوت.

ه- الخصائص الصسية :

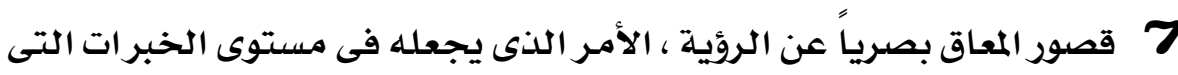

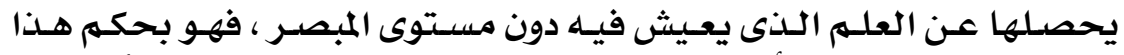

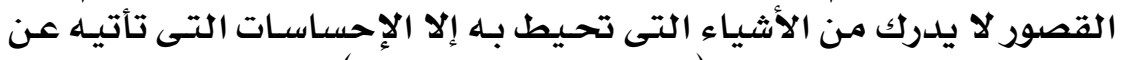

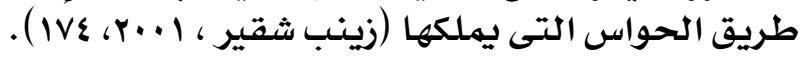

\section{$\wedge 9$}


المجلد الخاهس .. العكد الثخانيه .. هارس .. المآمه

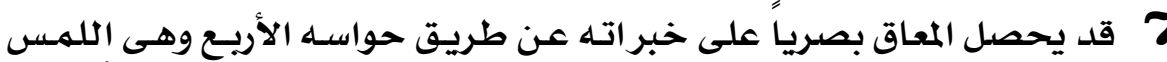

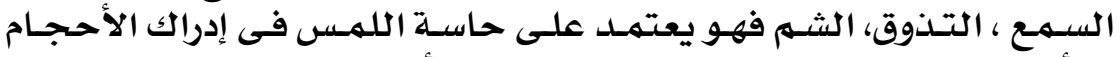

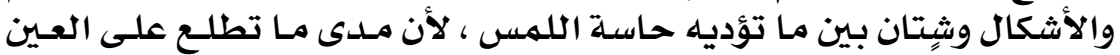

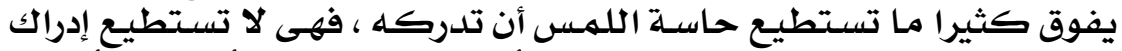

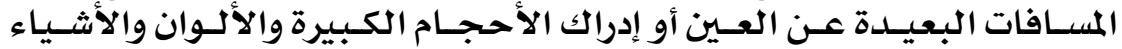

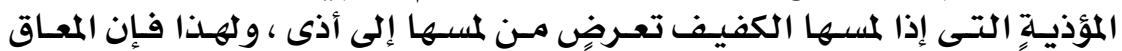

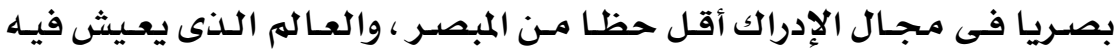

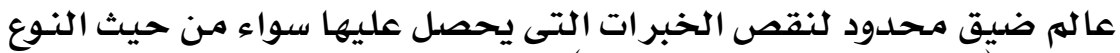

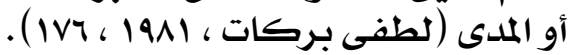

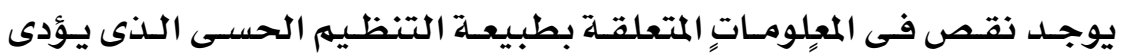

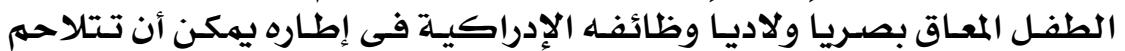

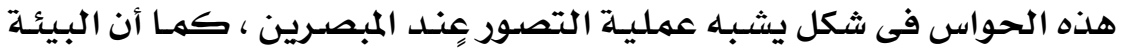

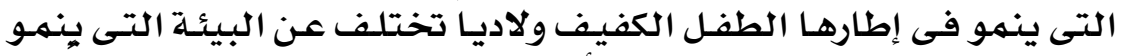

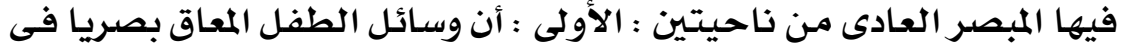

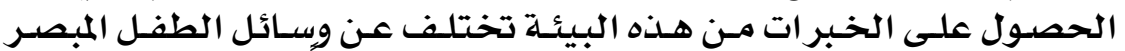

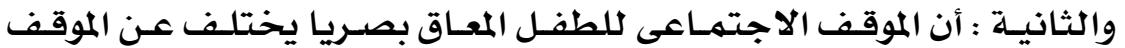

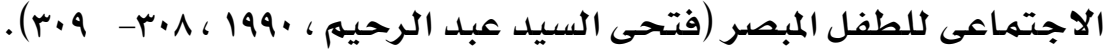

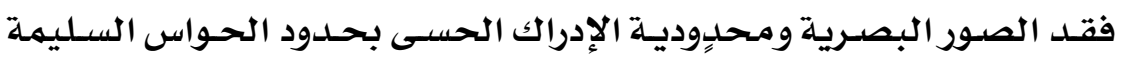

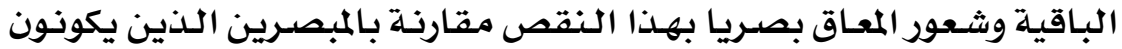

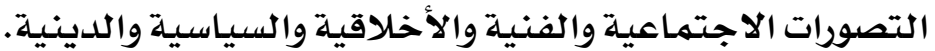

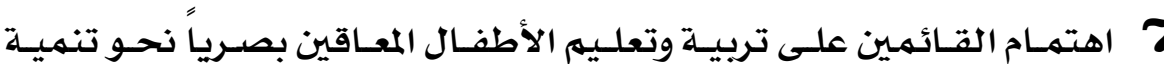

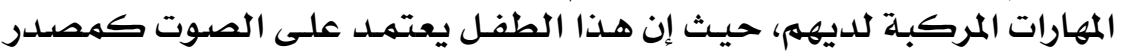

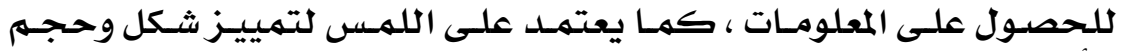

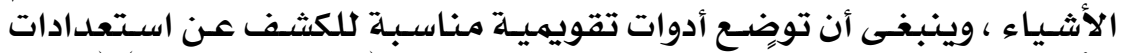

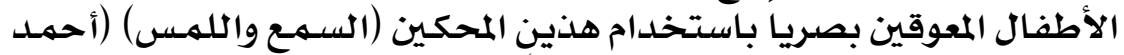

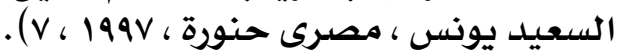

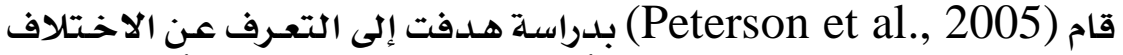

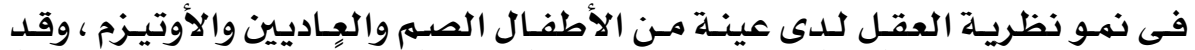

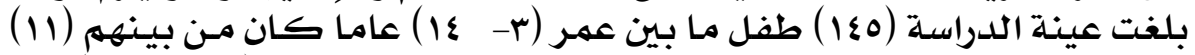

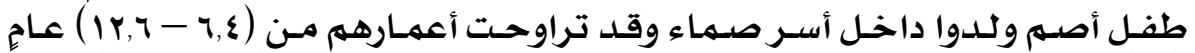

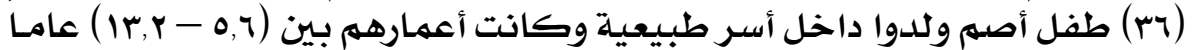

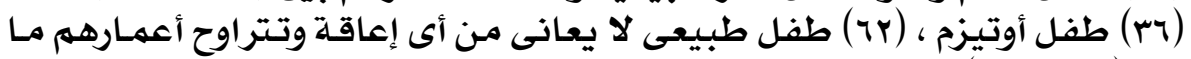

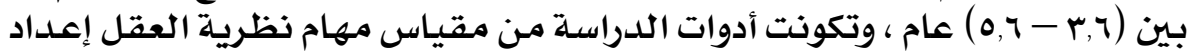

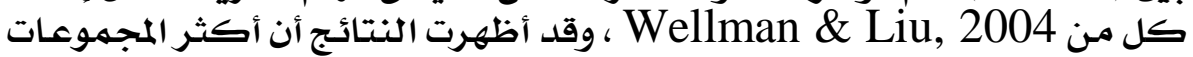

\section{9 .}


المجلد الخاهس .. العكد الثمانيه .. هارس .. المهم

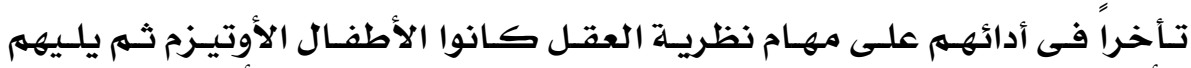

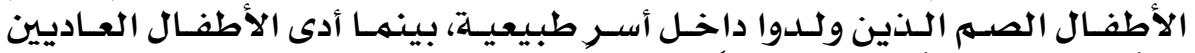

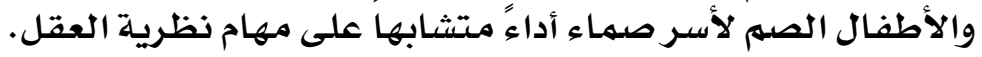

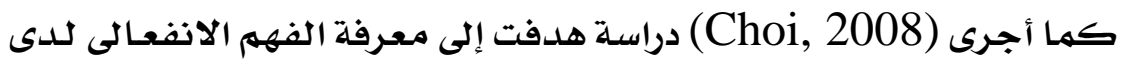

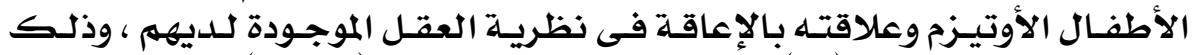

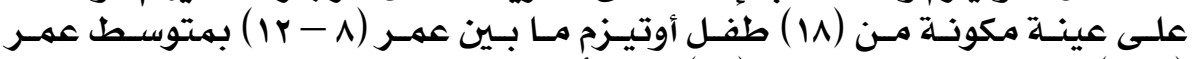

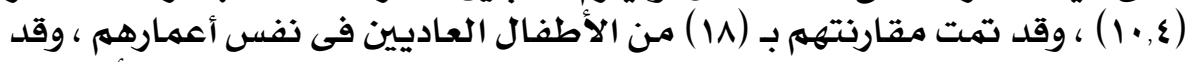

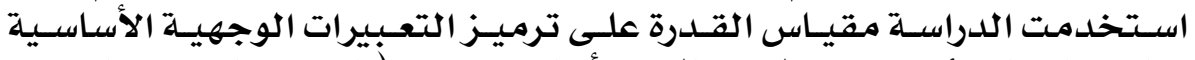

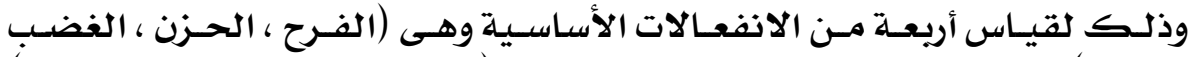

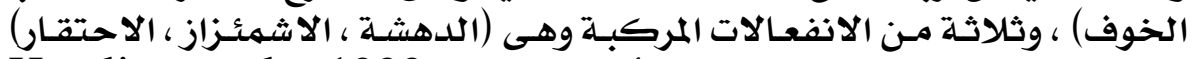

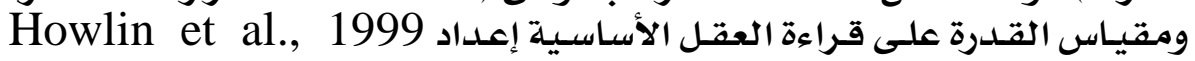

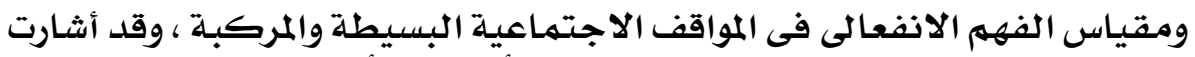

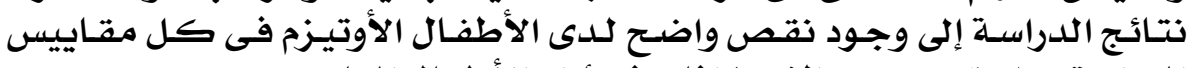

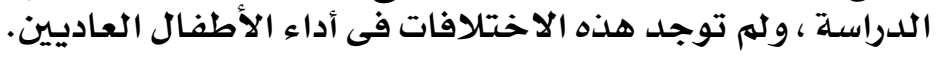

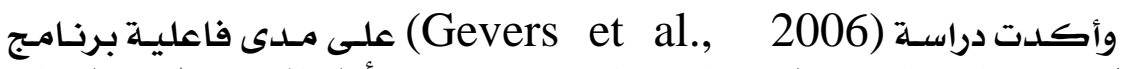

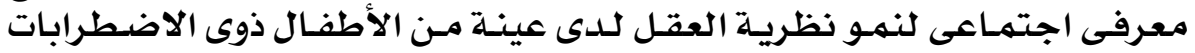

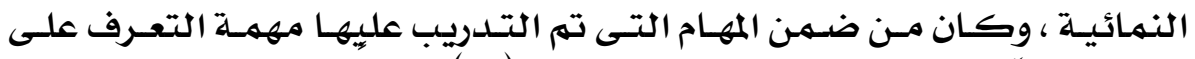

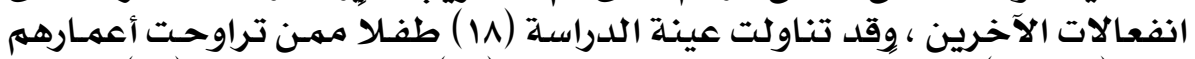

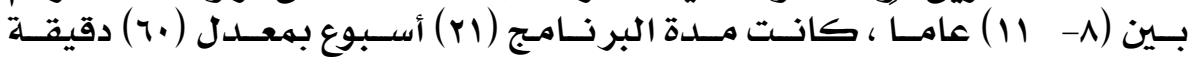

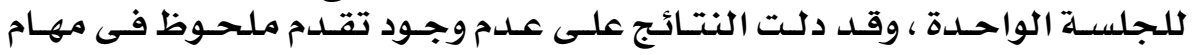

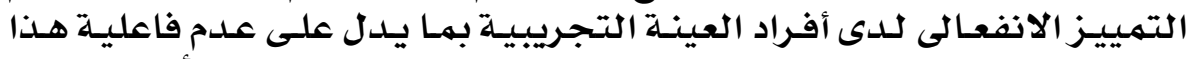

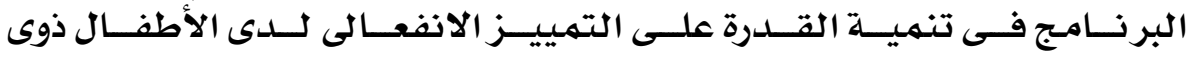
الاضطرابات النهمائيـة.

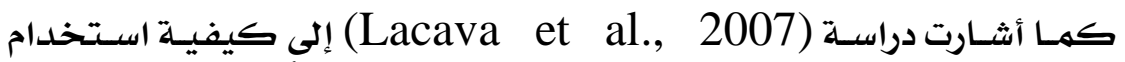

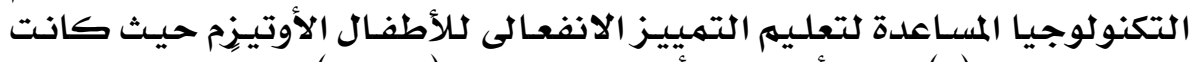

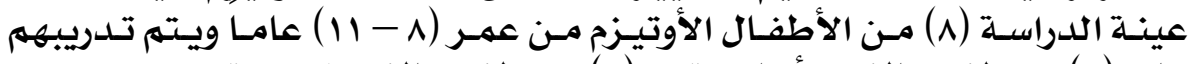

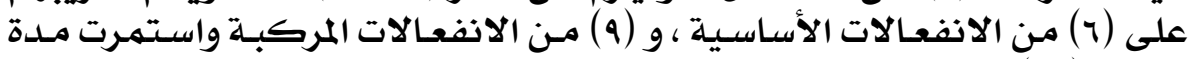

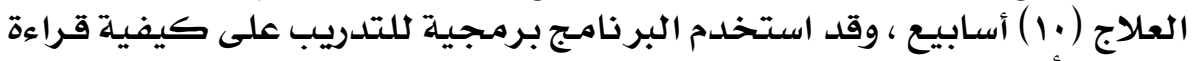

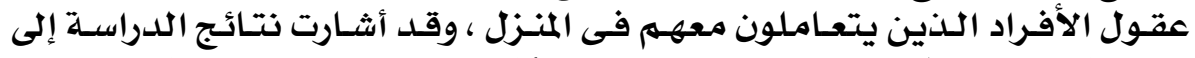

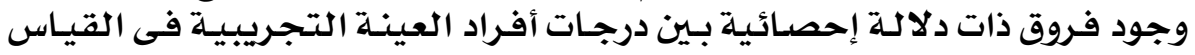

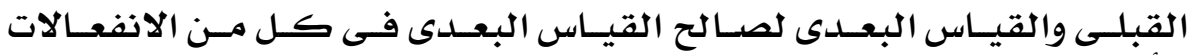

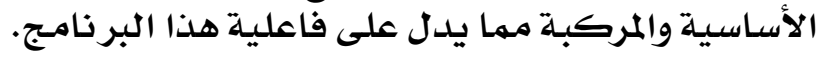

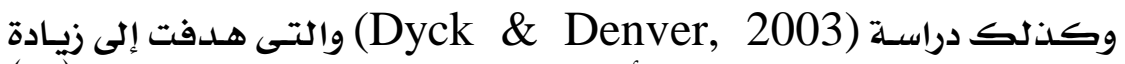

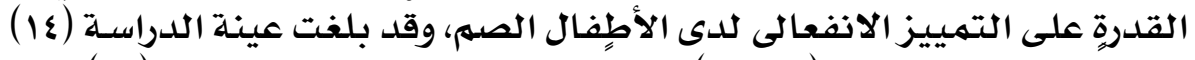

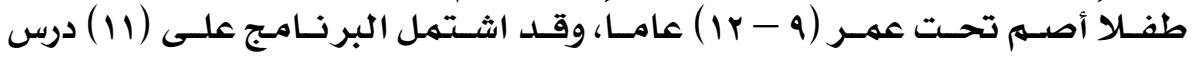

\section{1}

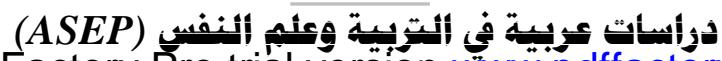

PDF created with pdfFactory Pro trial version www.pdffactory.com 
=

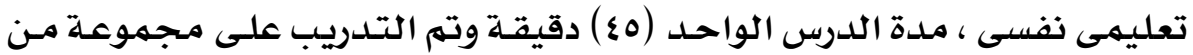

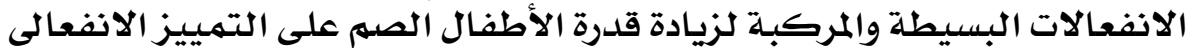

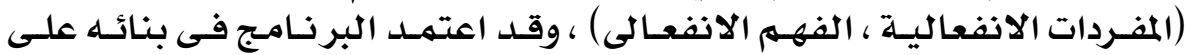

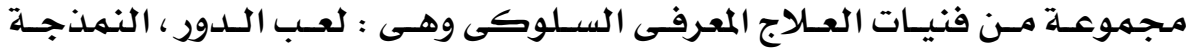

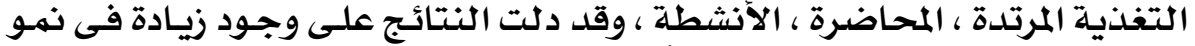

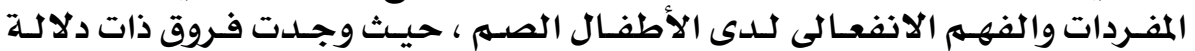

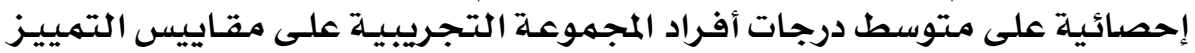

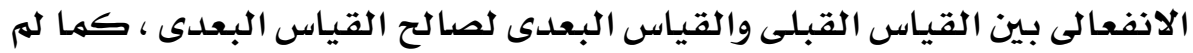

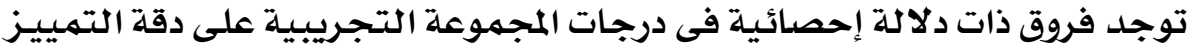

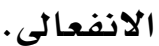

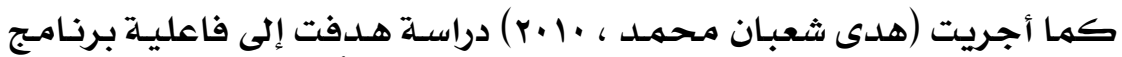

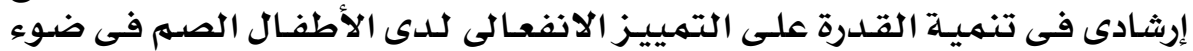

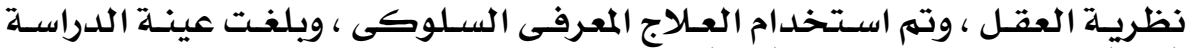

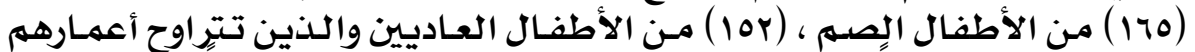

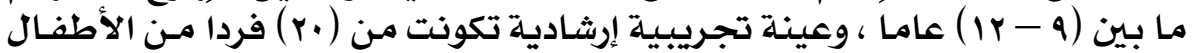

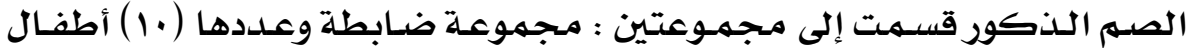

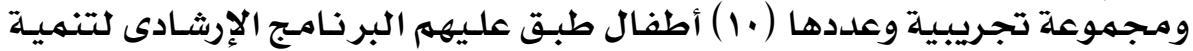

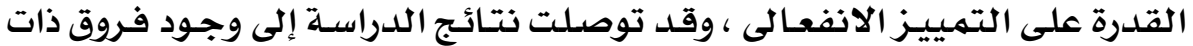

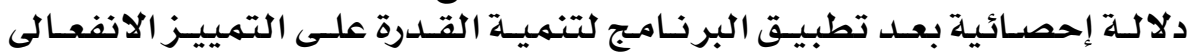

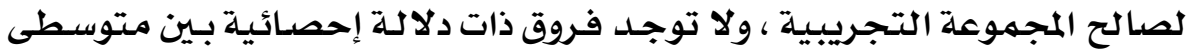

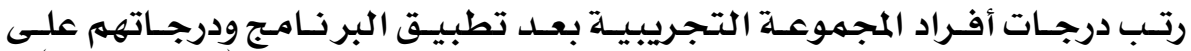

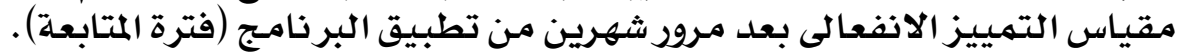

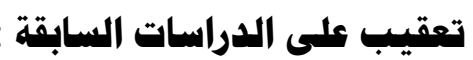

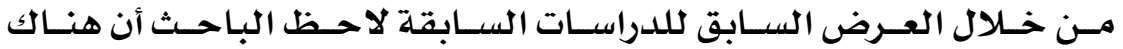

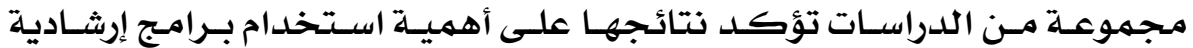

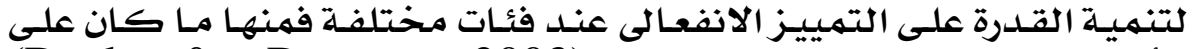

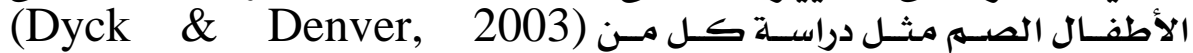

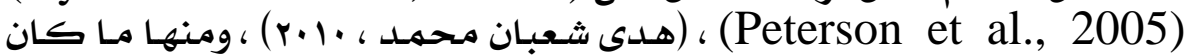

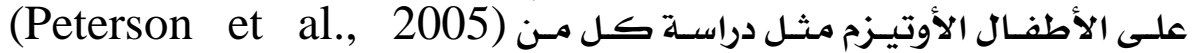

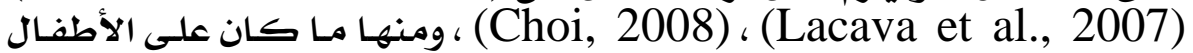
ذوى الاضطرابات النمائية مثل دراسـة (Gevers et al., 2006).

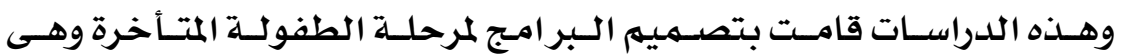

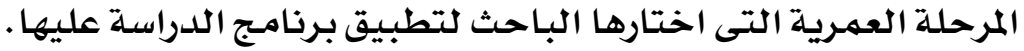

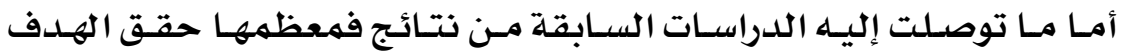

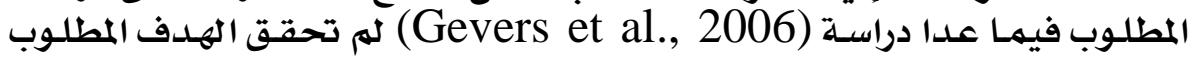

\section{$9 Y$}




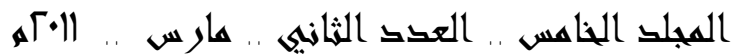

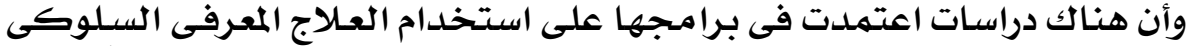

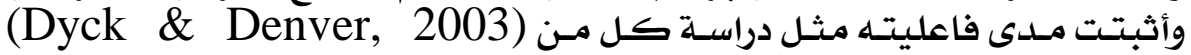

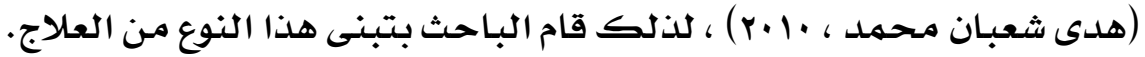

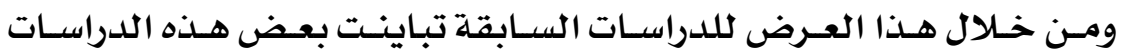

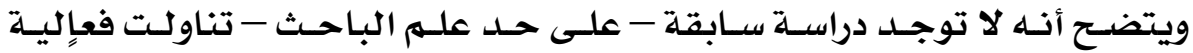

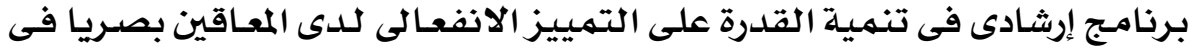
ضوي نظرية العقل.

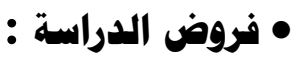

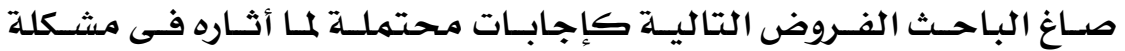

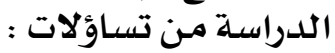

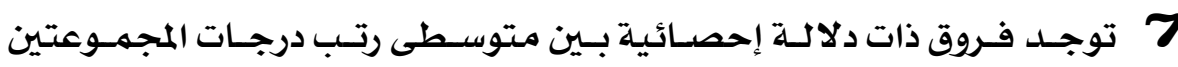

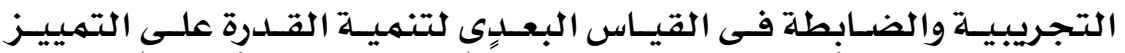

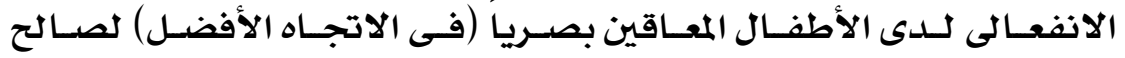
المجموعة التجريبية. الاندية.

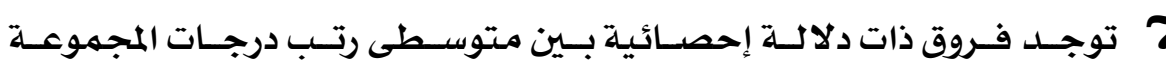

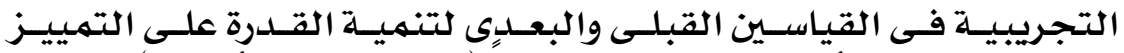

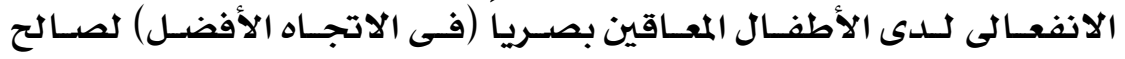

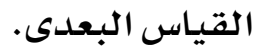

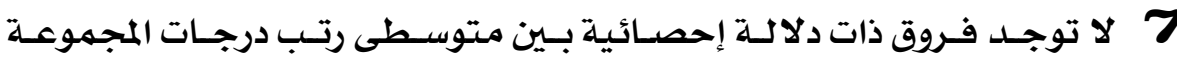

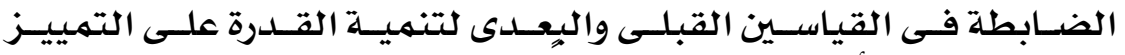

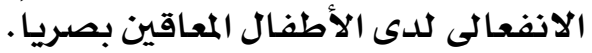

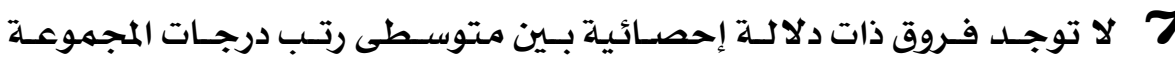

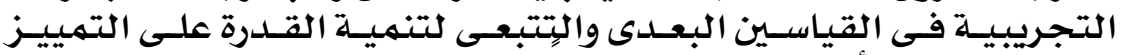

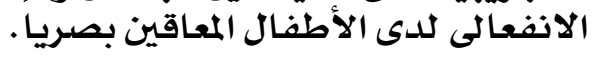

• إجراءات الدراسة : : منهج الدراستة الدراسة :

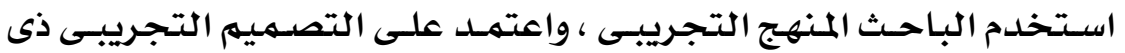

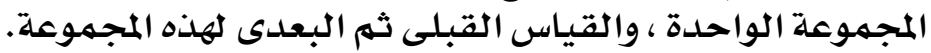

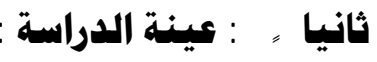

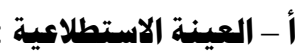

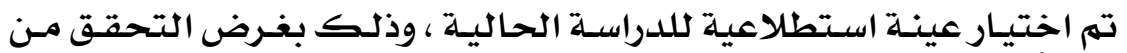

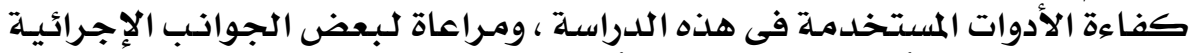

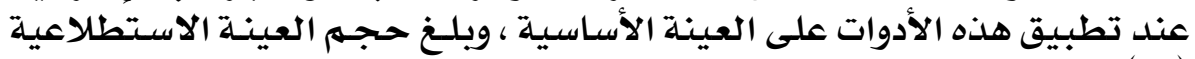

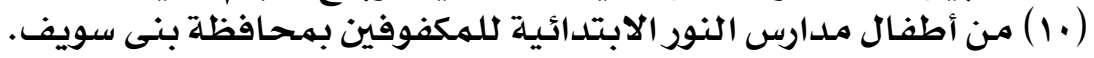

\section{4}




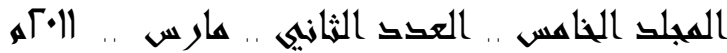

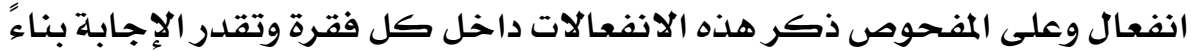

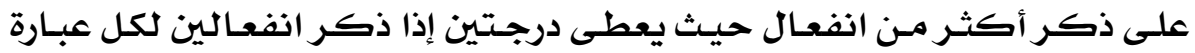

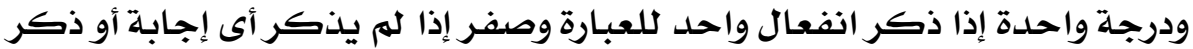

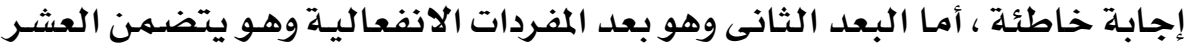

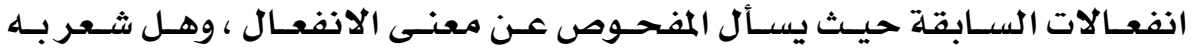

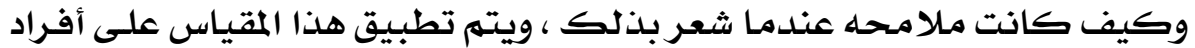

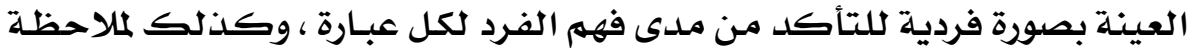

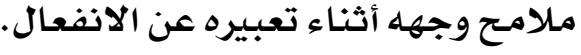

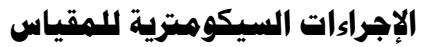

تم التحقق من صدق مقيدياس التمييز الانفعالى لدى المعـاقين بصـرياً وثباته كما يلى : : صدق المقياس :

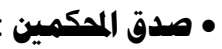

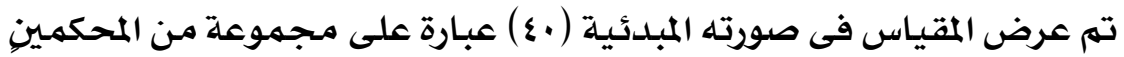

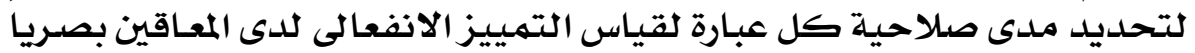

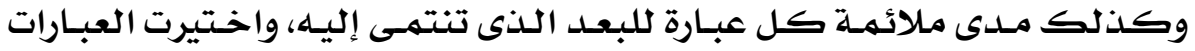

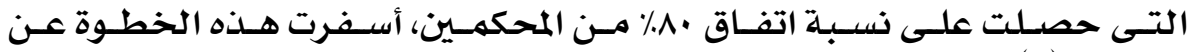
استبعاد (0) عبارات.

\section{• الصدق المرتبط بالمكات (الصدات (ارق التلازهى) :}

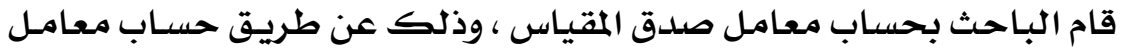

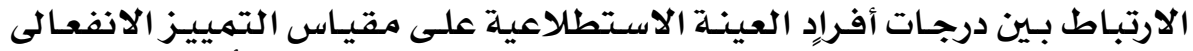

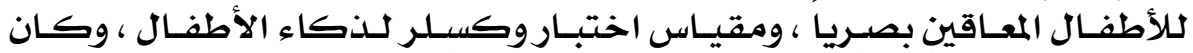

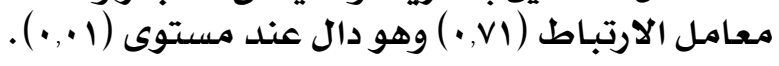

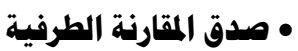

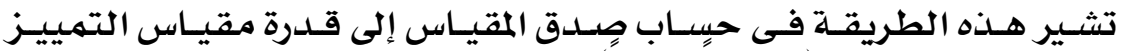

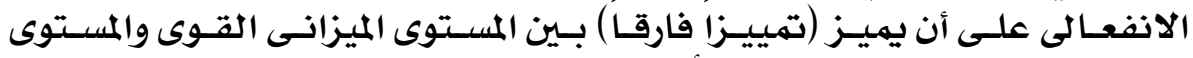

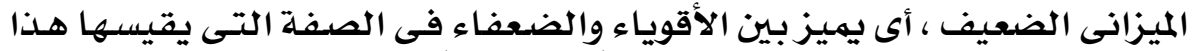

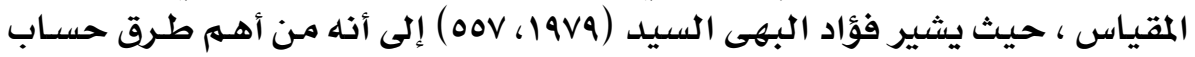

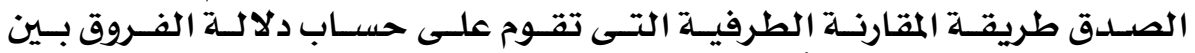

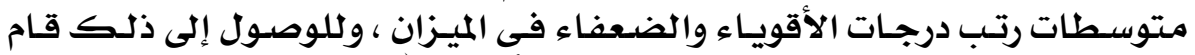

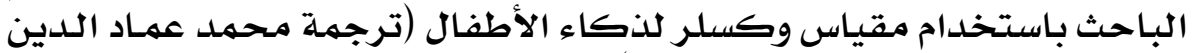

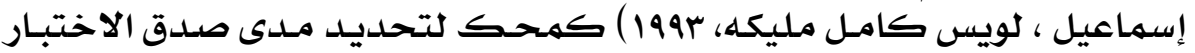

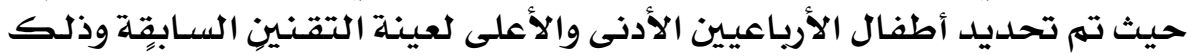

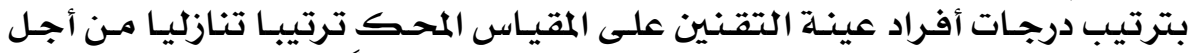

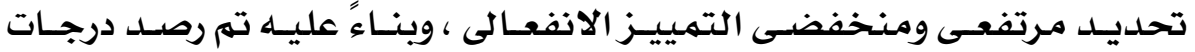

\section{0}

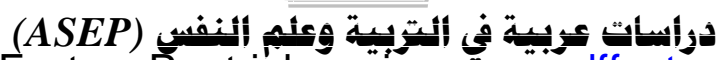

PDF created with pdfFactory Pro trial version www.pdffactory.com 
المجلد الخاهس .. العكد الثمانيه .. هارس .. المهم

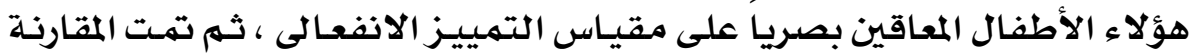

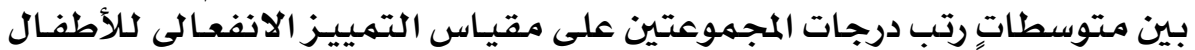

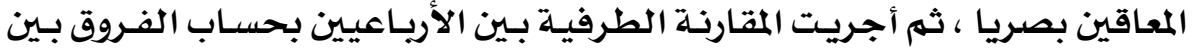

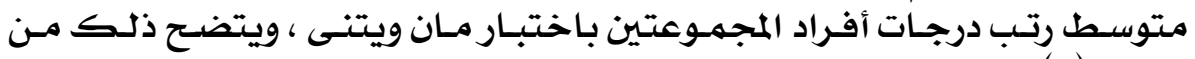
جدول (1). (1) متوسط

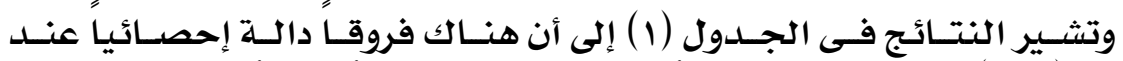

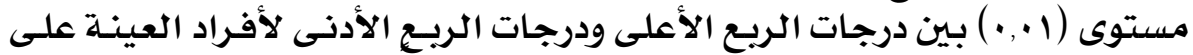

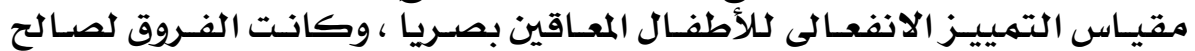

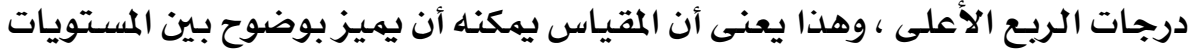

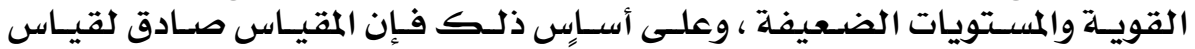

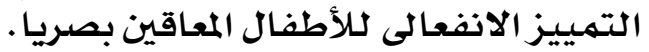

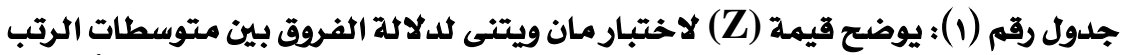

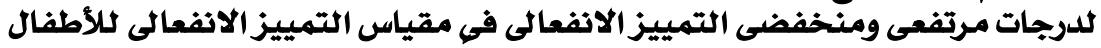
المعاقين بصريا

\begin{tabular}{|c|c|c|c|c|c|}
\hline مستوى الدلثلة & $\begin{array}{l}\text { قيمة } \\
(Z)\end{array}$ & مـجموع & متوسط الرتب & ن & مجموعتا المقارنة \\
\hline \multirow{2}{*}{ مستوى · دالة عن } & \multirow{2}{*}{$r, \Sigma 7$} & $10 \cdot, \ldots$ & $10, \ldots$ & 1. & مرتفعى التمييز الانفعالي \\
\hline & & $7 \cdot, \cdots$ & $7, \cdots$ & 1. & منخفضى التهييز الانفعالى \\
\hline
\end{tabular}

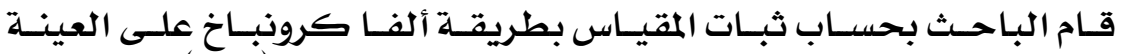

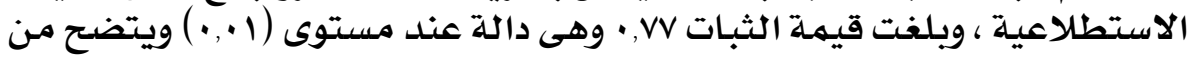

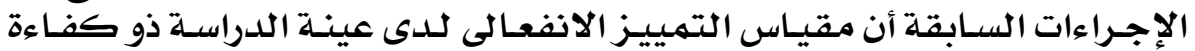

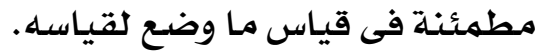
r- r مقياس وكسلر لذكاء الأطفال (إعداد وكسلر) ترحمة محمد عماد الدين إسماعيل ، لويس كامل مليكهة)

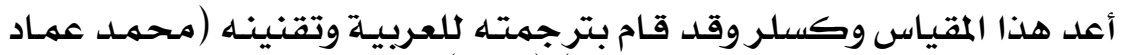

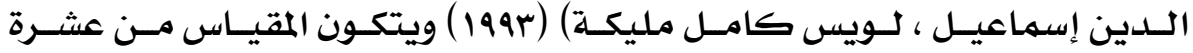

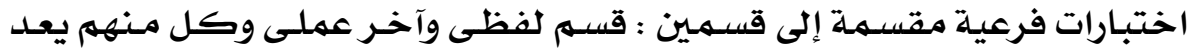

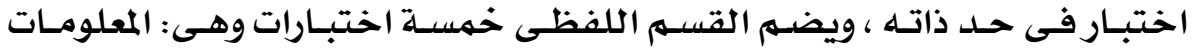

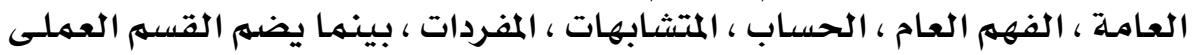

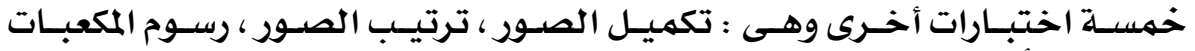

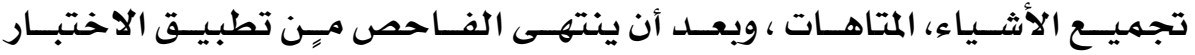

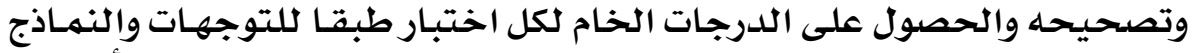

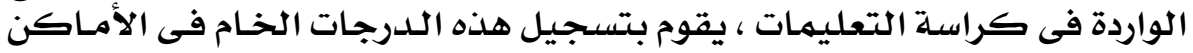

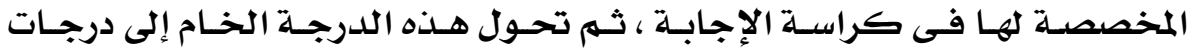

\section{7}


المجلت الخاهس .. العدق الثانيه .. هارس .. ال「هم

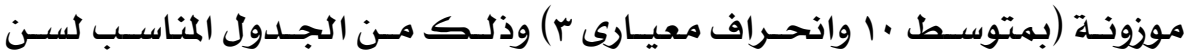

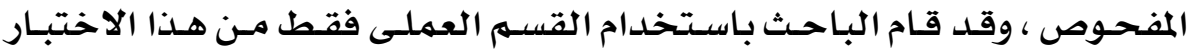

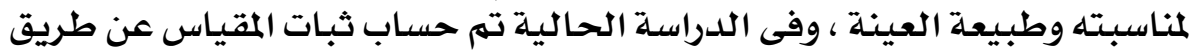

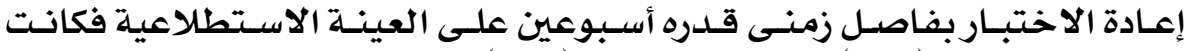

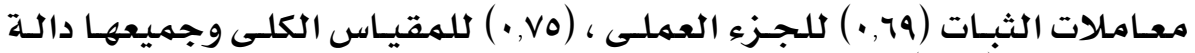

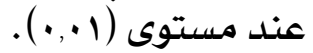

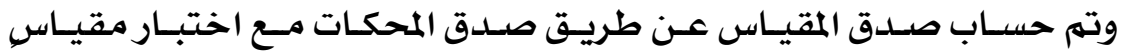
التمييز الانفعالى على نفس العينة الاستطلاعية وكان معام المعامل الارتباط مساويا

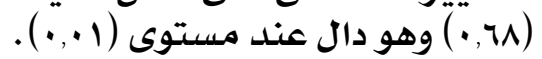

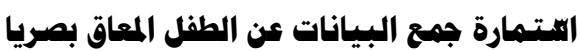

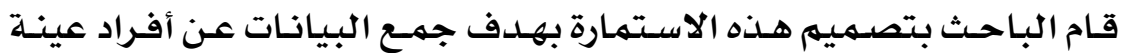

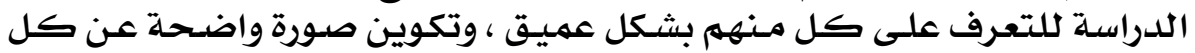
فرد من أفراد العينة التجريبية للدراسة الحالية.

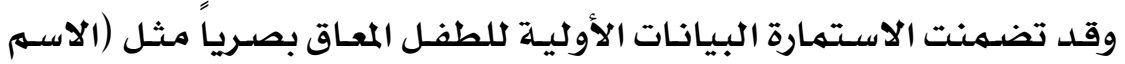

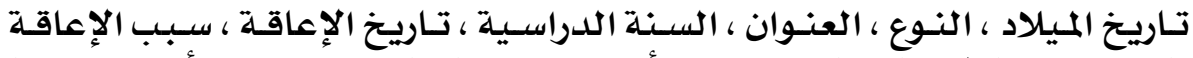

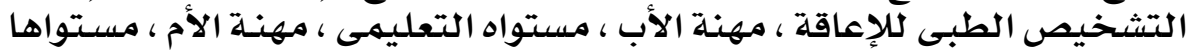
التعليهى ، الدخل الشهرى للأسرة ، عدد الأخوات ، ترتيب الطفل التهل بين أخواته هل هل

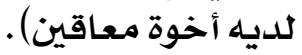

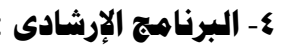

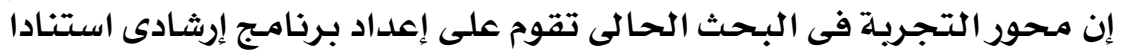

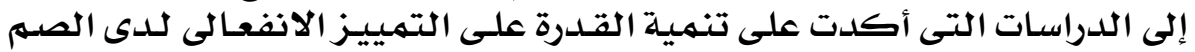

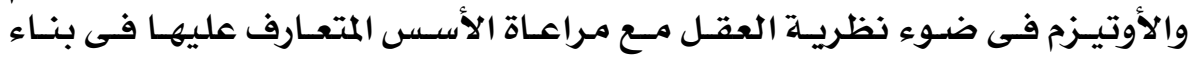

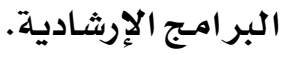

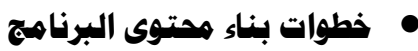

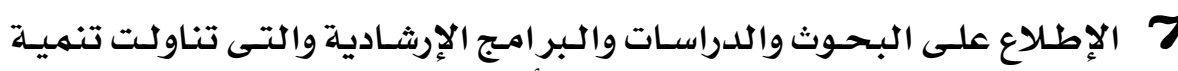

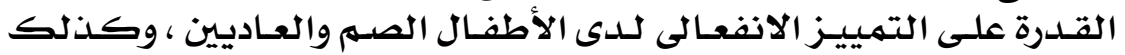

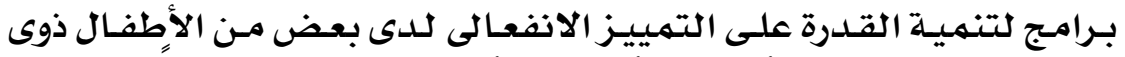

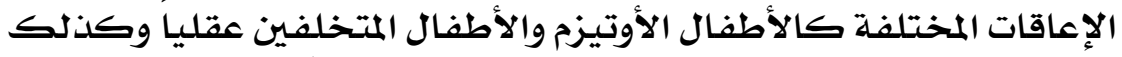

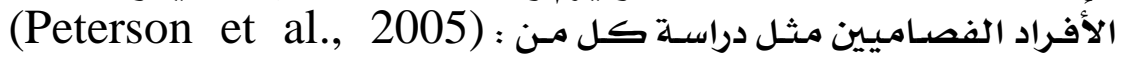
(Choi, ، (Gevers et al., 2006)، (Wellman \& Liu, 2004) (Lacava et al., 2007)، (Howlin et al., 1999)، 2008)

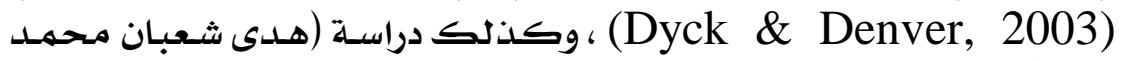

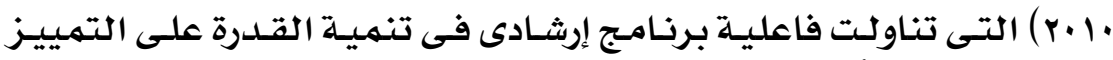
الانفعالى لدى الأطفال الصهم.

\section{$9 \mathrm{~V}$}




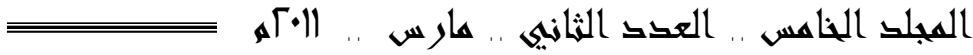

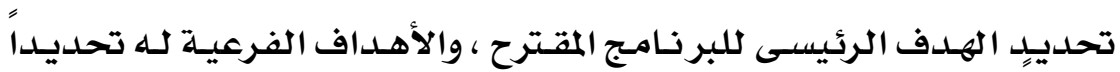

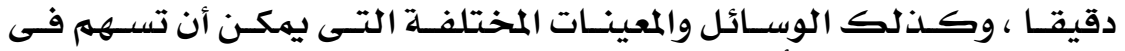
الوصول إلى تحقيق الأهداف.

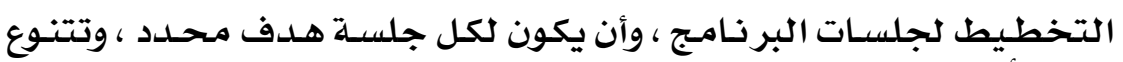
7

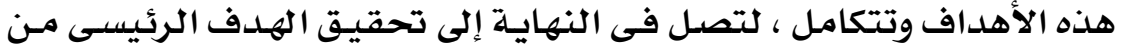

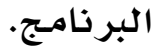

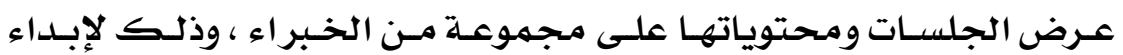

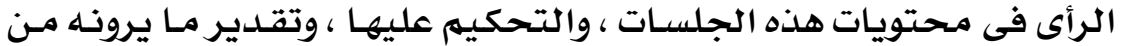

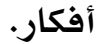

الأسس التى يقوم عليهار البرناهمج

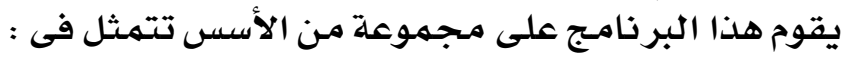

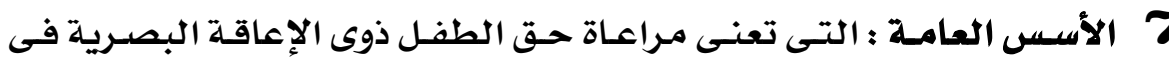

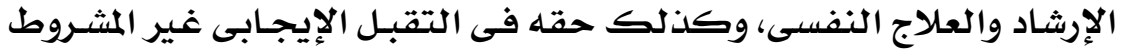

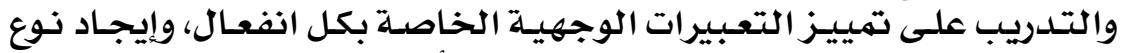

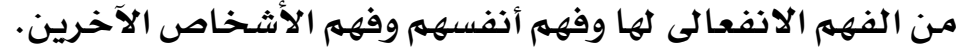

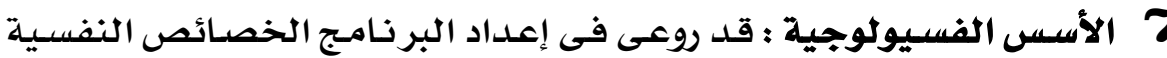

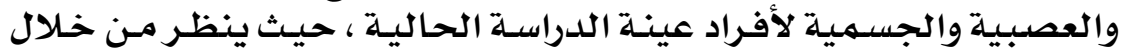

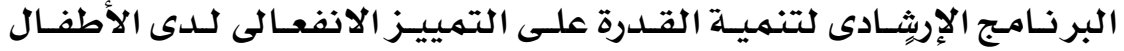

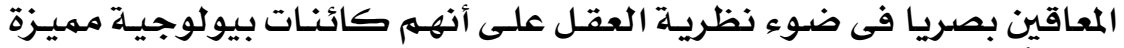

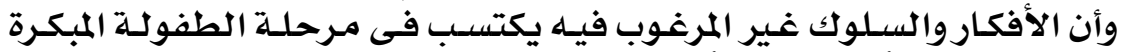

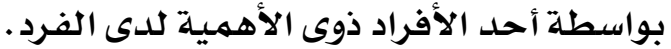

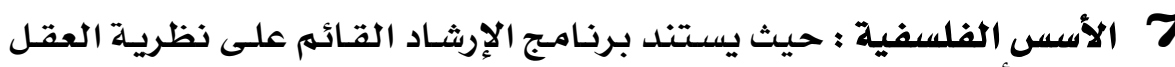

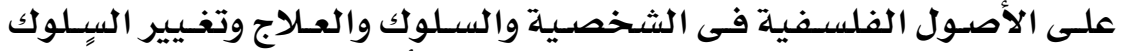

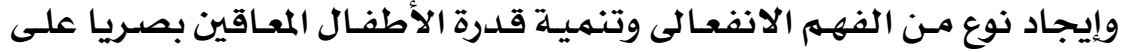

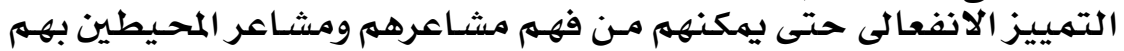

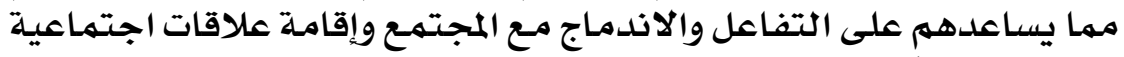
إيجابية مـ الآخرين.

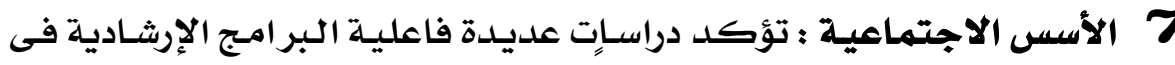

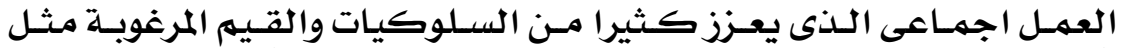

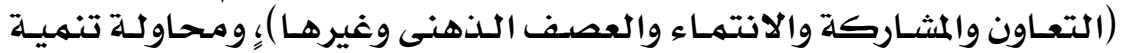

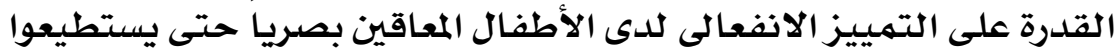

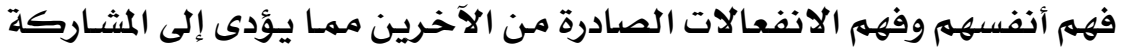

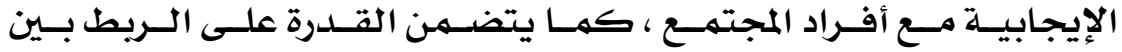

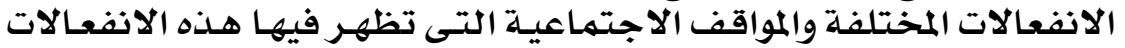

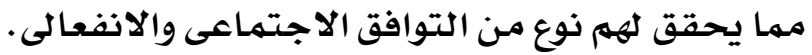

\section{$9 \wedge$}


المجلد الخاهس .. العكد المثانيه .. هارس .. المهم

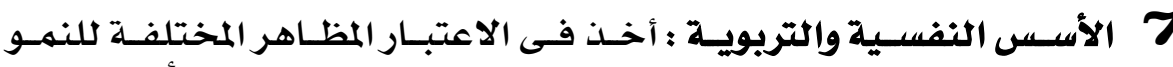

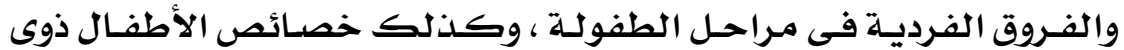

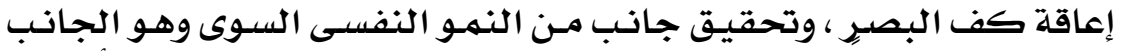

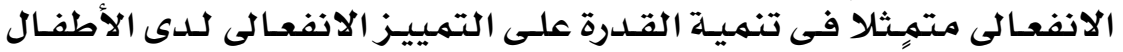

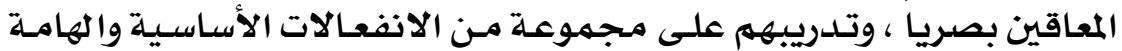

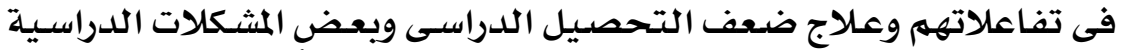

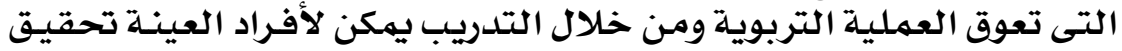

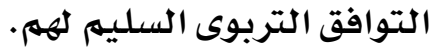

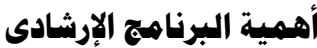

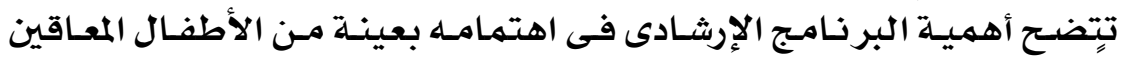

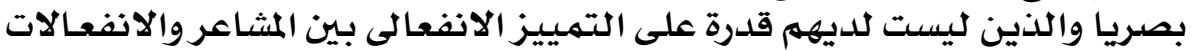

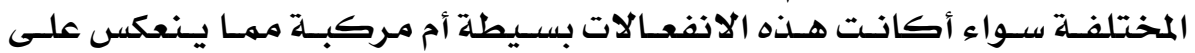

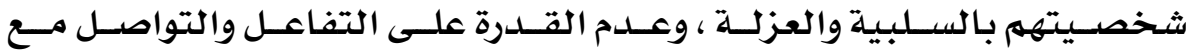

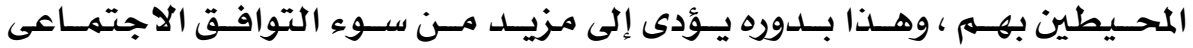

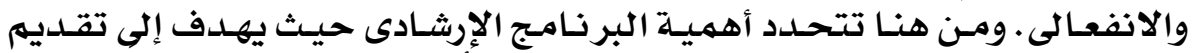

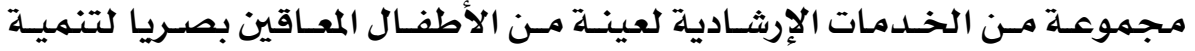

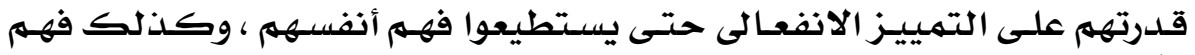

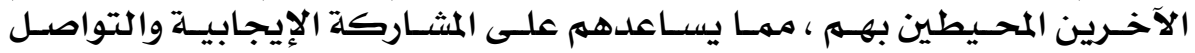

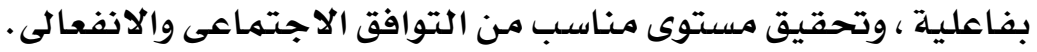

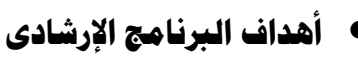

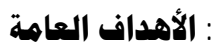

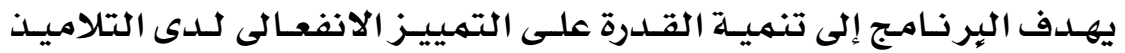

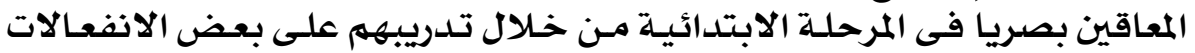

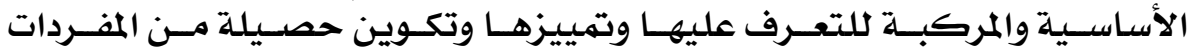

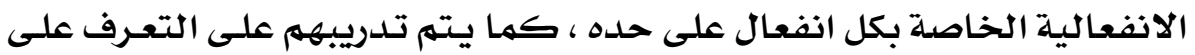
التعبيرات الوجهية الخاهية الخاصلة انفعل بكل انفعال.

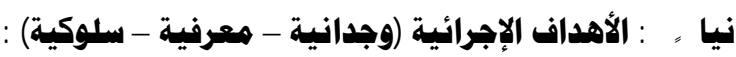 أ - الأهداف الوجدانية : الأوهانية}

7 أن يدرك الأطفال المعاقين بصرياً أهمية التعرف على الانفعالات وتمييزها.

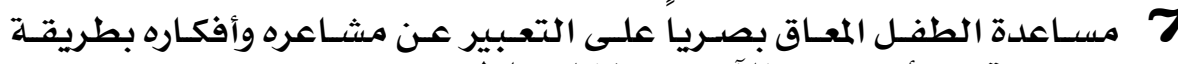

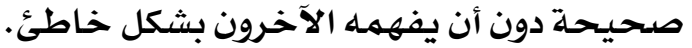

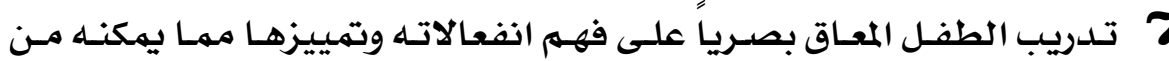

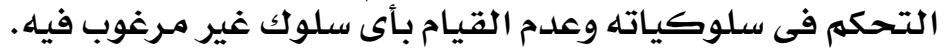

\section{9}




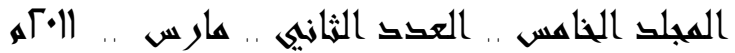

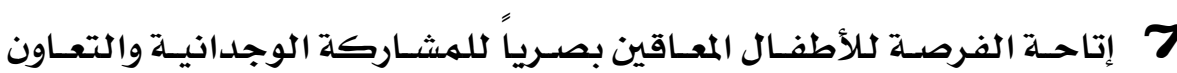
فيهما بينهم وبين الآخروين.

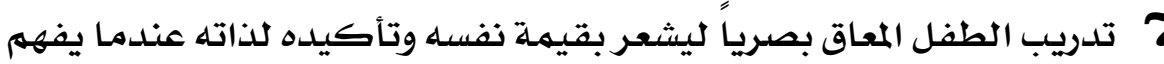

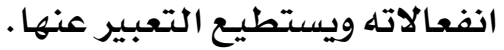

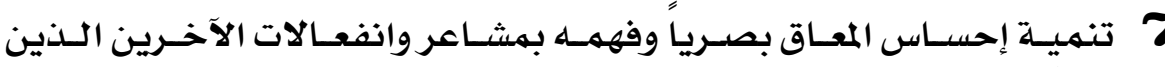
يتعامل معهم. إحمان

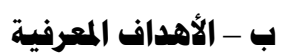

7 أن يتعرف الأطفال المعـاقين بصـرياً على مفهوم التميـيز الانفعـالى وعلاقته الأله

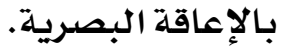
7 أن يتعرف الأطفال المعاقين بصرياً على معنى المشاعر والانفعالات.

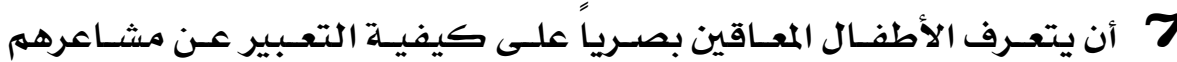
وانفعالاتهم.

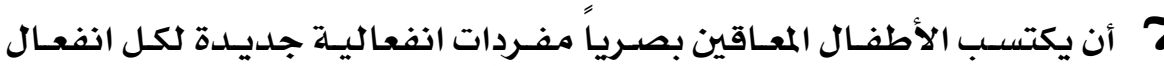

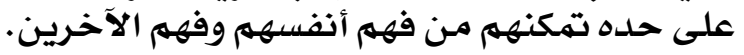

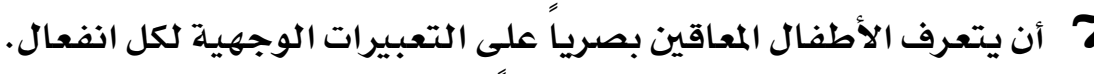

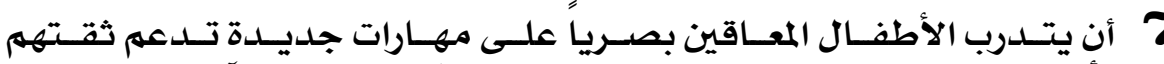
بأنفسهم وتسـاعدهم على التففاعل والتواصل المعل الإيجابى مـع الآخرين.

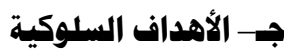

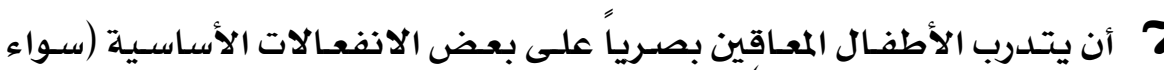

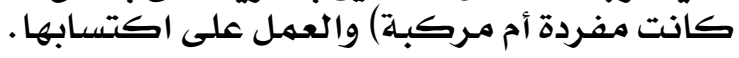

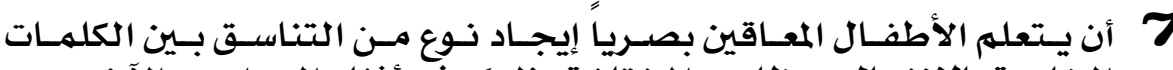

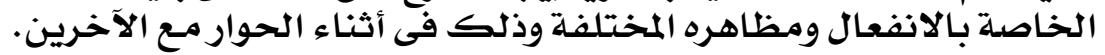

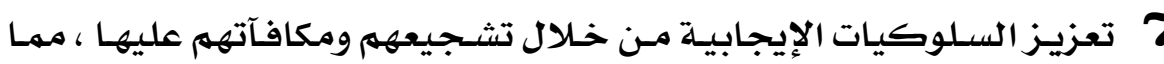

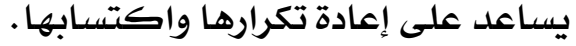

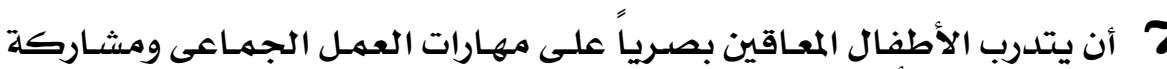

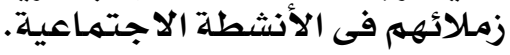

\section{الفنيات الإرشادية المستخدهة فى البرناهمج}

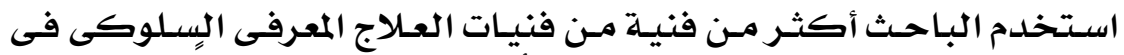

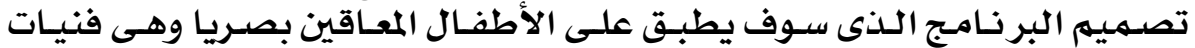

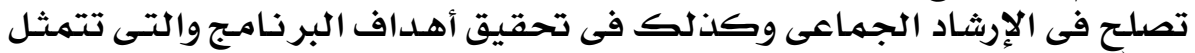

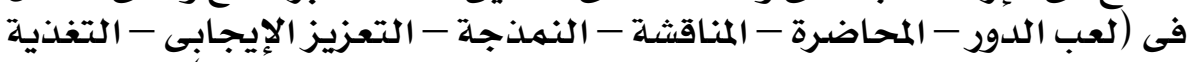

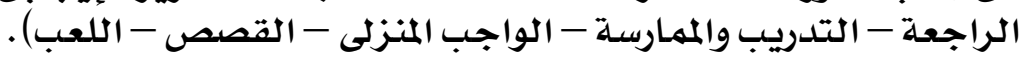

\section{$1+$}


المجلد الخاهس .. العدق الثخانيه .. هارس .. ال厂م.

تطبيق البرناهمج

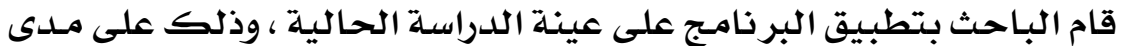

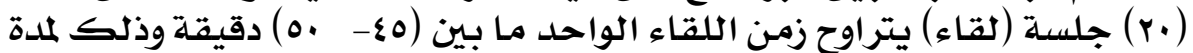

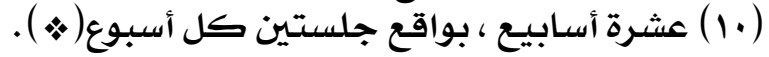

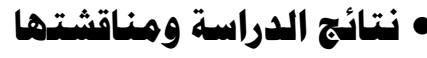 \\ الفرض الأول : اختباره ، وهناقشته :}

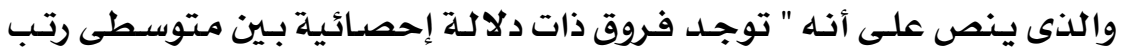

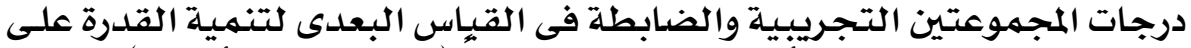

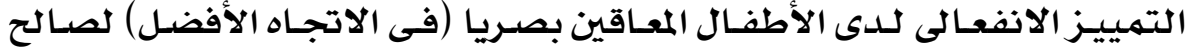

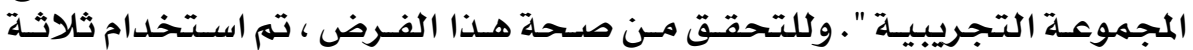

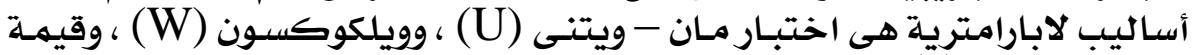

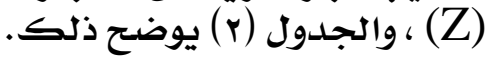

جدول رقم (r) : قيم U, W, Z ودلالتها للفرق بين متوسطات رتب درجات المجموعتين التجريبية

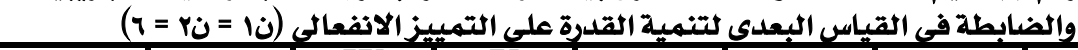

\begin{tabular}{|c|c|c|c|c|c|c|c|}
\hline الدلالة & قيمة Z & $\overline{\mathbf{W}}$ & $\widetilde{\mathbf{U}}$ & الرتجب & م الرتب & r & المجموعة \\
\hline$\cdot, \cdot 1$ & $r, V r$ & $r, q \Lambda$ & $1,0$. & $\begin{array}{l}00,0 . \\
Y Y, 0 .\end{array}$ & $\begin{array}{l}\text { 9, ro } \\
\text { r,vo }\end{array}$ & $\begin{array}{l}Y q, Y \varepsilon \\
\mid V, Y O\end{array}$ & الضجريبية \\
\hline
\end{tabular}

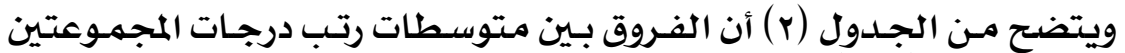

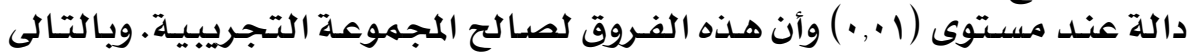

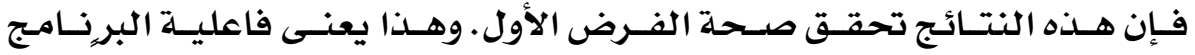

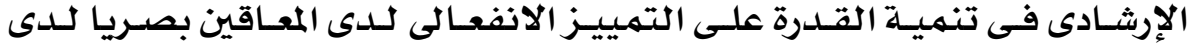

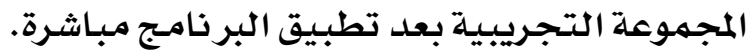

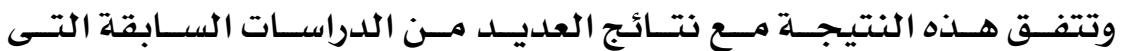

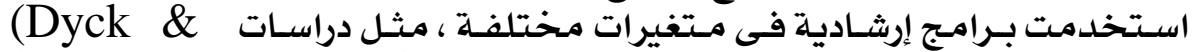

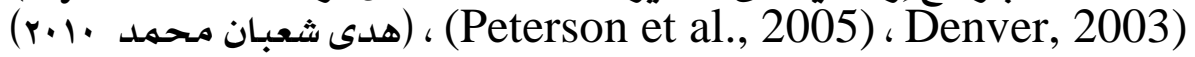

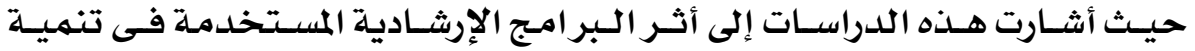

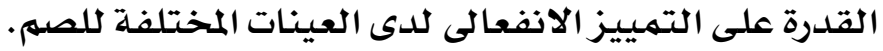

\section{الفرض الثانى : اختباره ، ومناقشته :}

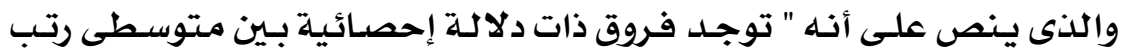

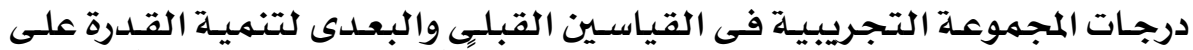

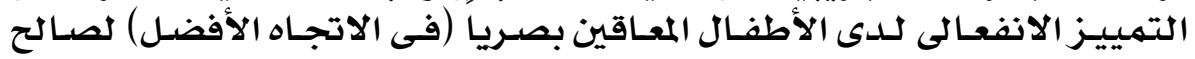

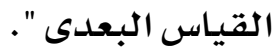

\section{$1 \cdot 1$}




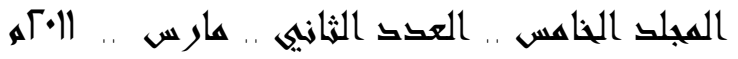

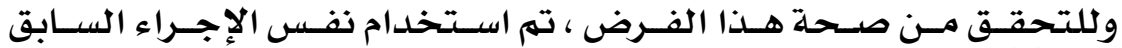

$$
\text { والجدول (r) يوضتح ذلك. }
$$

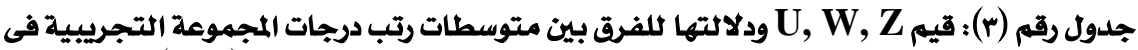

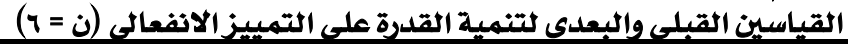

\begin{tabular}{|c|c|c|c|c|c|c|c|}
\hline الدلالة & قيمة Z & $\mathbf{W}$ & $\mathbf{U}$ & ارتّت & م الرتب & p & القياس \\
\hline$\cdot, \cdot 1$ & $r, V r$ & $r, 90$ & $1,0$. & $\begin{array}{l}\text { YY,O. } \\
00,0 .\end{array}$ & $\begin{array}{l}r, v o \\
Q, Y 0\end{array}$ & $\begin{array}{l}I V, 10 \\
Y Y, Y \varepsilon\end{array}$ & البعذىي \\
\hline
\end{tabular}

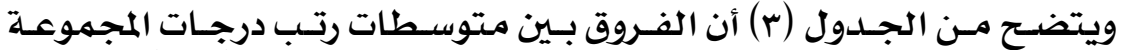

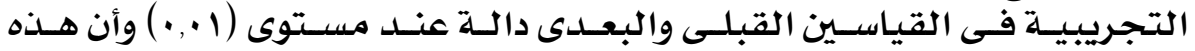

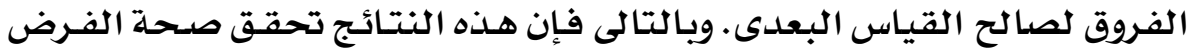

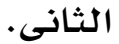

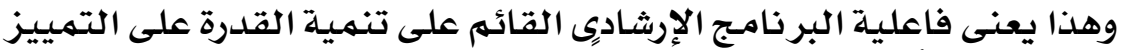

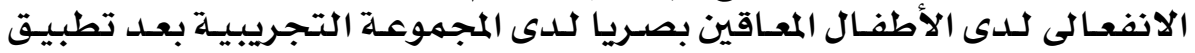

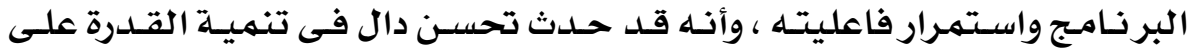

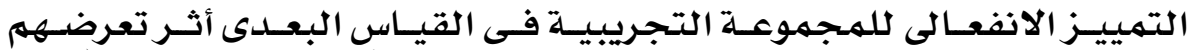

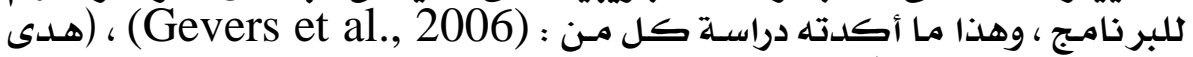

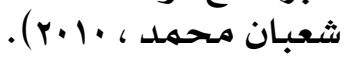

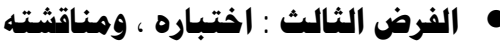

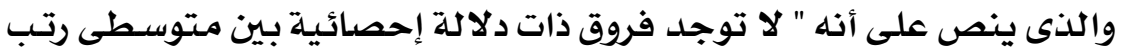

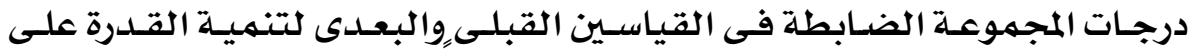

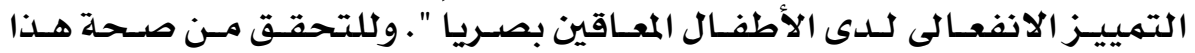

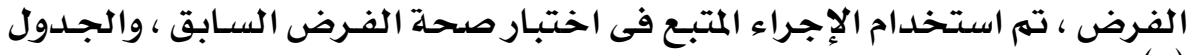

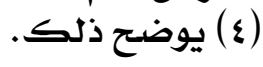

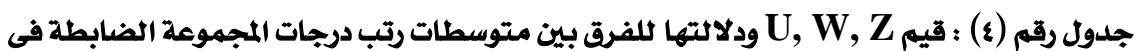

\begin{tabular}{|c|c|c|c|c|c|c|}
\hline الدلالة & قيمةل & W" & $\mathrm{U}$ & م-ج الرتب & م الرتـ & القياس \\
\hline غير & $\cdot, \wedge 1$ & $\cdot, 17$ & $1 r, \cdot \cdot$ & $\begin{array}{l}r r, \gamma . \\
\varepsilon r, \Lambda .\end{array}$ & $\begin{array}{l}0,7 . \\
V, r .\end{array}$ & البعذى \\
\hline
\end{tabular}

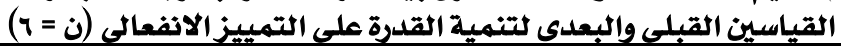

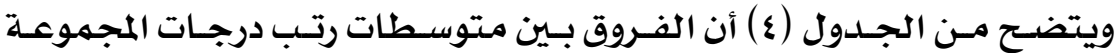

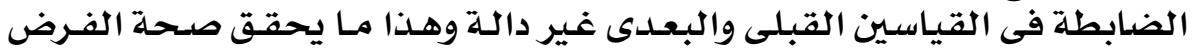

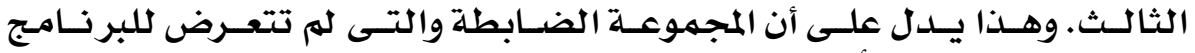

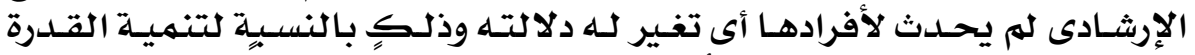

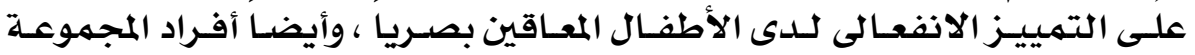

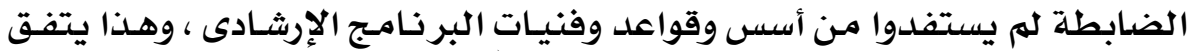

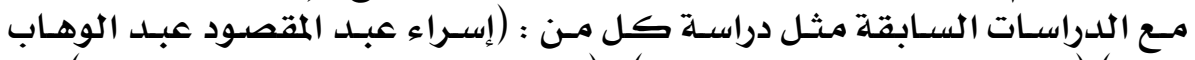

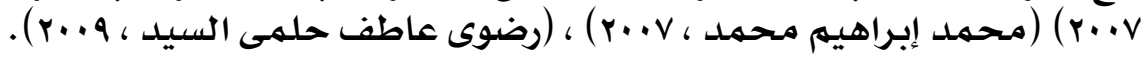

\section{$1 \cdot r$}


المجلد الخاهس .. العكد الثمانيه .. هارس .. 1ا•؟ه.

\section{• الفرض الرابع : اختباره ، وهناقشته :}

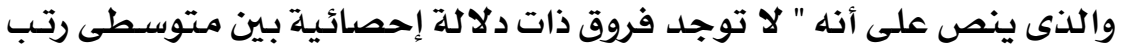

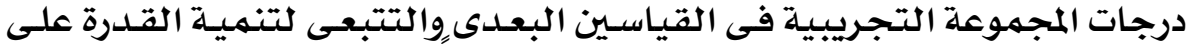

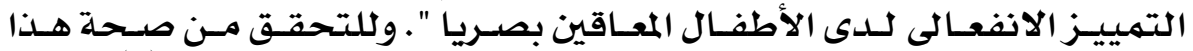

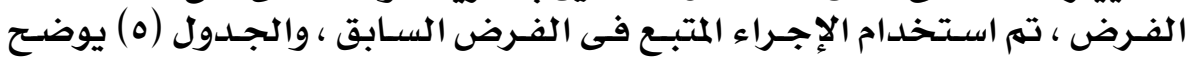
ذلك.

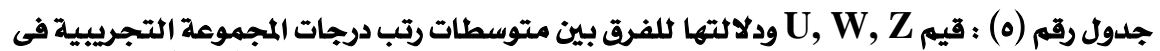

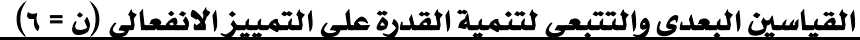

\begin{tabular}{|c|c|c|c|c|c|c|}
\hline الدلالة & قيمة & W & $\mathbf{U}$ & مـج الرتب & م الرتب & القياس \\
\hline لة & $1, \wedge \varepsilon$ & $\cdot, 11$ & Ir & $\begin{array}{l}00,0 . \\
0 ., 0 .\end{array}$ & $\begin{array}{l}\text { Q, Yo } \\
\text { Q,Vo }\end{array}$ & التبتعىى \\
\hline
\end{tabular}

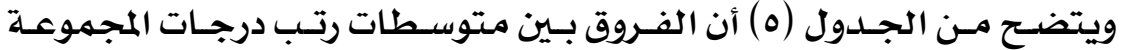

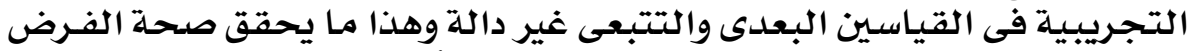

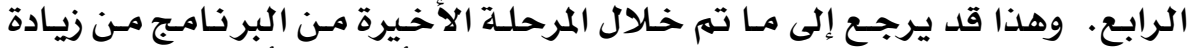

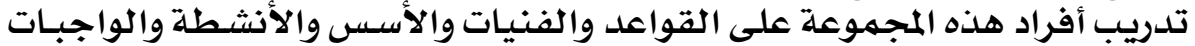

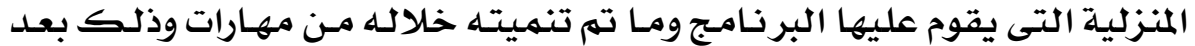

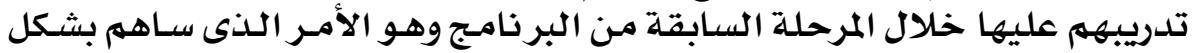

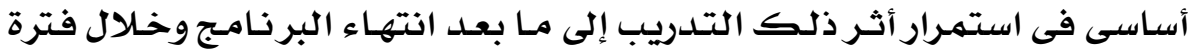

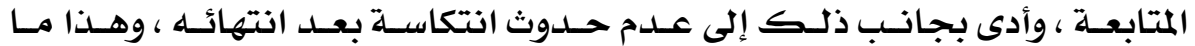

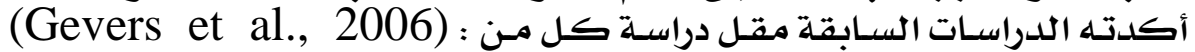
.(Choi, 2008) ، (Lacava et al., 2007)

\section{قائمة المراجع : المراجع الهربية :}

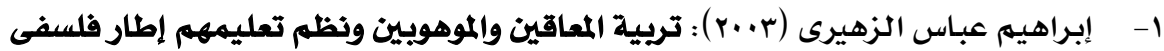

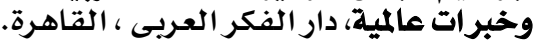

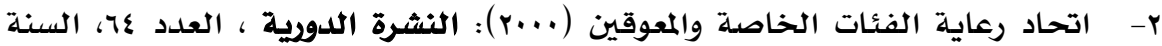
السـابعة عشرة، القاهـة الفئات الحرة.

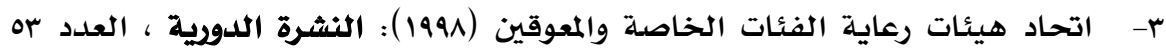
القاهرة، مـارس.

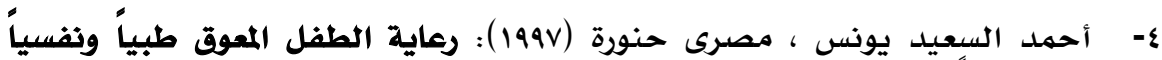

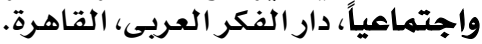

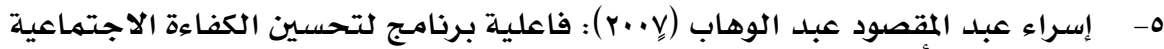

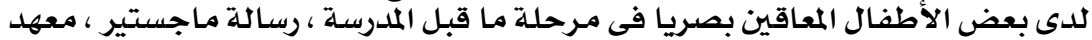

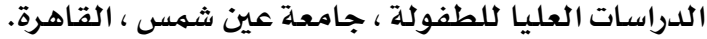

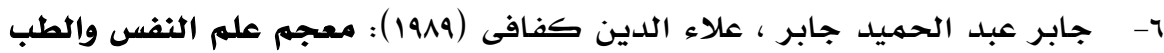
النفسى ، الجزء الجيد الثانى ، دار النهضيدة ، العـريية ، القاهرة.

\section{$1 \cdot r$}




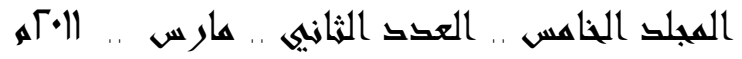

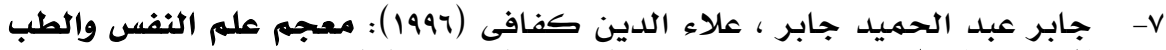
النفسى ، انجليزى - عربى ، جـي، دار النهضة العربي العربية ، القاهرة.

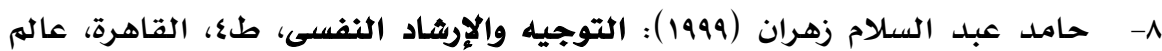

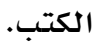

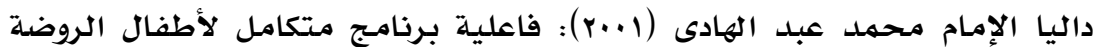

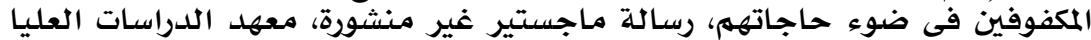

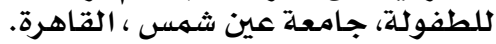

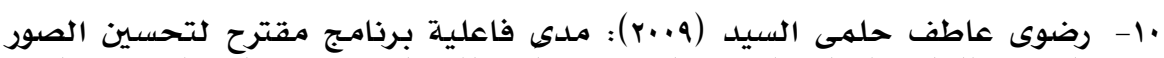

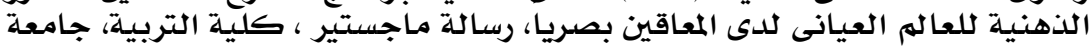
بنى سويف.

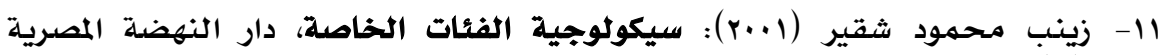

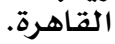

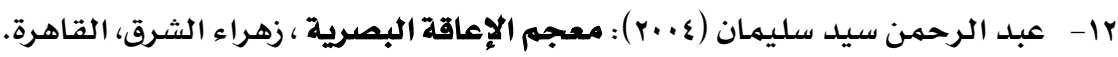

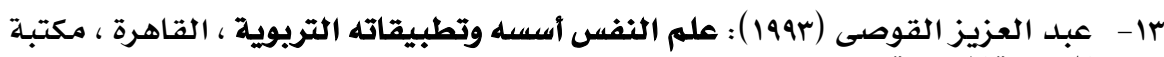
النهضة المصرية.

ع ا- عبد المجيد عبد الرحيم (199V) ) تنمية الأطفال المعاقين، دار غريب للنشر، القاهرة.

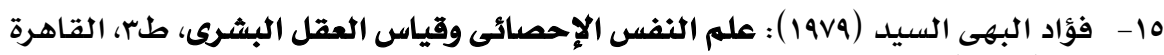

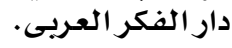

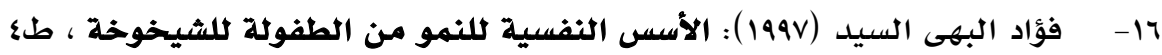

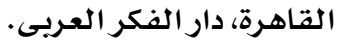

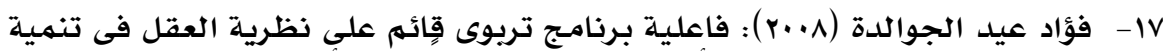

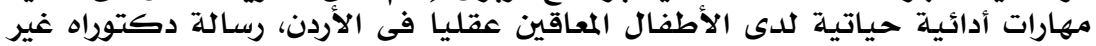

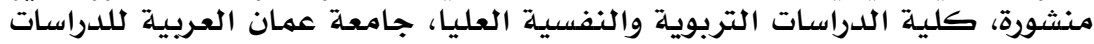

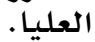

11- فتحى السيد عبد الرحيم (.199) ): سيكولوجية الأطفال غير العاديين، الطبعة الرابعة

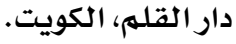

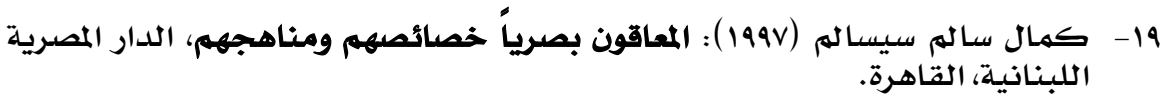

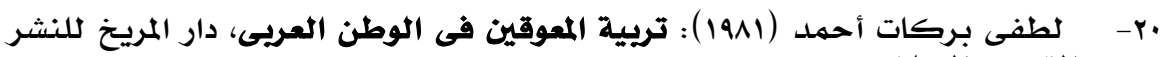
والتوزيع، الرياض.

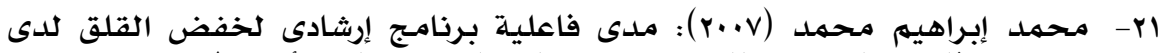
المراهقين فاقدى البصر، رسالة دكتوراه، كلية التربية، جامعة أسئة أسيوط.

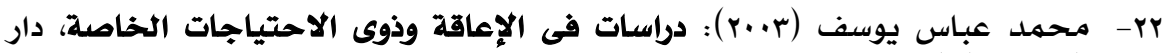
الغريب، القاهرة.

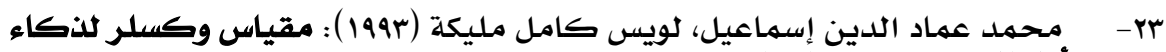
الأطفال، كراسة التعليمات، طجا، التقاهرة، دار النهضة العيكة العربية.

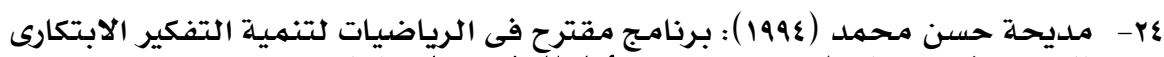

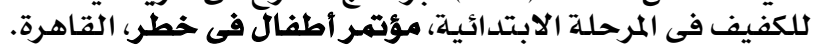

\section{$1 \cdot \varepsilon$}




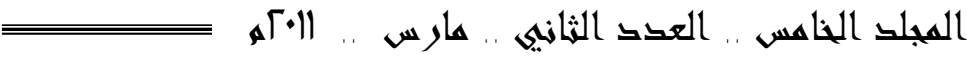

0-ro- مصطفى عشوى (199V): مدخل إلى علم النفس المعاصر ، صنعاء ، مكتبة الجيل

צr- ناهد حطبة (Y..r): محاضرات في التدريب الميدانى التعليم المبنى على الكفايات

لالاطفال العاديين وذوى الاحتياجات الخاصة، التخطيط، التنفيذ، التقويم، حورس الترات

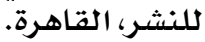

هدى شعبان محمد عوض (.1.r) -rV

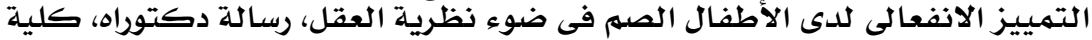

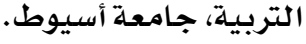

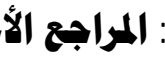

28- Aitshul, E. (2005): Social and emotional functioning of children with cochlear Implant. Unpublished Doctoral dissertation, Maryland University. Available at htt//www.progwest.com.

29- Astington, J., \& Barriault, T. (2001): Children's theory of mind: How young children come to understand that people have thoughts and feelings. Infants and Young Children,13(3):1-12.

30- Baker(1953):Introduction to Exceptional children Macmillan, New York.

31- Bosacki, S., \& Astington, J. (1999): Theory of mind in preadolescence: Reactions between social understanding and social competence. Social Development, 8(2), 237-255.

32- Casey, R., \& Fuller, L. (1994): Emotions and situations questionnaire. Journal of Nonverbal behavior, 188, 57-87.

33- Choi, W. (2008): Dysfunction in emotional decoding in autistic spectrum disorder: Theory of mind impairment or weak central coherence. Master of Social Sciences, Hong Kong University. Available at http//www. Progwest.com.

34- Doherty, M. (2009): Theory of mind: Theory of mind: How children's Understanding others thoughts and feelings. New York: Psychology Press.

35- Dyck, M., \& Denver, E. (2003): Can the emotion recognition ability of deaf children be enhanced? A pilot study. Journal of Deaf studies and deaf education, 8(3), 356-384.

36- Ekman, P., \& Freisen, W. (1976): Pictures of facial affect. Palo, Alto, CA: Counseling Psychology Press.

37- Givers, C., Manger, M., \& Boer, A. (2006): Brief report: A theory of mind school-aged children with pervasive developmental disorders: An open study of its effectiveness. Journal of Autism and Developmental Disorders, 36(4), 567571.

38- Goleman, D. (1995): Emotional intelligence. New York: Bantam books.

\section{$1 \cdot 0$}




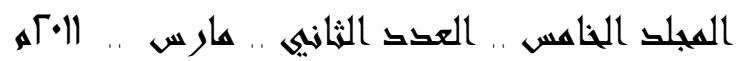

39- Hale, C. (2002): Social communication in children with autism: the role of theory of mind in discourse development. Unpublished Doctoral Dissertation, Massachusetts Boston University-available at http//www. Progwest.com.

40- Hughes, C., \& Leekman, S. (2004): what are links between theory of mind and social relation? Review reflections and new direction for studies of typical development. Social Development, 4, 590-519.

41- Keskin, B. (2005): The relationship between theory of mind symbolic transformation in pretend play and children's social competence. Unpublished Doctoral Dissertation, College of Education, Fluoride State University. Available at http//www .progwest.com.

42- Khabir Ahmad (2000): Who program gives hope to blind and partially sighted people in Africa, Lancet, Vol. 355, Issue 214: 1528-1531.

43- Lacava, P., Golan, O., Baron-Cohen, S., \& Smith, B. (2007): Using assistive technology to teach emotion recognition to students with asperger syndrome. Remedial and special Education, 28(3), 174-181.

44- Larsson, E.K. (2004): Short and long term follow up of ophthalmological findings in return infants and children, University Printers, Uppsala, Sweden, Vol. 65-04C of dissertation abstracts international: 992-1052.

45- Lee, E. (2000): Posture as stimulus for emotion decoding: comparing deaf and hearing subjects. Unpublished master dissertation, the American University. Available at http///www .progwest.com.

46- Love, J. (2007): Theory of mind ability in the preadolescent language Broken: Connections between language broking, social cognition and academic achievement. Unpublished Doctoral dissertation, California University available at http// www.progwest.com.

47- Lundy, J. (2000): The relationship of theory of mind to language variables and age of identification of congenital hearing loss in deaf children. Unpublished Doctoral Dissertation, Northern University, Colorado-available at http//www.progwest.com.

48- Marschark, M., Green, V., Hindmarsh, G., \& Walker, S. (2000): Understanding theory of mind in children who are deaf. Journal of Child Psychology, 41(8), 1067-1073.

49- Matsumoto, D., \& Ekman, P. (1988): Japanese and Caucasian facial expression of emotion (JACFEE), San Francisco, University.

50- Mountain, M. (1993): Victoria emotion recognition test. Unpublished Doctoral Dissertation, Victoria. University available at http//www. Progwest. Com.

\section{1,7}

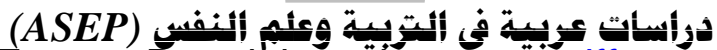




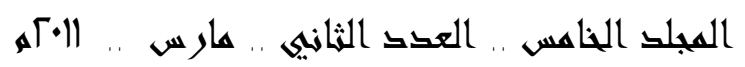

51- Nannies, E. (1988): A cognitive-developmental of emotional understanding and its implications for psychotherapy. In S.R. Shirk (Ed.), cognitive and child psychotherapy (pp. 91-115): New Press.

52- Nowicki, S., \& Duke, M. (1994): Individual differences in the non verbal communication of affect the diagnostic analysis of non verbal accuracy scale. Journal of Nonverbal Behavior, 18, 9-33.

53- Peterson, C., Wellmon, H., \& Lieu, D. (2005): Steps in theory of mind development for children with deafness or autism - child development. March/April, 76(2), 502-517.

54- Premack, D. \& Woodruff, G. (1978): Does the chimpanzee have a theory of mind? Behavior and Brain Sciences, 4, 515-526.

55- Reyes, D. (2005): Hearing-Impaired children's social/emotional understanding skills. Unpublished Doctoral dissertation, North Illinois University. Available at http//www.progwest.com.

56- Rose, P. (1998): The development of deaf and hearing children understanding of multiple emotions of varying valence and intensity. Unpublished Doctoral dissertation, Columbia University. Available at http//www. progwest.com.

57- Strong Man, K. (2003): The psychology of emotion. Fifth edition, Southern Gate Chi Chester: John Willey \& Sons.

58- Terwogt, M., \& Rieffe, C. (2004b): Behavioral problem in Deaf children: Theory of mind delay or communication failure? Journal of Developmental Psychology, (3), 231-240.

59- Thomas, H. (1980): An investigation of the recognition of facial expression of emotion after training of deaf students at residential school. Unpublished doctoral dissertation, Florida state University. Available at http//www,progwest.com.

60- Weisel, A. (1992): Role taking ability, non verbal sensitivity, language and social adjustment of deaf adolescent. Educational Psychology, 12(1), 3-13.

61- Wood Burn, E. (2008): The social aspects of learning: The role of theory of mind Understanding of teaching and social behavioral competence in school readiness. Unpublished Doctoral Dissertation, Pennsylvania University available http//www.progwest.com.

62- Yvette, A. (2002): Adult perception of emotional responding in children. Unpublished doctoral dissertation, way restate University, Michigan. Available at http//www. Progwest. Com.

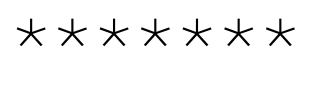

\section{$1 \cdot V$}

